\title{
Thermometry at the nanoscale
}

\author{
Carlos D. S. Brites, ${ }^{a}$ Patricia P. Lima, ${ }^{a}$ Nuno J. O. Silva, ${ }^{a}$ Angel Millán, ${ }^{b}$ Vitor S. Amaral, ${ }^{a}$ Fernando Palacio ${ }^{* b}$ \\ and Luís D. Carlos*a
}

Received 19th March 2012, Accepted 26th April 2012

DOI: 10.1039/c2nr30663h

\begin{abstract}
Non-invasive precise thermometers working at the nanoscale with high spatial resolution, where the conventional methods are ineffective, have emerged over the last couple of years as a very active field of research. This has been strongly stimulated by the numerous challenging requests arising from nanotechnology and biomedicine. This critical review offers a general overview of recent examples of luminescent and non-luminescent thermometers working at nanometric scale. Luminescent thermometers encompass organic dyes, QDs and $\mathrm{Ln}^{3+}$ ions as thermal probes, as well as more complex thermometric systems formed by polymer and organic-inorganic hybrid matrices encapsulating these emitting centres. Non-luminescent thermometers comprise of scanning thermal microscopy, nanolithography thermometry, carbon nanotube thermometry and biomaterials thermometry. Emphasis has been put on ratiometric examples reporting spatial resolution lower than 1 micron, as, for instance, intracellular thermometers based on organic dyes, thermoresponsive polymers, mesoporous silica NPs, QDs, and $\mathrm{Ln}^{3+}$-based up-converting NPs and $\beta$-diketonate complexes. Finally, we discuss the challenges and opportunities in the development for highly sensitive ratiometric thermometers operating at the physiological temperature range with submicron spatial resolution.
\end{abstract}

\section{Introduction: thermometry at the micro- and nanoscale}

The combined effects of thermal information at lower length scales and the unprecedented possibilities opened up by nanomaterials and nanotechnologies are paving the way for the development of thermometry on a sub-micron scale with high spatial resolution - defined as the minimum distance to move in order to get a temperature change greater than the sensitivity of the thermometer (eqn (1))., ${ }^{1,2}$ Indeed, current technological

${ }^{a}$ Department of Physics, CICECO, University of Aveiro, Campus Universitário de Santiago, 3810-193 Aveiro, Portugal. E-mail: carlos. brites@ua.pt; patriciapereira@ua.pt; nunojoao@ua.pt; vamaral@ua.pt; lcarlos@ua.pt; Fax:+351234 378197; Tel:+351 234370946

${ }^{b}$ Departamento de Fisica de la Materia Condensada, Facultad de Ciencias and Instituto de Ciencia de Materiales de Aragón, CSIC-Universidad de Zaragoza, 50009 Zaragoza, Spain.E-mail: amillan@unizar.es; palacio@ unizar.es demands in areas such as microelectronics, microoptics, photonics, microfluidics, and nanomedicine have reached a point such that the use of conventional thermometry is not able to make measurements when spatial resolution decreases to the submicron scale, as, for example, in intracellular temperature fluctuations $^{3-10}$ and temperature mapping of microcircuits ${ }^{11-15}$ and microfluids. ${ }^{16-21}$

For instance, solid-state thermometers based on the temperature dependence of the electrical resistance must have a highly accurate and precise design as effects like shot noise and tunnel junctions can be very significant at the nanoscale. ${ }^{22}$ Also, the thermometric property must remain stable over time and operating conditions to avoid frequent calibrations. Small changes in synthetic conditions can induce major changes in the thermometric property, thus affecting the reproducibility. Moreover, at the nanoscale many physical properties change, while other new ones arise: heat transfer and related thermodynamic phenomena,
Carlos Brites obtained the B.Sc. degree in Physics and Chemistry Teaching at University of Aveiro in 2004 and the M.Sc. in Optoelectronic and Lasers at University of Porto in 2007. From 2007 to present he is developing his PhD studies in Multifunctional Nanomaterials for Hyperthermia, with particular interest in temperature measurement at sub-micrometric scale using trivalent lanthanide ions.
Patricia Lima, born in 1975, obtained a PhD in Inorganic Chemistry at Federal University of Pernambuco (Brazil) and University of Aveiro in 2007 working on photoluminescence of lanthanide complexes incorporated into organic-inorganic hybrids. Currently, she is a postdoctoral researcher at University of Aveiro. Her current research is focused on the synthesis and optical characterization of luminescent materials for the development of optical thermometers. 
for instance, are drastically altered and materials behave differently than at larger scales. Sensing temperature in an accurate way with sub-micron resolution is therefore critical in order to understand the numerous features of micro- and nanoscale electronic and photonic devices, such as thermal transport, heat dissipation, and profiles of heat transfer and thermal reactions. ${ }^{1,23,24}$

Miniaturization of electronic and optoelectronic devices and circuits and ever faster switching speeds have increased the importance of localized heating problems and, thus, steady-state and transient characterization of temperature distribution is central for performance and reliability analysis. ${ }^{25,26}$ Furthermore, the precise mapping of the temperature of living cells, especially cancer cells that have higher temperatures than those of normal tissues due to the increased metabolic activity, ${ }^{6,9,27}$ strongly improves the perception of their pathology and physiology and, in turn, the optimization of premature diagnosis and therapeutic processes (e.g. in hyperthermal tumour treatment and photodynamic therapy). ${ }^{\mathbf{2 , 8 9}}$ Moreover, the temperature of living cells is modified during every cellular activity, e.g. cell division, gene expression, enzyme reaction and changes in metabolic activity, etc., ${ }^{4}$ thus leading to acute variations of intracellular temperatures from the normal state. ${ }^{10}$ There is a high demand for the development of devices capable of accurate temperature determination for such processes as well as the investigation of heat production and dissipation arising from most of them. ${ }^{9,10}$

Thermometry at the nanoscale requires, therefore, a new paradigm in the use of both materials and thermometric properties. Moreover, new synthetic techniques are helping to reduce materials limitation for sensing temperature at the nanoscale by either improving qualitatively inherent materials properties, e.g., size dispersion, surface roughness, or by opening entirely new possibilities based on new materials with new properties.

Nuno Silva graduated in Physics at University of Porto in 1999 and obtained a PhD in Physics in 2006 at University of Aveiro. He was at the ICMA between 2007 and 2009 as a Post-Doc. At present he is Researcher at CICECO. His interests include the magnetic, structural properties and modelling of ferrofluids and nanoparticles.

A. Millán received a PhD in Chemistry from the University of the Balearic Islands. After postdoctoral work in the Institute of Inorganic Chemistry of Czechoslovakia, the University of Nijmegen, the IMP-CNRS in Perpignan, and ICMA, he became a research scientist in the Consejo Superior de Investigaciones Cientificas (CSIC) in 2007. His primary research is in materials chemistry, with special interest in nanoparticles for biomedical applications and crystal growth.

Vitor Amaral is Full Professor in the Department of Physics at the University of Aveiro and researcher at CICECO and at ISOLDE$C E R N$ (Switzerland). His main research interests are related to magnetism in complex oxides, thin films, and nanoparticles and on the application of radioactive isotopes for nuclear solid state techniques. Recent topics are magnetothermal, magnetostructural and multiferroic effects.

The most popular approaches to nanothermometers have been the miniaturization of the geometrical size of conventional thermometers, although more radical alternatives have been proposed, as, for instance, ex situ thermometers based on the irreversible temperature-activated coalescence of silver NPs. ${ }^{28}$ Examples of such miniaturization encompass:

- Luminescent thermometers based on temperature-dependent emission intensity and/or lifetime of dye-sensitized Pdots, ${ }^{29,30}$ semiconducting QDs, ${ }^{8,31-35}$ and $\mathrm{Ln}^{3+}$-doped NPs; ${ }^{36-41}$

- Nanoscale IR thermometers from metal NPs based on blackbody radiation; ${ }^{42}$

- Scanning thermal microscopes based on $\mathrm{Ln}^{3+}$-doped NPs; ${ }^{12,43-45}$

- Nanoscale thermocouples fabricated from point contact junctions; ${ }^{23,46,47}$

- Liquid- and solid-in-tube nanothermometers fabricated from nanotubes and based on temperature-dependent thermal expansion of liquids (e.g. gallium inside $\mathrm{CNTs}^{48,49}$ or $\mathrm{Pb}$-filled $\mathrm{ZnO}$ nanotubes ${ }^{50}$ );

- Coulomb blockade nanothermometers from nanosized superconductor-insulator-metal tunnel junctions based on the Coulomb blockade of tunneling; ${ }^{51,52}$

- Complex structured nanothermometers from MEMS based on temperature-dependent resonator quality factor ${ }^{53}$ or Fermilevel shift. ${ }^{54}$

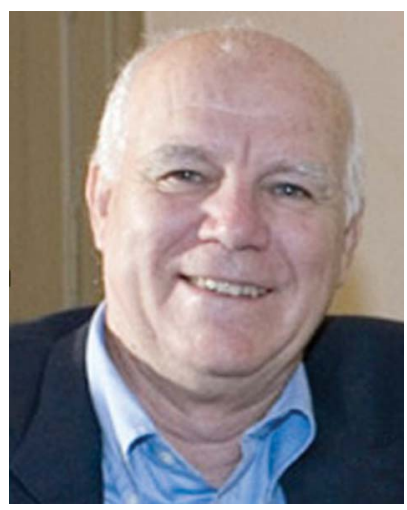

Fernando Palacio

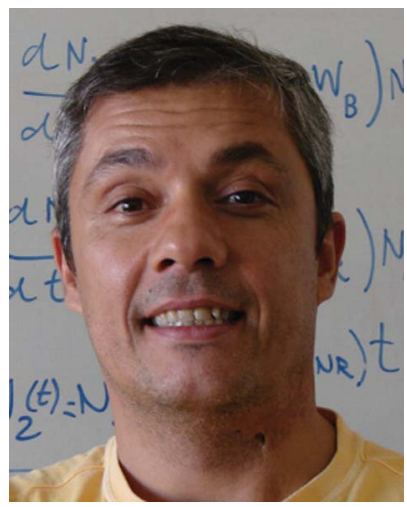

Luís D. Carlos
Fernando Palacio is Professor of Research at the Institute of Materials Science in Aragón (ICMA), Zaragoza (Spain). He is currently vice-director of the European Institute of Molecular Magnetism. His current scientific interests include the magnetism of molecular materials and nanoparticles, and the development of magnetic and multifunctional nanoparticles for biomedical applications.

Luis Carlos is Full Professor in the Department of Physics at the University of Aveiro, vicedirector of the Centre for Research in Ceramics and Composite Materials (CICECO), Aveiro (Portugal) and correspondent member of the Lisbon academy of sciences. His current scientific interests include light emission of organic-inorganic hybrids, applications of these materials in green photonics (solid-state lighting, luminescent solar concentrators and integrated optics), and luminescent/magnetic nanoparticles as new probes for multimodal imaging. 
Table 1 Summary of the advantages, disadvantages and general applications of high-resolution electrical, near- and far-field thermal techniques. The typical spatial $(\delta x)$, temporal $(\delta t)$ and temperature $(\delta T)$ resolutions of each method are also included. The table is adapted from those published by Asheghi and Yang ${ }^{25}$ and Christofferson et al. $^{26}$

High-resolution thermal measurement techniques in micrometer-nanometer range

\begin{tabular}{|c|c|c|c|c|c|}
\hline \multirow[b]{2}{*}{ Method } & \multirow[b]{2}{*}{ Principle } & \multicolumn{3}{|c|}{ Typical resolution } & \multirow[b]{2}{*}{ Advantages } \\
\hline & & $\delta x(\mu \mathrm{m})$ & $\delta T(\mathrm{~K})$ & $\delta t(\mu \mathrm{s})$ & \\
\hline \multirow[t]{2}{*}{$\begin{array}{l}\text { Infrared } \\
\text { thermography }\end{array}$} & $\begin{array}{l}\text { Planck blackbody } \\
\text { emission }\end{array}$ & 10 & $10^{-1}$ & 10 & $\begin{array}{l}\text { - Well implemented } \\
\text { commercial technique }\end{array}$ \\
\hline & & & & & $\begin{array}{l}\text { - Provides temperature } \\
\text { image profile of the } \\
\text { surface }\end{array}$ \\
\hline \multirow[t]{2}{*}{ Thermoreflectance } & $\begin{array}{l}\text { Temperature } \\
\text { dependence of the } \\
\text { reflection }\end{array}$ & $10^{-1}$ & $10^{-2}$ & $10^{-1}$ & $\begin{array}{l}\text { - High thermal and } \\
\text { temporal resolution }\end{array}$ \\
\hline & & & & & $\begin{array}{l}\text { - Quantitative and } \\
\text { qualitative measurement }\end{array}$ \\
\hline Raman & $\begin{array}{l}\text { Inelastic scattering of } \\
\text { monochromatic light }\end{array}$ & 1 & $10^{-1}$ & $10^{6}$ & $\begin{array}{l}\text { - No sample preparation } \\
\text { needed } \\
\text { - Works in solids and } \\
\text { liquids } \\
\text { - Small volumes }(<1 \mu \mathrm{m} \\
\text { diameter) can be probed }\end{array}$ \\
\hline Micro-thermocouple & Seebeck effect & $10^{2}$ & $10^{-1}$ & 10 & $\begin{array}{l}\text { - Precise temperature } \\
\text { calibration }\end{array}$ \\
\hline
\end{tabular}

Fluorescence
thermography

Near-field scanning optical microscopy

Liquid crystal thermography

Scanning thermal microscopy
Use near field to improve optical resolution

Crystal phase transitions (change colour)

AFM with thermocouple or $\mathrm{Pt}$ thermistor tip
- Spatial resolution (at one dimension) of $25 \mathrm{~nm}$

- Diverse experimental techniques to measure temperature - High temperature sensitivity - Ratiometric algorithms are independent of illumination source - Spatial resolution below the Rayleigh limit $(100 \mathrm{~nm})$

$\begin{array}{lll}10 \quad 10^{-1} \quad 10^{2} \quad & \bullet \text { Diverse materials } \\ & & \text { available commercially } \\ & \text { for different temperature } \\ & \text { ranges }\end{array}$

- Fully integrated with electronic devices

- Uses AFM tips to simultaneously measure temperature and determine the surface roughness

- Sub-micrometric spatial resolution
Disadvantages

- Detector saturation at high temperatures

- Difficulties on the precise estimation of the emissivity of the surface materials

- Spatial resolution for the temperature detection, which is Rayleigh limited (not all "hot bodies" are perfect blackbodies, in the physical meaning of the term)

- Requires the calibration of the reflectivity index

- Spatial resolution limited by the diffraction limit

- Thermoreflectance coefficient is not available for every material and depends on excitation wavelength and thickness of the optical layer

- Highly time-consuming technique implying image point analysis as slow as 0.5 point $\mathrm{s}^{-1}$

- Low signal and crosstalk with fluorescent molecules

- The thermometer is separated from the active region of the device limiting, at very short timescales, the access to it

- Additional fabrication effort required

- Voltage reflections and capacitive coupling limit the timescale for transient thermometry of the device

- Photobleaching limits the longterm intensity and lifetime determination

- High-expensive excitation sources and detectors to measure temperature using lifetime-based algorithms

- Depends on the surface characteristics

- Only access to surface temperature

- Slow temperature acquisition

- Vacuum and/or cryogenic

temperatures required

- Yields a semi-quantitative temperature map, unless a detailed calibration is performed

- A layer of the probe must be placed over the sample

- Not compatible with liquid systems

- Slow acquisition times

- Limited to solid samples

- Requires fundamental knowledge of tip-sample heat transfer 
Table 1 (Contd.)

High-resolution thermal measurement techniques in micrometer-nanometer range

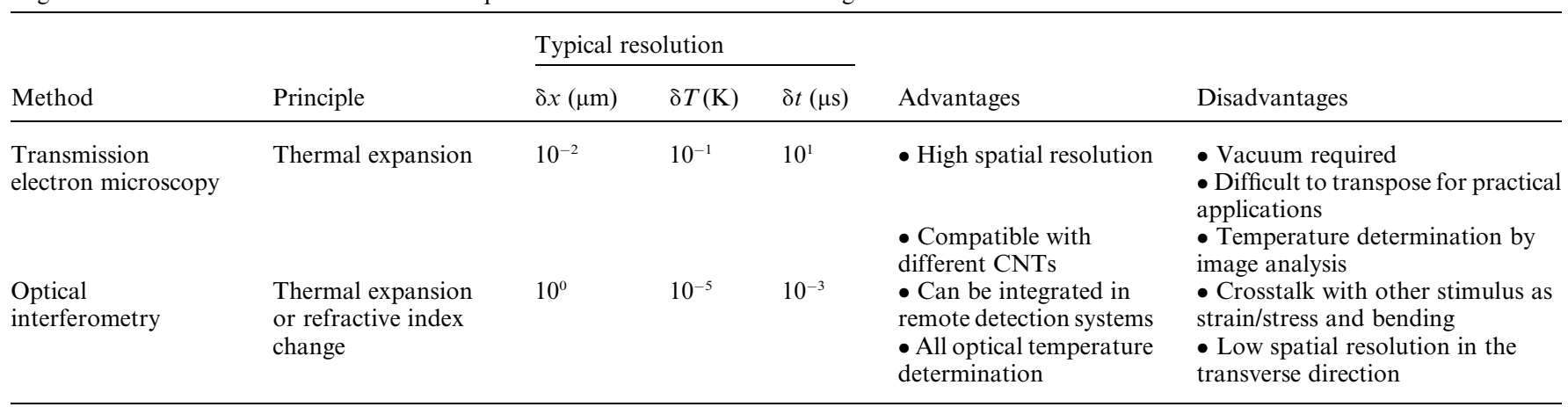

Thermometric systems can be classified as primary or secondary. The first are characterized by well-established state equations that directly relate measured values to absolute temperature without the need of calibration, while the second must be referred to a well-known temperature for their calibration. Secondary thermometers are sometimes difficult to calibrate at the nanoscale and can only act as sensors, providing temperature changes. Finally, there is a type of temperature sensing actuators (like some paraffins) that only reacts at a welldefined threshold temperature at which a specific change occurs. Although they can be accurate, these can only be considered as one-temperature thermometers. Therefore, not all the conditions expected for an ideal nanothermometer, namely, stability, accuracy and reproducibility, ${ }^{55}$ are fulfilled by the systems described in this review, independent to their validity as temperature sensors and actuators in the nanoscale.

As the size of systems where temperature has to be determined enters into the nanoscale, the question of whether temperature itself can be meaningful at such scale can become relevant. The minimal length scales for the existence of temperature have been carefully discussed by Hartmann et al. ${ }^{56,57}$

High-resolution thermometry techniques have been catalogued in many different manners, as, for instance, depending on whether they make use of electrical or optical signals or are based on near- or far-field applications. With this very general outline, it is common that the same technique is classified in different ways, for instance scanning thermal microscopy can be categorized as either an electrical or near-field thermometric method. ${ }^{25,26}$ However, independently of the classification, what really matters is a precise identification of the advantages and drawbacks of each method, as well as a proper selection according to the required spatial, temporal and temperature resolution. A summary of popular methods for high-resolution thermal measurements, highlighting the advantages and disadvantages of each, is presented in Table 1 .

The present review aims to describe the latest progress of submicron high-resolution thermometry adopting, however, a different approach involving the distinction between luminescent and non-luminescent thermometers. For the former thermometers the review addresses essentially far-field optical thermometry methods, whereas the non-luminescent examples involve near-field optical and electrical-resistance thermometry. Although the review does not intend to be comprehensive, illustrative examples of the rich variety of systems designed and developed to sense temperature at the nanoscale, such as luminescent thermometers containing organic dyes, ruthenium complexes, QDs, $\mathrm{Ln}^{3+}$ ions and temperature-responsive polymers, and non-luminescent thermometers like SThM, CNTs, nanolithography thermometry and biomolecules are described. The review covers essentially examples reported over the last five years and, concerning the luminescent thermometers, can be considered as being a follow up of two reviews on luminescent nanothermometers published recently based on $\mathrm{Ln}^{3+}$-based materials, essentially upconverting $\mathrm{NPs}^{41}$ and $\beta$-diketonate complexes. ${ }^{58} \mathrm{~A}$ more specific review circumscribing the development of modern thermometry in biologic applications and stressing part of the historical path through which thermometry has progressed into contemporary thermodynamics was issued in $2010 .^{2}$ A microreview on non-luminescent nanothermometers for use in TEM was published in $2010,{ }^{55}$ whereas in 2008 various contact and contactless microscale and nanoscale thermal characterization techniques that could be applied to active and passive devices and interconnects were surveyed. ${ }^{26}$ Early works on scanning microscopy-based thermometry employing diagnostic techniques ${ }^{24,59,60}$ and either electrical or scanning probe microscopy (with a particular emphasis on microelectronics and data storage devices) ${ }^{25}$ were available between 1999 and 2005. Three other reviews partially covering the subject and dealing with ceramic phosphors that can withstand extreme temperatures, ${ }^{61}$ multiple optical chemical sensors ${ }^{62}$ and temperature-stimuli polymers $^{63}$ have been published in 2011.

\section{Luminescent thermometers}

The well-known limitations of contact thermometers to work at submicron scale referred to in Table 1 lead to the development of non-contact thermometry techniques, such as, IR thermography, thermoreflectance, optical interferometry, Raman spectroscopy, and luminescence.

IR thermography - a concept that found numerous industrial applications in several variants of pyrometers or IR cameras infers the temperature distribution of a body according to the blackbody radiation spectral distribution of the emitted radiation and knowing the external surface emissivity of the material. Near-field methods opened a possible increase of the spatial resolution by two orders of magnitude ${ }^{64}$ and in practice resolutions of $\sim 10 \mathrm{~nm}$ can be achieved. ${ }^{64-66}$ Thermoreflectance and optical interferometry use the reflected light that provides information about the local heating state of the device or 
Table 2 Figures of merit of luminescent molecular thermometers displaying the maximum relative sensitivity values $\left(S_{\mathrm{m}}, \% \mathrm{~K}^{-1}\right)$, the temperature range of operation $(\Delta T, \mathrm{~K})$, the temperature at which $S_{\mathrm{m}}$ is maximum $\left(T_{\mathrm{m}}, \mathrm{K}\right)$ and the thermometric property associated with each example. Self-referencing (or ratiometric) examples are highlighted and, when reported, the spatial resolution is indicated

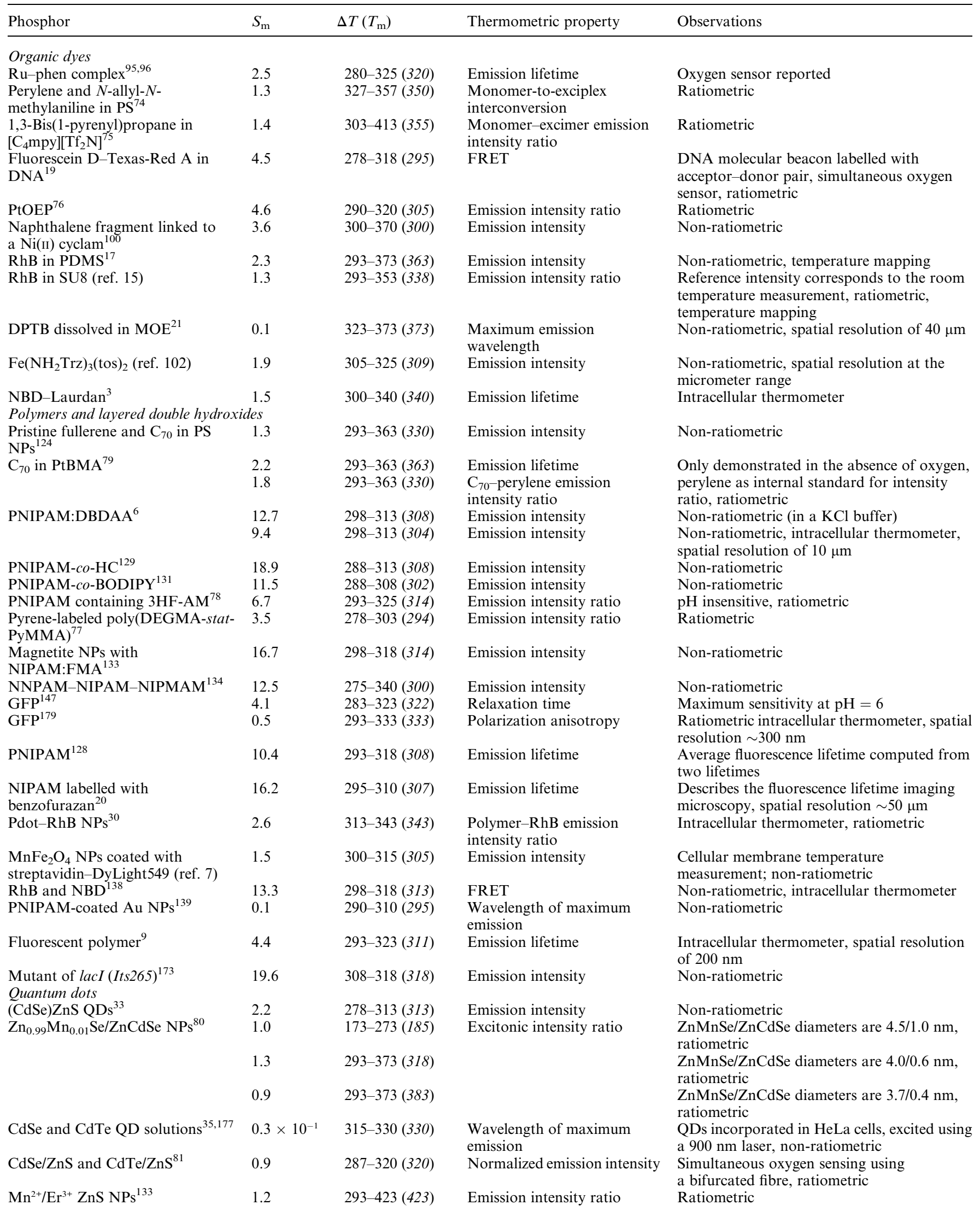


Table 2 (Contd.)

\begin{tabular}{|c|c|c|c|c|}
\hline Phosphor & $S_{\mathrm{m}}$ & $\Delta T\left(T_{\mathrm{m}}\right)$ & Thermometric property & Observations \\
\hline \multicolumn{5}{|l|}{$\mathrm{Ln}^{3+}$ phosphors } \\
\hline YAG:Ce NPs ${ }^{117}$ & 0.2 & $315-350(350)$ & Emission lifetime & Non-ratiometric \\
\hline $\mathrm{ZnO}: \mathrm{Er}^{3+} \mathrm{NPs}^{82}$ & 0.6 & $273-473(273)$ & Emission intensity & Ratiometric \\
\hline $\mathrm{PbF}_{2}: \mathrm{Er}^{3+} / \mathrm{Yb}^{3+} \mathrm{NPs}^{12,43}$ & 1.0 & $315-415(345)$ & $\begin{array}{l}{ }^{2} \mathrm{H}_{11 / 2} \rightarrow{ }^{4} \mathrm{I}_{15 / 2} /{ }^{4} \mathrm{~S}_{3 / 2} \rightarrow{ }^{4} \mathrm{I}_{15 / 2} \\
\text { intensity ratio }\end{array}$ & Ratiometric, spatial resolution below $500 \mathrm{~nm}$ \\
\hline $\begin{array}{l}\mathrm{Er}^{3+} / \mathrm{Yb}^{3+} \text { co-doped fluoride } \\
\text { amorphous glass particle }\end{array}$ & 1.1 & $335-375(342)$ & $\begin{array}{l}{ }^{2} \mathrm{H}_{11 / 2} \rightarrow{ }^{4} \mathrm{I}_{15 / 2} /{ }^{4} \mathrm{~S}_{3 / 2} \rightarrow{ }^{4} \mathrm{I}_{15 / 2} \\
\text { intensity ratio }\end{array}$ & Ratiometric, spatial resolution below $500 \mathrm{~nm}$ \\
\hline $\mathrm{NaYF}_{4}: \mathrm{Er}^{3+} / \mathrm{Yb}^{3+} \mathrm{UCNPs}^{40}$ & 1.0 & $298-318(298)$ & $\begin{array}{l}{ }^{2} \mathrm{H}_{11 / 2} \rightarrow{ }^{4} \mathrm{I}_{15 / 2} /{ }^{4} \mathrm{~S}_{3 / 2} \rightarrow{ }^{4} \mathrm{I}_{15 / 2} \\
\text { intensity ratio }\end{array}$ & Ratiometric intracellular thermometer \\
\hline \multirow[t]{2}{*}{$\mathrm{Er}^{3+} / \mathrm{Yb}^{3+}$ and $\mathrm{Tm}^{3+} / \mathrm{Yb}^{3+} \mathrm{UCNPs}^{87}$} & 2.3 & $293-318(318)$ & $\begin{array}{l}{ }^{2} \mathrm{H}_{11 / 2} \rightarrow{ }^{4} \mathrm{I}_{15 / 2} /{ }^{4} \mathrm{~S}_{3 / 2} \rightarrow{ }^{4} \mathrm{I}_{15 / 2} \\
\text { intensity ratio }\end{array}$ & \multirow[t]{2}{*}{ Ratiometric } \\
\hline & 0.2 & $293-318(315)$ & $\begin{array}{l}\text { Intensity ratio between two } \\
\text { sub-Stark energy levels of the } \\
\mathrm{Tm}^{3+}{ }^{3} \mathrm{H}_{4} \text { excited state }\end{array}$ & \\
\hline $\begin{array}{l}\text { Eu(tta })_{3} \mathrm{~L} \text { complexes embedded } \\
\text { into PTBS microbeads }\end{array}$ & 1.1 & $275-340(333)$ & Emission lifetime & $\begin{array}{l}\text { Using poly(vinyl methylketone) as support } \\
\text { polymer }\end{array}$ \\
\hline $\begin{array}{l}\mathrm{P}(\mathrm{VDC}-\mathrm{co}-\mathrm{AN}) \mathrm{NPs} \text { co-doped with } \\
\text { an } \mathrm{Eu}^{3+} \text { complex and } \mathrm{BBS}^{29}\end{array}$ & 7.2 & $273-323(323)$ & ${ }^{5} \mathrm{D}_{0} \rightarrow{ }^{7} \mathrm{~F}_{2} / \mathrm{BBS}$ intensity ratio & Two dimensional thermo-imaging, ratiometric \\
\hline Eu-DT embedded into BTD- & 6.8 & 283-323 (323) & ${ }^{5} \mathrm{D}_{0} \rightarrow{ }^{7} \mathrm{~F}_{2}$ intensity & Non-ratiometric \\
\hline PMMA NPs $^{37}$ & 3.2 & $283-323(320)$ & ${ }^{5} \mathrm{D}_{0}$ lifetime & \\
\hline Eu-DT and OASN in silica NPs ${ }^{39}$ & 7.2 & $283-323(323)$ & $\begin{array}{l}{ }^{5} \mathrm{D}_{0} \rightarrow{ }^{7} \mathrm{~F}_{2} / \mathrm{OSAN} \text { intensity } \\
\text { ratio }\end{array}$ & Ratiometric \\
\hline $\mathrm{Eu}^{3+}$ and $\mathrm{Tb}^{3+}$ embedded into & 1.7 & $283-323(310)$ & ${ }^{5} \mathrm{D}_{0} \rightarrow{ }^{7} \mathrm{~F}_{2}$ intensity & Non-ratiometric \\
\hline PAA-OTES hydrogels ${ }^{167}$ & 2.1 & $283-323(320)$ & ${ }^{5} \mathrm{D}_{4} \rightarrow{ }^{7} \mathrm{~F}_{5}$ intensity & \\
\hline $\begin{array}{l}\mathrm{Eu}^{3+} / \mathrm{Tb}^{3+} \beta \text {-diketonate complex } \\
\text { embedded into silica-coated }\end{array}$ & 4.9 & $10-330(143)$ & $\begin{array}{l}{ }^{5} \mathrm{D}_{0} \rightarrow{ }^{7} \mathrm{~F}_{2} /{ }^{5} \mathrm{D}_{4} \rightarrow{ }^{7} \mathrm{~F}_{5} \\
\text { intensity ratio }\end{array}$ & Ratiometric \\
\hline $\begin{array}{l}\text { magnetic } \mathrm{NPs}^{38} \text { and di-ureasil } \\
\text { film }^{38,89}\end{array}$ & 1.9 & $10-330(202)$ & $\begin{array}{l}{ }^{5} \mathrm{D}_{0} \rightarrow{ }^{7} \mathrm{~F}_{2} /{ }^{5} \mathrm{D}_{4} \rightarrow{ }^{7} \mathrm{~F}_{5} \\
\text { intensity ratio }\end{array}$ & $\begin{array}{l}\text { Ratiometric, spatial resolution up to } 3.2 \mu \mathrm{m} \\
\text { (di-ureasil film) }\end{array}$ \\
\hline
\end{tabular}

structure. Thermoreflectance explores the temperature dependence of the reflection coefficient of a material (its refractive index is temperature dependent), resulting in a temperature profile by analysis of the image produced by reflection with a spatial resolution limited by the optical imaging system. ${ }^{13}$ Developments in the past ten years also allowed micrometer/submicrometer spatial resolution (Table 1), see, for instance, the reviews by Cahill et al., ${ }^{67}$ Christofferson and Shakouri ${ }^{68}$ and Christofferson et al. ${ }^{26}$ Optical interferometry (in both active and passive modes) provides not only local temperature probing but also accurate measurements of the thermal expansion or deformation of a surface, with spatial and temperature resolutions in passive mode of $\sim 1 \mu \mathrm{m}$ and $\sim 10 \mu \mathrm{K}$, respectively ${ }^{25}$ (Table 1). Raman spectroscopy (as well as scanning microscopy) presents a reading velocity and processing that is limited (at least) by the probe movement and by the properties of the material and of the surface. This technique is well suited for large temperature changes, due to the low sensibility, and in spatial terms limited to the laser spot size $(\sim 0.5 \mu \mathrm{m})$.

Amongst non-invasive spectroscopic methods for determining temperature, the thermal dependence of phosphor luminescenceband shape, peak energy and intensity, and excited states lifetimes - is an accurate technique (often referred to as thermographic phosphor thermometry). It works remotely with high detection sensitivity and spatial resolution in short acquisition times, even in biological fluids, strong electromagnetic fields and fast-moving objects. ${ }^{19,61,69-73}$ The thermal probes encompass organic dyes, ruthenium complexes, spin crossover NPs, polymers, LDHs, semiconductor QDs, and $\mathrm{Ln}^{3+}$-based materials. Apart from these simple systems, in which a single component acts as a temperature-responsive emitting centre, there are complex systems, in which the changes in the emission intensity and/or lifetime of the emitting state of a particular component are induced by a second one that is the real temperature responsive material. In most of the cases, this temperature sensitive material is a polymer or an organic-inorganic hybrid host.

This section describes the latest progress of non-invasive (or semi-invasive) luminescent molecular thermometers based on the thermal probes aforementioned, with particular emphasis on examples (Sections 2.4 and 2.5) that effectively illustrate the temperature sensing/mapping at micron and sub-micron scale. The temperature sensing algorithms are briefly reviewed highlighting their advantages and drawbacks and the performances of the different molecular thermometers are compared using the thermometers' relative sensitivity as a figure of merit (Table 2 and Fig. 1-4). This relative sensitivity is defined as:

$$
S=\frac{\left(\frac{\partial Q}{\partial T}\right)}{Q}
$$

where $Q$ corresponds to the quenching of luminescence with temperature. The $Q$ values were calculated fitting the 


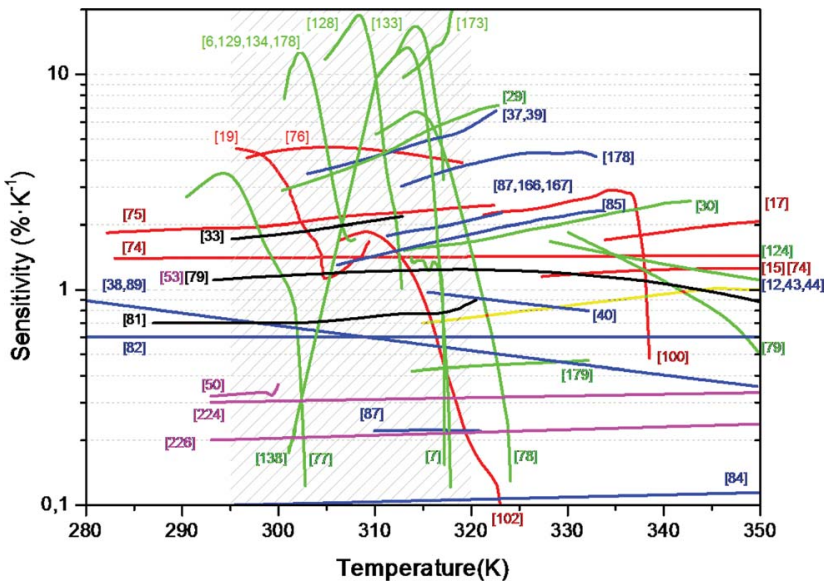

Fig. 1 Temperature dependence of the maximum relative sensitivity value $S_{\mathrm{m}}$ for the series of thermometers reported in Tables 2 and 3. The dye-, polymer-, QDs- and $\mathrm{Ln}^{3+}$-based luminescent thermometers are displayed in red, green, black and blue, respectively. The non-luminescent thermometers are shown in magenta. The physiological temperature range area is shadowed.

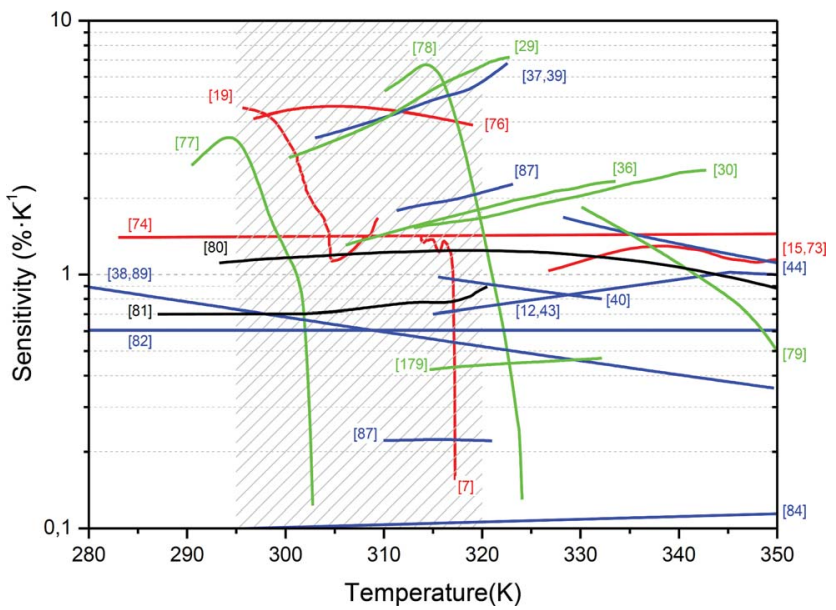

Fig. 2 Temperature dependence of the relative sensitivity values for the series of luminescent ratiometric thermometers reported in Table 2. The dye-, polymer-, QDs- and $\mathrm{Ln}^{3+}$-based thermometers are displayed in red, green, black and blue, respectively.

experimental data graphically reported in literature to polynomial interpolations implemented with MatLab®. A cut-off on the relative sensitivity values is assumed when the absolute temperature resolution $\Delta T$ is below $1 \mathrm{~K}$. This is estimated by $\Delta Q / S_{\text {a }}$, where $\Delta Q$ is the resolution of $Q$, calculated from the standard deviation of the interpolation, and $S_{\mathrm{a}}=\partial Q / \partial T$ is the absolute sensitivity. $S_{\mathrm{m}}$ and $T_{\mathrm{m}}$ represent the maximum value of the relative sensitivity and the temperature at which that value occurs, respectively. In all the examples addressed here the dependence on temperature of the relative sensitivity was computed from published data using eqn (1).

The temperature dependence of the relative sensitivity for nonratiometric and ratiometric luminescent thermometers is displayed in Fig. 1 and 2, respectively, whereas Fig. 3 illustrates that dependence estimated from lifetime or decay time measurements. Examples of the relatively small number of thermometers

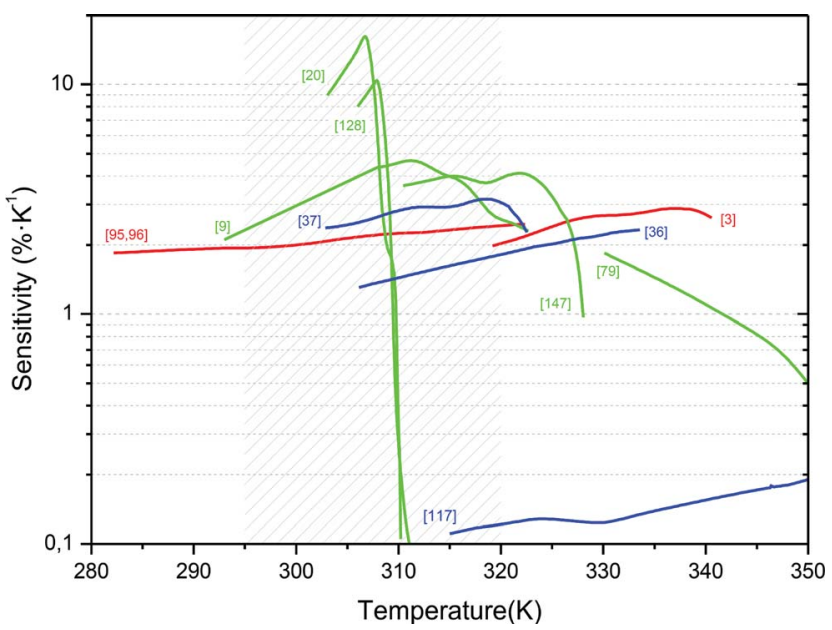

Fig. 3 Temperature dependence of the relative sensitivity values estimated from lifetime or rise time measurements of the examples reported in Table 2

(luminescent and non-luminescent) that effectively demonstrate temperature sensing or mapping at micron and sub-micron scale are depicted in Fig. 4.

The temperature determination by optical means (essentially through luminescence) exploits several methods of examination of the sensitive material. Intensity-based methods are applied when the luminescence of the thermographic phosphors is photoexcited continuously and the resulting intensity is measured in a continuous way. On the other hand, if the time dependence of the intensity of a particular transition (decay curve) is measured, the thermometric information temperature is inferred through the lifetime $\tau$ of the phosphor emitting level. ${ }^{62,73}$ Decay time methods use a pulsed excitation source and, in most cases, after each excitation pulse the emitting level exhibits exponentially decaying emission characterized by the following lifetime temperature dependence:

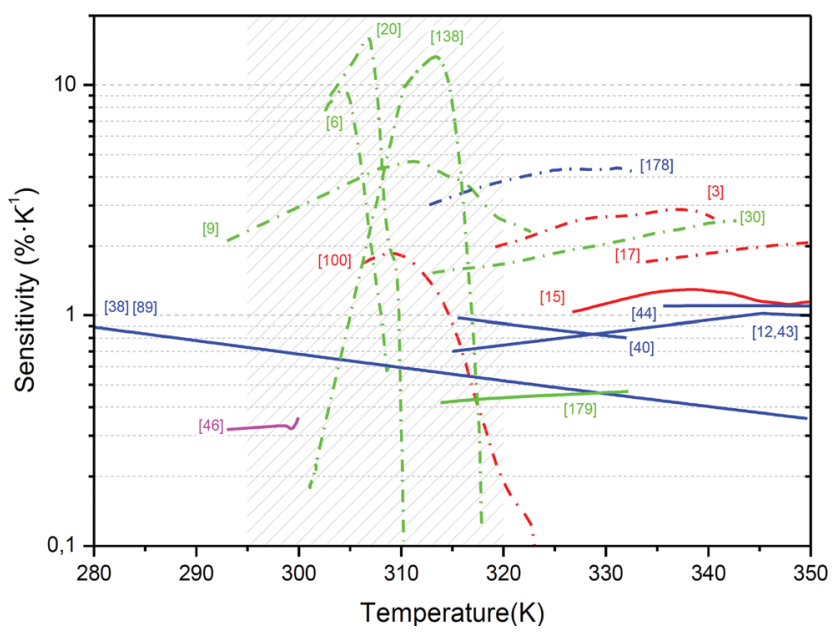

Fig. 4 Temperature dependence of the relative sensitivity values for the series of thermometers reported in Tables 2 and 3 that display spatial resolution on the micron and submicron scale (the non-ratiometric luminescent thermometers are marked as dotted lines). 


$$
\tau=\frac{1}{W_{\mathrm{r}}+W_{\mathrm{nr}}(T)}=\frac{1}{\tau_{0}^{-1}+k \exp \left(-\frac{\Delta E}{k_{\mathrm{B}} T}\right)}
$$

where $W_{\mathrm{r}}$ and $W_{\mathrm{nr}}$ are the radiative and non-radiative probability, respectively, $\tau_{0}$ is the radiative lifetime (at zero absolute temperature $T$ ), $k$ is a pre-exponential factor, $\Delta E$ is the energy gap between the emitting level and the higher excited state, and $k_{\mathrm{B}}$ is the Boltzmann constant.

Lifetime-based methods present the critical advantage of virtually not being affected by light scattering or reflection, by the intensity fluctuation of the excitation light field or inhomogeneous distribution of the phosphor. Lifetimes are measured in the timedomain or frequency-domain modes. ${ }^{62}$ In time-domain fluorometry, a square-shaped light pulse excites the fluorophore and the luminescence rises and drops with a typical characteristic that is dependent on the luminescence decay time of the probe. In the frequency-domain approach the luminophore is excited by sinusoidally modulated light and the luminescence follows the excitation frequency with a lifetime-dependent delay. Two luminophore species are sometimes employed, as in the dual-lifetime referencing and dual-lifetime determination approaches. Whereas in the former method, one luminophore species references the lifetime of the other (both species must present similar photobleaching), in the latter one both lifetimes are determined (the lifetimes can be only separated if their ratio is greater than 10). ${ }^{62}$

Lifetime determination, however, may be, in certain conditions laborious and time-consuming, disadvantages that can be easily overcome by intensity-based methods. These algorithms use directly the intensity of one or more transitions to detect temperature. The intensity of each transition is proportional to the total number of atoms (population) in a given excited state at temperature $T$ :

$$
I \propto g A h \nu \exp \left(-\frac{E}{k_{\mathrm{B}} T}\right)
$$

where $g$ is the degeneracy of the state, $A$ is the spontaneous emission rate, $h$ is the Planck constant, $\nu$ is the frequency, and $E$ is the energy of the level.

Frequently two transitions assigned to the same phosphor are used and the ratio between their fluorescent intensities $\left(I_{1}\right.$ and $\left.I_{2}\right)$ named fluorescence intensity ratio, FIR (or two-colour response), is taken as a measurement of absolute temperature, since:

$$
\frac{I_{1}}{I_{2}}=\frac{g_{1} A_{1} h \nu_{1}}{g_{2} A_{2} h \nu_{2}} \exp \left(-\frac{\Delta E_{12}}{k_{\mathrm{B}} T}\right)=B \times \exp \left(-\frac{\Delta E_{12}}{k_{\mathrm{B}} T}\right)
$$

where $B$ is a constant.

The main advantage of this FIR numerical technique is the fact that one single emission spectrum contains all the information needed to compute the absolute temperature. The FIR employs a Boltzmann distribution in electrons between adjacent emitting energy levels that is a function of temperature and is manifested as a temperature-dependent intensity ratio between emissions from two distinct lines in the spectrum.

Intensity measurements based on one transition depend crucially on variations of the sensor concentration, small material inhomogeneities (particularly in imaging non-planar surfaces, such as biological tissues) and optoelectronic drifts of the excitation source and detectors, making them, thus, inappropriate for precise temperature sensing. Lifetime data and ratiometric (or self-referencing) FIR measurements, in contrast, are not compromised by those disadvantages and, thus, are much more reliable. ${ }^{29-32,39-41,58}$ Nevertheless, real-time temperature mapping through decay time measurements requires more sophisticated equipment, when compared to the faster, easier and cheaper ratiometric luminescence intensity readout. Moreover, for complicated distributions of emitting centres and/or strong interactions between them (for instance energy transfer) lifetime determination may be laborious and time-consuming, as it involves a fit procedure (that could be rather complicated) to the decay curves. Therefore, it is unquestionable that an optimal luminescent nanothermometer should produce a ratiometric intensity response to temperature changes. Ratiometric techniques can be easily implemented typically with a UV excitation lamp and a handheld spectrometer or even a simple apparatus combining a dichroic filter set to the isosbestic point and two photodetector diodes, each set to detect the excitonic or the dopant emission.

Examples of ratiometric (or self-referencing) luminescent thermometers (Table 2 and Fig. 2) include:

- Perylene- $N$-allyl- $N$-methylaniline exciplex interconversion $;{ }^{74}$

- Monomer-excimer interconversion of 1,3-bis(1-pyrenyl) propane dissolved in the $\left[\mathrm{C}_{4} \mathrm{mpy}\right]\left[\mathrm{Tf}_{2} \mathrm{~N}\right], \mathrm{IL}^{.75}$

- Aqueous solution of Fluorescein D-Texas-Red A anchored to a DNA chain; ${ }^{19}$

- Platinum octaethyl porphyrin dye ${ }^{76}$

- Pyrene-labeled poly(DEGMA-stat-PyMMA); ${ }^{77}$

- PNIPAM containing 3HF-AM; ${ }^{78}$

- Fullerene $\mathrm{C}_{70}$ and perylene (internal standard) dispersed in PtBMA $;{ }^{79}$

- Semiconducting Pdots embedded RhB ${ }^{30}$

- Thin layer of the epoxy-based negative photoresist SU8 incorporated $\mathrm{RhB} ;^{15}$

- $\mathrm{Zn}_{1-x} \mathrm{Mn}_{x} \mathrm{Se}-\mathrm{ZnCdSe}(x \approx 0.01)$ core-shell QD structures; ${ }^{31,32,80}$

- CdSe-ZnS and CdTe-ZnS QDs embedded in a sol-gel derived organic-inorganic hybrid; ${ }^{\mathbf{8 1}}$

- P(VDC-co-AN), NPs embedded the (tris(benzoylacetonato) mono(phenanthroline)) $\mathrm{Eu}^{3+}$ complex and the BBS organic dye, ${ }^{29}$

- $\mathrm{Er}^{3+}$-based nanocrystals, ${ }^{\mathbf{8 2 , 8 3}}$

- $\mathrm{Er}^{3+} / \mathrm{Yb}^{3+}$ (ref. 12, 40, 41, 43, 44 and 84-86) and $\mathrm{Tm}^{3+} / \mathrm{Yb}^{3+}$ based $^{87}$ UCNPs;

- Magnetic hybrid NPs co-doped with $\mathrm{Eu}^{3+}$ and $\mathrm{Tb}^{3+}$ tris( $\beta$-diketonate) chelates; $;^{38,58}$

- Di-ureasil ${ }^{88}$ layer embedding superparamagnetic maghemite NPs and $\mathrm{Eu}^{3+}$ and $\mathrm{Tb}^{3+}$ tris( $\beta$-diketonate) complexes; ${ }^{89}$

- Siloxane hybrid NPs formed by a BTD-PMMA core covered with a silica outer layer incorporating (in the core) the Eu-DT complex and a OASN reference. ${ }^{39}$

\subsection{Thermometers based on organic dyes}

Since the organic dyes were patented in 1941 as "temperature indicators", many advances have been made. RhB, ${ }^{90}$ fluorescein isothiocyanates, ${ }^{91}$ and cyanine dyes ${ }^{92}$ have become very popular in fluorescence imaging or temperature determination in a biological context. A large set of organic complexes are 
commercially available and can be picked up a la carte from an extensive list, attending to the excitation/emission wavelength range required, solubility, facility of vectorization, etc. The design of all kinds of sensors is virtually possible, setting up the analyte and defining the experimental conditions to be used. Many examples can be found in the literature describing assemblies with organic dyes for labelling antibodies and antigens, ${ }^{93,94}$ or hosting organic dyes in a polymeric matrix, ${ }^{95,96}$ for improving their mechanical and chemical stability.

An illustrative example is NPs of Ruphen and PtTFPP embedded in polyacrylonitrile. ${ }^{95,96}$ In order to produce pressure sensitive paints knowledge of the temperature is fundamental. Ruphen allows the measuring of the temperature that is used to calibrate the PtTFPP pressure response. The polyacrylonitrile is employed as a support medium that shields both Ruphen and PtTFPP from oxygen quenching. Ruphen presents a maximum temperature relative sensitivity of $2.5 \% \mathrm{~K}^{-1}$ at $320 \mathrm{~K}$ (ref. 95 and 96) (Table 2 and Fig. 1).

More complete approaches can be achieved either by means of a ratio of intensities coming from the monomer and excimer/ exciplex or decay of emission lifetimes. An excimer is an excited dimer whereas an exciplex is a combination of two different atoms that exists only in an excited state, e.g. excited electron donor-acceptor complex. In order to rationalize the temperature dependence of the emission intensity (or lifetime) a two-state equilibrium model is used. These two states are assigned to conformational changes (or protonation) of one of the emitting species and are responsible due to the temperature driven change of the fluorescence emission intensity. The existence of an isoemissive point in the emission spectra is strong evidence that corroborates this simple two-state model for temperature dependence. This simple and rational model conjugated with the fact that organic dyes present severe photobleaching and low quantum yields caused great research interest in the monomerto-exciplex interconversion and monomer-to-excimer emission intensity ratio.

An important example reports the temperature-dependent change of a perylene monomer-exciplex, as an organic dye molecular thermometer. ${ }^{74}$ The ratiometric variation of the emission intensities of monomer-exciplex species was studied using a two-state equilibrium model in the temperature range 290-360 K with $S_{\mathrm{m}}=1.3 \% \mathrm{~K}^{-1}$ at $350 \mathrm{~K}$ (ref. 74) (Table 2 and Fig. 1). The authors anticipated that the strategy could be easily extended to other aromatic hydrocarbon acceptor-aniline donor systems, such as benzene-aniline or anthracene-aniline, showing two colour emissions as a function of temperature. Further studies addressing photobleaching, solvent properties and biological compatibility would be desirable.

In contrast to monomer-exciplex molecular thermometers, IL-based thermometers ${ }^{75}$ are not limited to the boiling point of common organic solvents, instead, they are critically dependent on the thermal stability of the fluorophore itself. The operating temperature range of IL-based thermometers extends to that of monomer-exciplex molecular thermometers with reduced photobleaching. One of the most relevant examples uses [ $\left.\mathrm{C}_{4} \mathrm{mpy}\right]$ $\left[\mathrm{Tf}_{2} \mathrm{~N}\right]$ as matrix and 3-bis(1-pyrenyl)propane as phosphor, exhibiting an error in temperature lower than $0.35 \mathrm{~K}$ and an UV photobleaching of $15 \%$ (at $333 \mathrm{~K}$ during $24 \mathrm{~h}, 10 \mathrm{~mW}$ ). Reversibility and robustness are demonstrated in $303-413 \mathrm{~K}$ heating-cooling cycles during $8 \mathrm{~h}$ with a maximum of $0.3 \mathrm{~K}$ deviation from the operating calibration curve. A maximum temperature relative sensitivity of $1.4 \% \mathrm{~K}^{-1}$ at $355 \mathrm{~K}$ can be estimated from published data ${ }^{75}$ (Table 2 and Fig. 2). Interestingly enough, some IL gels have been reported to be biocompatible with enzymes, proteins and even living cells. ${ }^{97}$ Nevertheless, as far as we know, IL-gels presenting a ratiometric temperature response have not been reported yet.

An example of a ratiometric highly sensitive molecular thermometer based on a platinum octaethyl porphyrin was described by Lupton. ${ }^{76}$ The intensity ratio uses two transitions of the PtOEP: the first excited triplet level, at $650 \mathrm{~nm}$, and one band, at $540 \mathrm{~nm}$, the origin of which is not entirely clear. PtOEP is able to monitor temperature changes in the range $290-320 \mathrm{~K}$ with a maximum relative sensitivity of $4.6 \% \mathrm{~K}^{-1}$ at $305 \mathrm{~K}$ (Table 2 and Fig. 2). Reportedly, the heating does not contribute to the material cleavage, which is governed by photo-oxidation. ${ }^{76}$

A different methodology explores the determination of temperature by monitoring the luminescence change induced by molecular spin crossover. The process involves the switching between two molecular spin states (the so-called HS and LS configurations) in (pseudo)octahedral $3 \mathrm{~d}^{4}-3 \mathrm{~d}^{7}$ transition metal complexes by the action of an external stimulus, e.g. temperature, pressure, light irradiation and others. ${ }^{98,99}$ In the case of temperature-induced crossover, the change in the spin state is accompanied by a change in the optical properties of the compound. One of the first examples reported the temperature dependence of the luminescent intensity of a naphthalene fragment covalently linked to a $\mathrm{Ni}$ (II) tetraazamacrocyclic complex, cyclam. ${ }^{100}$ The intensity of the cyclam emission is partially quenched by an energy transfer mechanism whose efficiency decreases with temperatures between 300 and $338 \mathrm{~K}$, resulting in a temperature dependent emission with a maximum relative sensitivity of $3.6 \% \mathrm{~K}^{-1}$ at $300 \mathrm{~K}$ (Table 2 and Fig. 1). More recently, Quintero et al. ${ }^{101}$ and Salmon et al. ${ }^{102}$ reported twocomponent luminescent thermometers also based on the combination of spin-crossover and luminescence in $\mathrm{Rh}-110$ doped ultra-small $\left[\mathrm{Fe}\left(\mathrm{NH}_{2} \text { Triazole }\right)_{3}\right](\mathrm{X})_{2} \mathrm{NPs}$ (where $\mathrm{X}$ stands for tosylate or $\left.\mathrm{NO}_{3}{ }^{-}\right){ }^{101,102}$ The absorption changes of the transition metal complex during the thermal crossover process modulate the Rh-110 luminescence intensity. When deposited on top of nickel nanowires ( 5 wires, $500 \mathrm{~nm}$ wide, $40 \mu \mathrm{m}$ long, separated by $4 \mu \mathrm{m})$, where temperature changes were induced by resistive heating, spatial resolution at the micrometer scale was estimated. ${ }^{102}$ The thermometer operates in the range $305-325 \mathrm{~K}$ with $S_{\mathrm{m}}=1.9 \% \mathrm{~K}^{-1}$ at $309 \mathrm{~K}$ (Table 2 and Fig. 4).

The temperature mapping on microfluidic devices using dyes as fluorescent thermometers was also considered by Samy et al. ${ }^{17}$ and, more recently, by Jung et al. ${ }^{15} \mathrm{RhB}$ was incorporated in PDMS and SU8 polymer matrices and the temperature was determined from the optically active thin layer covering the microfluidic device. Samy et al. ${ }^{17}$ used an intermediate substrate between the fluid and the sensing layer, while Jung et al. ${ }^{15}$ followed a new approach rendering the intermediate layer unnecessary; both examples showed spatial resolutions in the order of hundreds of microns. The correspondent maximum relative temperature sensitivities are $S_{\mathrm{m}}=2.3 \% \mathrm{~K}^{-1}$, at $363 \mathrm{~K}$ (ref. 17) (Table 2 and Fig. 1) and $S_{\mathrm{m}}=1.3 \% \mathrm{~K}^{-1}$ at $338 \mathrm{~K}$ (ref. 15) (Table 2 and Fig. 2). 
A quite different dye-based luminescent molecular thermometer able to map the temperature gradient on a fluid was recently developed by Feng et al. ${ }^{21}$ It consisted of a pyrene-containing triarylboron molecule, DPTB, showing temperature-dependent green to blue luminescence with quantum yield greater than 0.64 over the temperature range $223-373 \mathrm{~K}$, that was dissolved in MOE. The temperature can be determined by the blueshift of the broad emission spectra, ascribed to the thermal equilibrium between twisted intramolecular charge transfer and local excited state of the DPTB molecule. The maximum relative temperature sensitivity is $0.1 \% \mathrm{~K}^{-1}$ at $373 \mathrm{~K}$ (Table 2 and Fig. 4) and the spatial resolution is below $40 \mu \mathrm{m}$ (ref. 21).

Photobleaching is the main limitation of the dye-based thermometers, precluding continuous long-term temperature measurement, which is essential to follow temperature changes at different time scales.

\subsection{Thermometers based on quantum dots}

Semiconductor QDs have been proposed for small-scale thermometry, since they present temperature dependent photoluminescence (intensity changes or emission peak shifts). Their size-tuneable absorption and emission frequencies, high quantum yield and photostability have made QDs an active field of research and development for imaging, labelling and sensing in many areas. Besides optoelectronics, biology and medicine stand out as the most appealing areas, since bioconjugation of QDs can make them target selective.

Standard colloidal synthesis methods provide nanocrystalline semiconductor particles of various sizes (1-10 nm range), with tuneable emission, from UV to infra-red, depending on composition. Common materials are Cd-based binary or ternary semiconductors (e.g. CdSe, CdS and $\mathrm{CdSeTe}$ ). For many purposes, a core-shell structure is preferred, in order to isolate and protect the toxic Cd-based core by a $\mathrm{ZnS}$ shell capsule (1-6 monolayer) resulting in an advantageous increase in the photoluminescence yield. ${ }^{103}$

In earlier reports, ${ }^{33} \mathrm{ZnS}$ coated CdS QDs (5 nm size) were shown to present a considerable change (by a factor of 5) in the photoluminescence intensity in the temperature range 100 to $315 \mathrm{~K}$, accompanied by a $20 \mathrm{~nm}$ blueshift of the $600 \mathrm{~nm}$ range emission band. Those properties were demonstrated with the QD dispersed in a variety of matrices (e.g. poly(lauryl methacrylate) and $\mathrm{TiO}_{2}$ sol-gel derived films) and were obtained in a broad excitation frequency range. A linear and reversible change in the integrated emission intensity near room temperature with $S_{\mathrm{m}}=$ $2.2 \% \mathrm{~K}^{-1}$ at $313 \mathrm{~K}$ (ref. 33) (Table 2 and Fig. 1) was achieved as the main thermometric feature of the composites.

The interest in analysing thermal phenomena at small scales fostered studies of single QDs as local thermal sensors. Li et al. ${ }^{34}$ demonstrated that the time-averaged emission spectra from individual ZnS-coated CdSe QDs, observed through a microscope, are capable of sensing temperature changes with characteristics similar to the ones reported in composite assemblies of QDs. However, the size and shape distribution of QDs leads to differences in the individual characteristics, precluding their use as an absolute thermometer, although relative spectra changes are more reliable. With their technique, a minimum of 1200 QDs (size area with $200-300 \mathrm{~nm}$ diameter) were needed to obtain a precision of one degree. The spectral shift $\left(0.105 \mathrm{~nm} \mathrm{~K}^{-1}\right)$ was reported as the most accurate thermometric property. ${ }^{34}$

To avoid well-known problems associated with the instability and uncertainty of excitation sources or photobleaching and/or photoblinking, the use of dual emission materials is actively being explored. Such dual processes from two excited states in the same QD enable self-calibration of the system and increase the robustness and reliability of intensity-based spectroscopy thermometry allowing ratiometric methods as mentioned in Section 2. This was first reported by Vlaskin et al. in $\mathrm{Zn}_{1-x} \mathrm{Mn}_{x} \mathrm{Se}-\mathrm{ZnCdSe}$ core-shell QD structures. ${ }^{80}$ The solubility of such Mn-doped colloidal semiconductor QDs in water was recently achieved, enabling their use in biophysical applications. ${ }^{31,32}$ These Mn-doped QD nanocrystals exhibit dual emission processes: the direct excitonic and the $\mathrm{Mn}^{2+}$ dopant ion emissions, represented schematically in Fig. 5A and B. The thermally assisted population transferred between the dopant and the excitonic states determines the dynamics of the processes between the levels involved and therefore the intensity ratio of those two emissions. The development of these QDs required the compositional tuning of sufficiently large semiconductor gaps, to leave the $\mathrm{Mn}^{2+}$ levels inside the gap. The use of core-shell structure facilitated the optimization of the properties in a dual step: core doping and energy-gap tuning on the shell. It has been found that the relative intensity of excitonic emission increases with temperature. A discussion of the thermal population mechanisms and its effect on photoluminescence was presented by Beaulac et al. ${ }^{104}$ and Vlaskin et al. ${ }^{80}$ The maximum relative sensitivity values reported near room temperature for these QDs are $1.3 \% \mathrm{~K}^{-1}$ at $318 \mathrm{~K}$ (ref. 80 ) (Table 2 and Fig. 1) and detection responds to $0.2 \mathrm{~K}$ variations (Fig. $5 \mathrm{C}-\mathrm{E}$ ).

Jorge et al. ${ }^{81}$ reported the simultaneous temperature and oxygen sensing using a sophisticated optical fibre setup. A fibre taper doped with an oxygen sensitive sol-gel derived glass was connected to one arm end of a bifurcated fibre, whereas coreshell CdSe-ZnS and CdTe-ZnS QDs embedded in a sol-gel derived hybrid were placed at the end of the other arm to determine temperature. The temperature behaviour of different samples was tested using an optical fibre bundle to excite and collect the QDs' nanocrystals emission (with peak emission wavelengths ranging from 520 to $680 \mathrm{~nm}$ ). The temperature was determined either by the shift of the peak maximum or the normalized intensity. Using the intensity-based algorithm, the QDs demonstrate ratiometric and linear temperature response $(287-320 \mathrm{~K})$ with relative maximum sensitivity of $0.9 \% \mathrm{~K}^{-1}$ at $320 \mathrm{~K}$ (Table 2 and Fig. 2).

Several factors still preclude the use of commercially available QDs in nanoscale thermometry, particularly the bluing, the bleaching, and the blinking under continuous illumination, ${ }^{105-107}$ and the size distribution of the QDs that leads to a non-homogeneous luminescence individual response. The poor solubility, the agglutination, the instability in different environments, and the toxicity to biological systems can also be drawbacks. For example, under acidic $(\mathrm{pH}<5)$ or isotonic conditions, QDs aggregate easily and lose luminescence in an intracellular environment and the degradation of QDs has been shown to release toxic heavy metal ions such as $\mathrm{Cd} .{ }^{108}$ To overcome these disadvantages, the surfaces of QDs need to be coated with inert materials. ${ }^{107}$ Furthermore, the intense activity in the use of QDs 

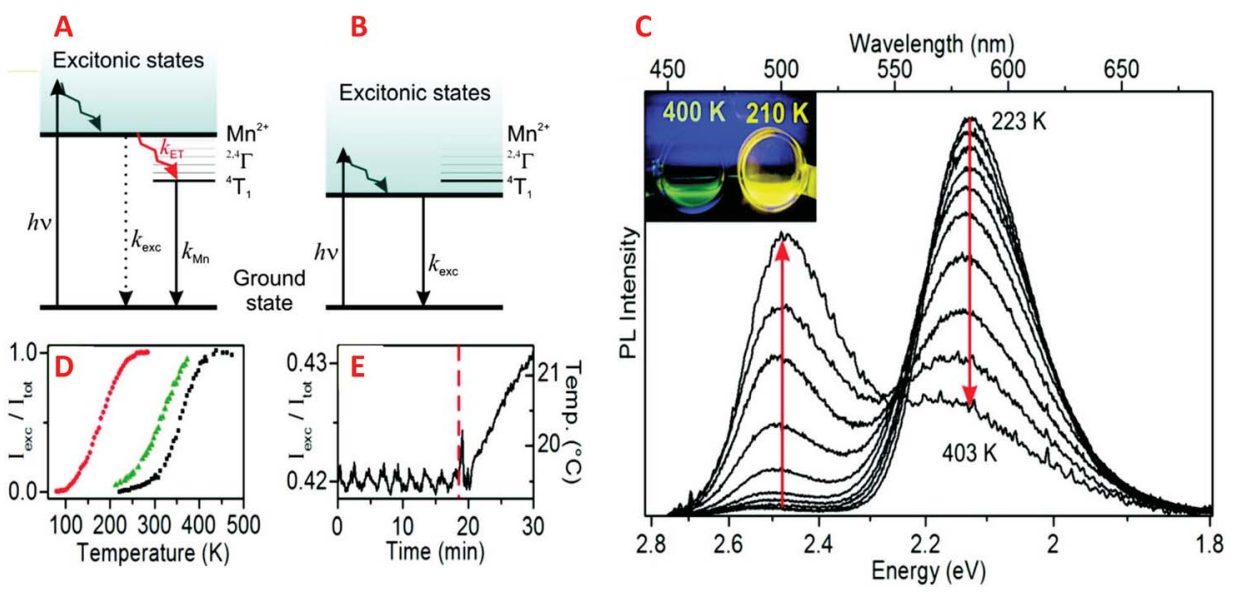

Fig. 5 Schematic representation of electronic structures related to photoluminescence (PL) in colloidal Mn ${ }^{2+}$ QDs, showing the particular cases when $\mathrm{Mn}^{2+}$ states reside within the (A) and outside (B) of the semiconductor gap. The resulting PL spectra as a function of temperature and corresponding colour upon UV excitation are presented in (C). The tunability of the active temperature window is demonstrated by $I_{\text {exc }} / I_{\text {tot }} v s$. temperature response curves for three different samples (D). PL response to $\pm 0.2 \mathrm{~K}$ temperature oscillations (E), and steady warming (dashed line) of Mn ${ }^{2+} \mathrm{QD}$. Reproduced with permission from ref. 80. Copyright American Chemical Society 2010.

for biomedical applications, e.g. imaging, ${ }^{109}$ should pave the way to their use in thermometry. However toxicity and cellular uptake raise problems that still require much research to achieve reproducible and safe methodologies in clinical applications. ${ }^{110,111}$

\subsection{Thermometers based on $\mathrm{Ln}^{3+}$ phosphors}

There are a lot of examples illustrating the temperature dependence of the intensity of the intra-4f transitions and of the lifetime of a particular $4 \mathrm{f}$ excited state. For a comprehensive review of the subject see, for instance, the works on high-temperature thermographic phosphors, ${ }^{61,73}$ and temperature-sensitive paints (the $\mathrm{Ln}^{3+}$ indicator probe is incorporated into a polymer binder and the resulting paint sprayed onto a surface to map temperature distribution). ${ }^{6,112}$ In an interesting and seminal example Wang et al. explored the $\mathrm{Mn}^{2+}$ and $\mathrm{Eu}^{3+}$ emissions in the range 293 to $423 \mathrm{~K}$ using co-doped $\mathrm{Mn}^{2+} / \mathrm{Eu}^{3+} \mathrm{ZnS}$ NPs. ${ }^{113}$ The ratiometric thermometer displays a maximum relative sensitivity of $1.2 \% \mathrm{~K}^{-1}$ at $423 \mathrm{~K}$ (Table 2 and Fig. 2). In this review, however, we put emphasis on the few examples of $\mathrm{Ln}^{3+}$-based thermographic phosphors that effectively illustrate the temperature sensing/mapping at micron and sub-micron scale (Mitsuishi et al. reported millimetre resolution in a polymer optode thin film embedded a $\mathrm{Eu}^{3+}$ tris( $\beta$-diketonate) complex $\left.{ }^{114}\right)$ :

- A metal stripe covered with a thin film of perdeutero-PMMA heavily doped with a Eu(tta) ${ }_{3}$ complex; ${ }^{11}$

- $2 \mathrm{D}$ distribution maps using ${ }^{5} \mathrm{D}_{0}$ rise time temporal response in $\mathrm{Y}_{2} \mathrm{O}_{3}: \mathrm{Eu}^{3+},{ }^{115}$

- A scanning thermal microscope with $\mathrm{Er}^{3+} / \mathrm{Yb}^{3+}$ co-doped fluoride glass (ref. 44) or $\mathrm{PbF}_{2} \mathrm{UCNPs}^{12,43}$ glued at the tip extremity;

- Magnetic hybrid NPs co-doped with $\mathrm{Eu}^{3+}$ and $\mathrm{Tb}^{3+}$ tris( $\beta$-diketonate) chelates, ${ }^{38,58}$

- Di-ureasil ${ }^{88}$ hybrid films (thickness of $\sim 10 \mu \mathrm{m}$ ) embedding $\mathrm{Eu}^{3+} / \mathrm{Tb}^{3+} \quad \operatorname{tris}(\beta$-diketonate $) \quad$ complexes ${ }^{38,58}$ and superparamagnetic maghemite NPs and $\mathrm{Eu}^{3+} / \mathrm{Tb}^{3+}$ tris $(\beta$-diketonate) complexes. ${ }^{89}$

The intracellular thermometers based on UCNPs and $\beta$-diketonate complexes will be deeply discussed in Section 2.5.

The first report demonstrating high-resolution thermal imaging with potential application to integrated circuit diagnostics was presented by Kolodner and Tyson using a metal stripe covered with a thin film of perdeutero-PMMA heavily doped with a $\mathrm{Eu}(\mathrm{tta})_{3}$ complex (concentration of $\sim 40 \mathrm{wt} \%$ ). Thermal images of the luminescent film were obtained with $0.7 \mu \mathrm{m}$ spatial resolution and temperature resolution of $0.08 \mathrm{~K} .{ }^{11}$ Temperature mappings of integrated circuits with better spatial resolutions (up to $0.35 \mu \mathrm{m}$ ) were more recently reported combining thermoreflectance measurements under non-coherent UV, visible and NIR illumination. ${ }^{116}$

The rise time response of the ${ }^{5} \mathrm{D}_{0}$ excited state in $\mathrm{Y}_{2} \mathrm{O}_{3}: \mathrm{Eu}^{3+}$ (3-4\% mole concentration) phosphor was calibrated against a temperature range of 473-973 K demonstrating 2D rise time thermal imaging over an area of $\sim 500 \mathrm{~mm}^{2}$ (diameter of the laser beam on the target). ${ }^{115}$ A state-of-the-art high-speed imaging camera (acquisition rate of 1 million frames per second) was used to capture the $\mathrm{Eu}^{3+}$ temporal response (rise and decay times) that was subsequently post-processed in Matlab ${ }^{\circledR}$ to disclose the thermal map. The uncertainty in the temperature measurements is relatively high, $\sim 20 \%$ at $673 \mathrm{~K}$, although a decrease of the $\mathrm{Eu}^{3+}$ activator concentration could significantly lengthen the rise time and then the accuracy of the thermometer. A maximum relative sensitivity of $2.6 \% \mathrm{~K}^{-1}$ at $973 \mathrm{~K}$ (ref. 115) is computed (Table 2 and Fig. 3), while the spatial resolution was not reported and the temperature determination algorithm is rather complicated, relative to those of decay time and intensity-based measurements, requiring more sophisticated equipment and post-processing computational analysis. ${ }^{115}$ Another example that illustrates the sensing of temperature through a decay time algorithm was reported by Allison et al. for YAG:Ce NPs (average size $\sim 30 \mathrm{~nm}$ ). ${ }^{117}$ The decay lifetimes for the NPs varied from $18(280 \mathrm{~K})$ to $27 \mathrm{~ns}(350 \mathrm{~K})$ with $S_{\mathrm{m}}=0.2 \% \mathrm{~K}^{-1}$ at $350 \mathrm{~K}$ 

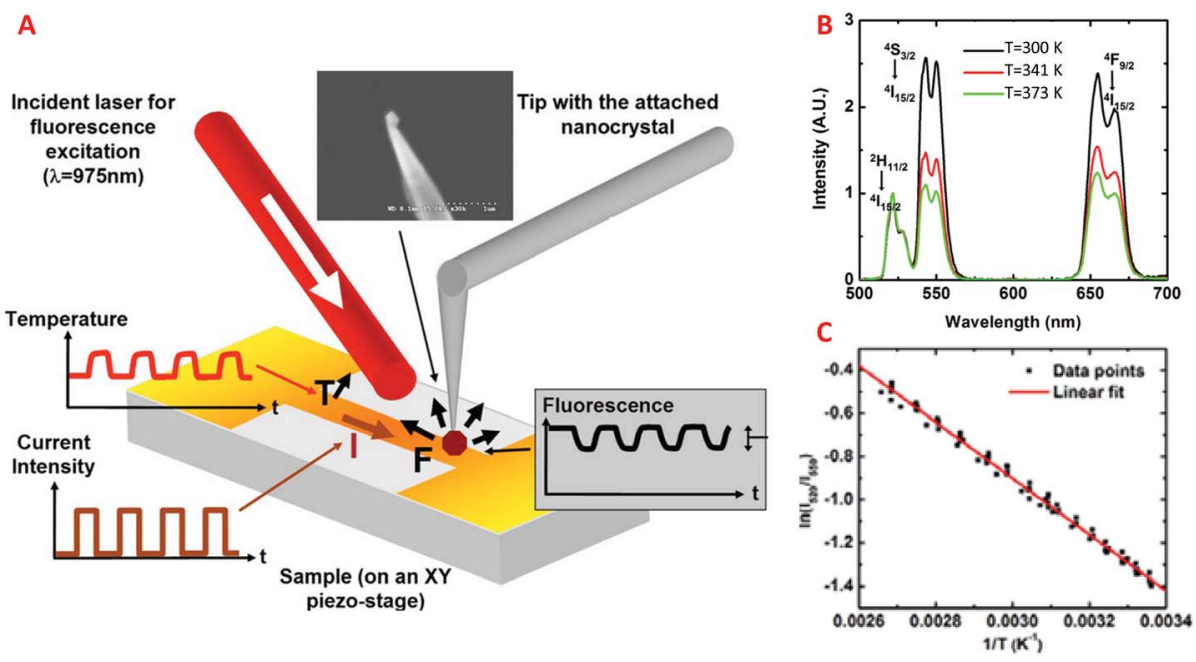

Fig. 6 (A) Schematic SThM-based thermometer developed by Aigouy and collaborators illustrating the excitation laser, the metal strip and the $\mathrm{PbF}_{2}: \mathrm{Er}^{3+} / \mathrm{Yb}^{3+}$ or $\mathrm{Er}^{3+} / \mathrm{Yb}^{3+}$ co-doped fluoride amorphous glass NPs at the end of an AFM tip. The heating of the metal stripe leads to a temperature fluctuation monitored by the fluorescence signal. (B) Emission spectra of $\mathrm{Er}^{3+} / \mathrm{Yb}^{3+}$ co-doped fluoride amorphous glass NPs at the different indicated temperatures. (C) The evolution of the logarithm of the fluorescence intensity ratio as a function of the inverse of the temperature (temperature calibration curve). Reproduced with permission from refs. 43, 44. Copyright American Institute of Physics and Institute of Physics, respectively, 2009.

(Table 2 and Fig. 3) and this significant variation, coupled with the high signal strength that was observed, suggested the utilisation of YAG:Ce NPs as useful thermographic nanophosphors.

Generally, UCNPs consist of $\mathrm{Ln}^{3+}$ ions embedded in crystalline host matrices (e.g. fluorides, oxides, phosphates or sulphides). ${ }^{118,119}$ When excited in the UV-visible range these NPs display down-conversion emission, although they are capable of emitting visible luminescence when excited with NIR light (UC mechanism). The advantage of using $\mathrm{Ln}^{3+}$-based UCNPs depends on the fact that weighty and expensive ultrafast lasers are not necessary, since the NPs can be stimulated using low power and commercial NIR lasers (working on the biological window of tissues, $700-1000 \mathrm{~nm}$ ). Such features makes UCNPs promising as bioimaging probes with attractive features, such as no auto-fluorescence from biological samples and a large penetration depth, and UCNPs have emerged as novel imaging agents for small animals, including tumour-targeted imaging, lymphatic imaging, vascular imaging and cell tracking. ${ }^{125}$ The most studied UCNP-based thermometer uses the $\mathrm{Yb}^{3+} / \mathrm{Er}^{3+}$ ion pair. ${ }^{12,40,41,43,44,82,84-86} \mathrm{The} \mathrm{Yb}^{3+}$ ions were excited by a $975 \mathrm{~nm}$ NIR laser, through an NIR-to-visible UC process in which two low energy photons are "added up" to give one high energy photon. ${ }^{118}$ This NIR excitation is very efficient because, at this wavelength, the $\mathrm{Yb}^{3+}$ ions have a large absorption cross-section. Once excited, they transfer their energy to adjacent $\mathrm{Er}^{3+}$ ions that will glow in the green $\left({ }^{2} \mathrm{H}_{11 / 2} \rightarrow{ }^{4} \mathrm{I}_{15 / 2}\right.$ and ${ }^{4} \mathrm{~S}_{3 / 2} \rightarrow{ }^{4} \mathrm{I}_{15 / 2}, \sim 525$ and $550 \mathrm{~nm}$, respectively) and red $\left({ }^{4} \mathrm{~F}_{9 / 2} \rightarrow{ }^{4} \mathrm{I}_{15 / 2}, \sim 660 \mathrm{~nm}\right)$ spectral regions. These $\mathrm{Er}^{3+}$ transitions are temperature dependent and their intensities were used to determine the temperature using the ratiometric FIR algorithm. One example reporting temperature-dependent FIR between the green and the red UC $\mathrm{Er}^{3+}$ emissions was demonstrated by Wang et al. in $\mathrm{ZnO}: \mathrm{Er}^{3+}$ nanocrystals. ${ }^{82}$ The intensity boost of the green and the red UC emissions, as the annealing temperature increases, with the concomitant increase of the energy gap between the ${ }^{2} \mathrm{H}_{11 / 2}$ and the ${ }^{4} \mathrm{~S}_{3 / 2}$ levels, are ascribed to the decrease of the non-radiative relaxation and the enhancement of the crystal field effect around the $\mathrm{Er}^{3+}$ ions, respectively. The relative sensitivity was computed and the result was $S_{\mathrm{m}}=0.6 \% \mathrm{~K}^{-1}$ at $273 \mathrm{~K}$ (ref. 82) (Table 2 and Fig. 2).

The UC mechanism still presents some drawbacks that need further improvements, both in the materials (e.g. relative concentration, ratio of the dopants, host material, size control) and in the optical point of view (the quantum yields are low and the maximum relative sensitivity values are around $\sim 0.5 \% \mathrm{~K}^{-1}$ at the physiological temperature range, Table 2). Moreover, resolving temperature with a precision lower than 0.1 degree is still to be demonstrated by this approach. ${ }^{41}$

The scanning thermal microscope developed by Aigouy and collaborators ${ }^{12,43,44}$ is able to measure the heating of electrically excited stripes, micro- and nanowires, by gluing $\mathrm{Er}^{3+} / \mathrm{Yb}^{3+}$ codoped fluoride amorphous glass particles or $\mathrm{PbF}_{2}: \mathrm{Er}^{3+} / \mathrm{Yb}^{3+}$ nanocrystals at the end of a sharp AFM tip (Fig. 6). By adjusting the electrical current that flows in the structure, the resulting temperature variations modulate the $\mathrm{Er}^{3+}$ particle emission, giving rise to the thermal contrast. Although the luminescence is affected both by the near-field optical distribution and by temperature variations, this thermal contribution can be treated separately by comparing the obtained images with reference ones recorded when the device is not driven by a current. The temperature is determined analysing the thermal quenching of the $\mathrm{Er}^{3+}$ emission. Since the fluorescent probe is not in direct contact with the wire's surface, the experimental values actually correspond to an average temperature. The results obtained are in good agreement with numerical simulations of the heat dissipation of the micro- and nanowires. ${ }^{44}$

For the scanning thermal microscope using $\mathrm{PbF}_{2}: \mathrm{Er}^{3+} / \mathrm{Yb}^{3+}$ NPs as fluorescence probes $S_{\mathrm{m}}=1.0 \% \mathrm{~K}^{-1}$ at $345 \mathrm{~K}$ (ref. 12 and 43) (Table 2 and Fig. 2) and the thermometer presents a spatial 
resolution in the range of the fluorescent particle size $(<500 \mathrm{~nm})$. For the SThM with the $\mathrm{Er}^{3+} / \mathrm{Yb}^{3+}$ co-doped fluoride amorphous glass particles, $S_{\mathrm{m}}=1.1 \% \mathrm{~K}^{-1}$ at $342 \mathrm{~K} .{ }^{44}$ Tikhomirov et al. ${ }^{85}$ and Singh and $\mathrm{Rai}^{84}$ used an analogous UC mechanism to fabricate optical nanoheaters of fluoride $\mathrm{Yb}^{3+} / \mathrm{Er}^{3+}$ and $\mathrm{Gd}_{2} \mathrm{O}_{3}: \mathrm{Yb}^{3+} / \mathrm{Er}^{3+}$ co-doped UCNPs, respectively. The NPs were excited by NIR radiation (diode laser at $\sim 975 \mathrm{~nm}$ ) that is dissipated via phonon relaxation, resulting in a temperature increase, measured by FIR of the ${ }^{2} \mathrm{H}_{11 / 2} \rightarrow{ }^{4} \mathrm{I}_{15 / 2}$ and ${ }^{4} \mathrm{~S}_{3 / 2} \rightarrow{ }^{4} \mathrm{I}_{15 / 2}$ transitions until $1173 \mathrm{~K}$. While for fluoride $\mathrm{Yb}^{3+} / \mathrm{Er}^{3+}$ co-doped NPs the sensitivity is not reported (and cannot be computed due to the absence of data), ${ }^{85}$ Singh and Rai estimate $S_{\mathrm{m}}=0.2 \% \mathrm{~K}^{-1}$ at $600 \mathrm{~K}$ (Table 2 and Fig. 2). ${ }^{84}$

The last two examples listed above that effectively illustrate the temperature sensing/mapping at micron and sub-micron scale encompass organic-inorganic hybrids and will be discussed in the next section.

\subsection{Complex thermometric systems}

The use of polymers in luminescence thermometers exploits their extraordinary structural properties. They can play a passive role, simply as a physical support conferring their unique mechanical properties, or they can be an active component in complex thermometric structures thanks to their sensitivity to temperature changes. Actually, the sensing capacity of polymers has been extensively explored, in general (see the reviews of $\mathrm{Hu}$ and $\mathrm{Liu}^{\mathbf{1 2 0}}$ and Guo et al. ${ }^{121}$ ), and in particular for temperature measurements (see the recent review by Pietsch et al. ${ }^{63}$ ). This is also the case for organic-inorganic hybrids, including LDH materials. ${ }^{122,123}$ Here we focus on the specific characteristics dealing with the nanoscale and on the comparative performances of these thermometers.

2.4.1 Polymer based systems. Polymers have first been used in optical temperature-responsive materials as supporting media to optically active molecules due to their well-known good processibility and mechanical properties. ${ }^{63}$ An example is the use of PS and polyacylonitrile to increase the solubility of $\mathrm{C}_{70}$, avoiding simultaneously the luminescence crosstalk with oxygen. ${ }^{124}$ Pristine fullerene $\mathrm{C}_{70}$ encapsulated in polymer presents delayed fluorescence/prompt fluorescence intensity ratio that is temperature dependent. The thermally activated delayed fluorescence of the $\mathrm{C}_{70}$-based thermometer was shown to follow temperature changes in a ratiometric algorithm (perylene was incorporated as an internal standard) in the range 293-363 K (ref. 124) with $S_{\mathrm{m}}=1.3 \% \mathrm{~K}^{-1}$ at $330 \mathrm{~K}$ (Table 2 and Fig. 1). Dispersion of $\mathrm{C}_{70}$ in PtBMA enabled a wider temperature range (293-363 K), to be covered..$^{79}$ Both delayed fluorescence lifetime and intensity based thermometers were proposed to measure temperature in the absence of oxygen. The maximum relative sensitivities are $1.8 \% \mathrm{~K}^{-1}$ at $330 \mathrm{~K}$, for intensity ratio, and $2.2 \% \mathrm{~K}^{-1}$ at $363 \mathrm{~K}$, for delayed fluorescence lifetime. ${ }^{79}$ Another example is the use of PVA films to embed thermofluorescent PDA supramolecules and cast the composite on resistance random access memory devices in order to determine imprinted temperature gradients associated to filamentary defects. ${ }^{125}$ This is implemented based on the irreversible fluorescence intensity increase of PDAs when temperature increases from room temperature to $\sim 350 \mathrm{~K}$.

The optical principles in complex thermometric systems are similar to those already explained for simple systems, and include temperature induced fluorescence enhancement, quenching or lifetime change, temperature emission shifts, FRET, absorbance enhancement or quenching, absorbance shifts, plasmon resonance, exciton-plasmon interaction, etc. ${ }^{63}$ The temperature sensing mechanism is typically based on a polymer transition from hydrophilic-swollen-globule-state to hydrophobiccollapsed-coil-state. ${ }^{126}$ These two processes are interconnected in such a way that the polymer conformation affects the optical emitter environment, such as polarity, microviscosity and donoracceptor average distances in the case of FRET. Optical emitters representing all the types described in previous sections (organic dyes, QDs and $\mathrm{Ln}^{3+}$ phosphors) have been used in these polymer structures. An illustration of polymer-phosphor configurations is shown in Scheme 1. The simplest system of this kind is that containing a thermo-responsive polymer and an organic dye, which is grafted to the polymer's backbone or simply encapsulated. ${ }^{63}$

The most explored polymers are PNIPAM, which has a lower critical solution transition at $305 \mathrm{~K},{ }^{6,20,78,127-139}$ together with others polymers of the same family, such as NNPAM or NIPMAM. ${ }^{134}$ Other examples include PEG-based polymers, ${ }^{77,140-144}$ PMMA $^{145}$ and helix-forming polysaccharides (schizophyllan). ${ }^{146}$ In the great majority of these examples, the optically active component is an organic dye and the polymer's main role is to change the polarity of the dye surrounding media. ${ }^{6,20,77,78,127-129,132,134,135}$ Most of these systems are based on changes in the emission intensity and lifetime ${ }^{20,128,129,131}$ (e.g. Gota et al. reported a $S_{\mathrm{m}}$ value of $10.4 \% \mathrm{~K}^{-1}$ at $308 \mathrm{~K},{ }^{128}$ Table 2 and Fig. 1). Lee et al. ${ }^{142}$ have reported an interesting example of a thermometer based on a change in intensity (non-ratiometric). The thermometer was designed for biological applications since it is composed of a FDA-approved biocompatible PEG-based copolymer and a fluorescent dye emitting in the NIR region allowing intra-tissue sensing in the 274-353 $\mathrm{K}$ temperature range. PNIPAM can, for example incorporate hemicyanine (PNIPAM- $\mathrm{co}-\mathrm{HC}^{129}$ ), boron-dipyrromethene (PNIPAM-coBODIPY ${ }^{131}$ ) or fluorescent modified acrylamide (PNIPAM:FMA ${ }^{133}$ ).

Another example based on NIR emission designed for biomedical applications is composed of indocyanine green dye encapsulated in a micelle of PEO-PPO copolymer. ${ }^{144}$ The

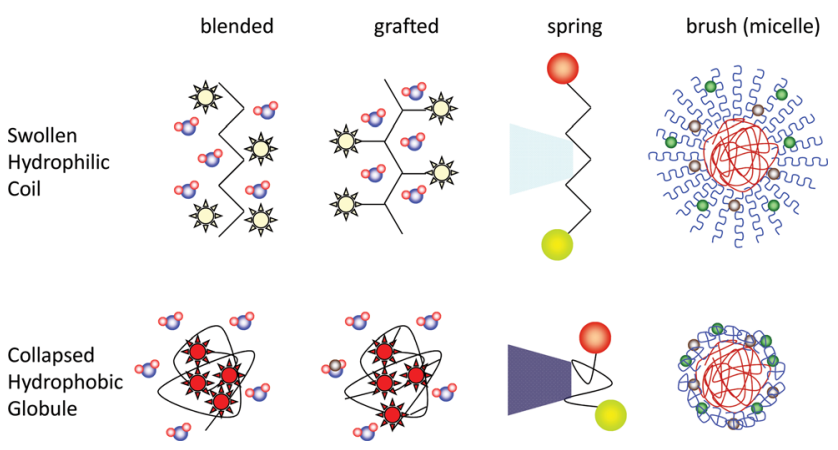

Scheme 1 Polymer-phosphor thermometer structures. 
micelle's volume reduces almost 5-fold when the temperature increases from 290 to $310 \mathrm{~K}$, producing an enhancement of the luminescence emission (non-ratiometric) by $\sim 6$ times.

Other thermometers are based on the temperature dependence of an intensity ratio (the ratiometric thermometers listed above), and on the change of the wavelength at which absorption ${ }^{132,146}$ or fluorescence ${ }^{136}$ is maximum. The ratiometric thermometer reported by Pietsch et al..$^{77}$ uses the excimers-to-monomers emission intensity ratio of pyrene. Below the polymer phase transition, pyrene molecules are exposed to the polar environment leading to the formation of excimers, with the corresponding increase of their fluorescence. The ratiometric thermometer reported by Chen and $\mathrm{Chen}^{78}$ is based on a dualband dye (3-hydroxyflavone) associated to normal excited state intramolecular charge transfer and tautomer excited state intramolecular proton transfer. The latter is suppressed in highly polar environments, as that provided by PNIPAM in the low temperature swollen state, leading to a change in the relative normal and tautomer fluorescence intensities. Another approach has been proposed to improve reproducibility problems based on the fluorescence resonance energy transfer between a fluorescent donor, NBD, and an acceptor, RhB. ${ }^{138}$ In this case, the donor is also sensitive to $\mathrm{pH}$. This thermometer works between 293 and $323 \mathrm{~K}$ with $S_{\mathrm{m}}=13.3 \% \mathrm{~K}^{-1}$ at $313 \mathrm{~K}$ (Table 2). The PNIPAMporphyrin system reported by Yan et al. ${ }^{132}$ displays a blue-shift in the absorption maximum upon heating, possibly associated with the change in local polarity. An extended operation range is elegantly achieved by using porphyrins coordinated to different metal ions.

Normally, the operation range is restricted to the phase transition region (typically $300-310 \mathrm{~K}$, in the case of PNIPAM), with some hysteresis being observed. The range can be extended as described in the preceding example by Yan et al. ${ }^{132}$ using polymers with an upper critical solution transition, such as PMMA ${ }^{145}$ or by using other members of the NIPAM monomer family and their copolymers. ${ }^{127}$ However, the possible integration of these polymers in an "all-in-one" responsive thermometer is still to be shown. A typical limitation of the thermometers based on polymers is the hysteresis, i.e., differences in the output, for the same temperature value, depending on if the temperature is increasing or decreasing. ${ }^{134}$ This translates to an error in the temperature determination that may extend into a relevant fraction of the operation range. In such conditions the sensitivity depends also on the optical active component as fluorescent dyes whose response is connected to the polarity of the surrounding media, a widely used choice. Alternatively, hysteresis can be reduced by using PEG-based methacrylates. ${ }^{77,143}$

Concerning both the hysteresis and limited operation range issues, a significant improvement was presented by Gota et al. ${ }^{134}$ using a smart combination of polymeric thermometers to cover different temperature ranges with higher sensitivity. Using an ionic component to prevent intermolecular aggregation of $N$-alkylacrylamide and fluorescent components, it has reported four fluorescent polymeric thermometers that offer good temperature resolution (e.g. $<0.2 \mathrm{~K})$. The temperature dependence was rationalized by a temperature-induced structural change in aqueous solution that generates a large fluorescence enhancement with a small increase in temperature. In fact, this clever phosphor blend results in a fluorescent polymeric thermometer, covering the temperature range $277-340 \mathrm{~K}$, with $S_{\mathrm{m}}=12.5 \% \mathrm{~K}^{-1}$ at $300 \mathrm{~K}$ (ref. 134) (Table 2 and Fig. 1).

An interesting strategy, followed by Wong et al. ${ }^{147}$ uses the relaxation time of fluctuations in the fluorescence of a protein (associated with reversible protonation). This depends on $\mathrm{pH}$ and temperature and a bifunctional sensor was demonstrated working in the $283-323 \mathrm{~K}$ temperature range with $S_{\mathrm{m}}=4.1 \% \mathrm{~K}^{-1}$ at $322 \mathrm{~K}$ (ref. 147) (Table 2 and Fig. 1).

Most of the preceding examples are named micro-, nano- or molecular thermometers, although the name represents only the size of the responsive unit and not the spatial resolution achieved in a temperature measurement. The exceptions are the intercellular thermometers reported by Gota et al. ${ }^{6}$ and $\mathrm{Ye}$ et al. ${ }^{30}$ (Section 2.5) and the micro-fluidics thermometer reported by Graham et al. displaying a resolution of $\sim 50 \mu \mathrm{m}$ around $305 \mathrm{~K}^{20}$ This latter example is a PNIPAM water-soluble thermometer based on the temperature dependence of the fluorescence lifetime of a benzofurazan copolymer. The temperature was determined using a microscope-coupled CCD camera, by pixel-by-pixel emission intensity decay analysis, resulting in a maximum relative sensitivity of $16.2 \% \mathrm{~K}^{-1}$ at $307 \mathrm{~K}$ (ref. 20) (Table 2 and Fig. 4).

The optical limitations of organic dyes, which have already been explained in detail (Section 2.1), can be overcome by using metal nanoparticles or QDs as the optical emitter component. A convenient choice is gold nanoparticles. In a typical case, such as presented by Mitsuishi et al., ${ }^{139}$ gold NPs are assembled to PNIMAN copolymers that show folded to extended conformational changes in the 293 to $313 \mathrm{~K}$ temperature range inducing a shift in the UV-visible absorption peak of the assembly from $540 \mathrm{~nm}$ to $546 \mathrm{~nm}$, corresponding to $S_{\mathrm{m}}=0.1 \% \mathrm{~K}^{-1}$ at $295 \mathrm{~K}$. Another example of a thermometer based on the temperature dependent position of the absorption maximum is that reported by Honda et al. ${ }^{137}$ In this case, PNIPAM coats Au NPs and acts as a dielectric with a temperature dependent refractive index that changes the Au surface plasmon peak wavelength. When the optical component is a $\mathrm{QD}$, the polymer transition produces a change on the average inter-QDs that is reflected on the emission properties. ${ }^{1,140,148}$ For instance, CdTe QDs show increased quantum yields when incorporated into a temperaturesensitive PNIPAM hydrogel and both the fluorescence intensity and the maximum emission wavelengths were sensitive (in a completely reversible way) to external temperature stimuli that induce the typical coil-globule transition of PNIPAM. ${ }^{148}$

A further improvement has been the introduction of plasmonic metaresonance sensors. ${ }^{149} \mathrm{~A}$ reversible nanothermometer is built from two different NPs connected by a polymer acting as a molecular spring. This type of complex system was introduced by Kotov et al. ${ }^{140}$ The underlying optical mechanism involves plasmon resonance and exciton-plasmon interaction. A typical structure consists of $\mathrm{Au}$ nanoparticles $(\sim 20 \mathrm{~nm}$ large $)$ surrounded by CdTe NPs with a smaller size ( $\sim 4 \mathrm{~nm}$ large) linked to the Au surface by a linear polymer (e.g. PEG). The variation of the length of the linker polymer in the temperature range of 293-333 K changes the inter-Au-CdTe distance-dependent resonance conditions of the $\mathrm{CdTe}$ emission. The relative sensitivity cannot be computed due to the absence of published data. ${ }^{140}$ The CdTe-PEG-Au system is, therefore, an intriguing example of a nanoscale superstructure that undergoes 
a reversible structural change in response to the environmental conditions. The combination of this property with plasmonexciton interactions that display a high sensitivity of the optical output on the distance modulations represents the foundation of a new family of sensing and optoelectronic devices. ${ }^{140}$

$\mathrm{Ln}^{3+}$ phosphors are also used as optical emitters in complex polymer systems. Most of the examples are comprised of $\mathrm{Ln}^{3+}$ $\beta$-diketonate complexes as temperature sensors through a thermally driven energy back transfer mechanism between the intra$4 \mathrm{f}$ levels that are resonant with the lowest ligand triplet excited state. ${ }^{72,150}$ Luminescent molecular thermometers based on $\mathrm{Eu}^{3+}$ tris( $\beta$-diketonate) coordination compounds were proposed in the past decades involving isolated complexes ${ }^{62,72,150}$ or complexes embedded into polymers ${ }^{11,29,36,114,151,152}$ and organic-inorganic hybrid materials (see below). ${ }^{37-39,58,89}$ A serious drawback of $\mathrm{Ln}^{3+}$ $\beta$-diketonate complexes relates to their photodecomposition under UV irradiation, ${ }^{153}$ which decreases luminescence intensity and, thus, makes molecular thermometers based on these complexes not suitable for long-term monitoring. The incorporation of the complexes into polymers ${ }^{154}$ and organic-inorganic hybrid hosts, ${ }^{153,155}$ however, considerably improves the UV photostability, overcoming, therefore, the main drawback of the use of such complexes as long-term monitoring luminescent thermometers.

One interesting example of polymer-containing $\mathrm{Eu}^{3+}$ chelates for simultaneous luminescent sensing of temperature and oxygen was reported by Borisov and Wolfbeis using $\mathrm{Eu}(\mathrm{tta})_{3} \mathrm{~L}$ complexes $(\mathrm{L}=$ dipyrazolytriazine derivative) and a palladium porphyrin oxygen indicator embedded into PTBS microbeads. ${ }^{36}$ Both indicators of the dual sensor can be excited by a $405 \mathrm{~nm}$ LED and their luminescence is easily separated using appropriate filters. Based on the temperature dependence of the ${ }^{5} \mathrm{D}_{0}$ lifetime of the $\mathrm{Eu}(\mathrm{tta})_{3} \mathrm{~L}$ complex a luminescent thermometer working in the range 273$333 \mathrm{~K}$ with $S_{\mathrm{m}}=1.1 \% \mathrm{~K}^{-1}$ at $333 \mathrm{~K}$ was demonstrated ${ }^{36}$ (Table 2 and Fig. 3). An illustrative example of a ratiometric polymercontaining $\mathrm{Eu}^{3+}$ thermometer is the encapsulation of two colour luminescent dyes (tris(benzoylacetonato)mono(phenanthroline) europium(III) and BBS) in gas-impermeable $\mathrm{P}(\mathrm{VDC}-\mathrm{co}-\mathrm{AN})$ NPs. ${ }^{29}$ The polymer NPs shows full reversible temperature response enabling rapid colorimetric temperature estimation in the range $273-323 \mathrm{~K}$. A photographic readout produces a quantitative two-dimensional thermo-imaging. The relative sensitivity is $S_{\mathrm{m}}=7.2 \% \mathrm{~K}^{-1}$ at $323 \mathrm{~K}$ (Table 2 and Fig. 2).

Polymer-based thermometers have some drawbacks, such as hysteretic phase transitions, already mentioned, and a possible non-uniform response across the polymer-bead in the case where the optical response depends on the local chemical environment. The multi-optical response of the system to temperature, $\mathrm{pH}$, oxygen content and saline conditions may constitute a drawback since the temperature response may be hindered by the change in other parameters but it is also an opportunity to design multiresponsive logic devices. ${ }^{156,157}$ Polymer-based thermometers have the advantage of having higher sensitivities if only a narrow range (typically around room temperature) is requested. Also, these polymers can be designed as biocompatible beads, which is of fundamental importance for in vivo applications.

A special case of complex thermometric systems based on polymer conformation transitions is the one using DNA that will be presented in Section 2.5 due to its implication in biological systems. The unique $\pi$-sack structure of double-helical DNA can be used to develop novel DNA-based nanodevices, as the electronic properties depend strongly on the orientation of the $\pi$-staking. ${ }^{158-160}$ Thus, transitions between double-stranded DNA structures from B- to Z-DNA conformations can be induced by changes in temperature. Differences in the electronic properties of each $\pi$-stacking and in the charge transfer process from a fluorescent probe, like, for instance, 2-aminopurine, result in marked changes in emission that can be readily monitored. Based on these results, Tashiro and Sugiyama have proposed a molecular nanothermometer and shown that fluorescence intensity correlates reproducibly with temperature in the range between 275 and 305 K. ${ }^{161}$

Barilero et al. ${ }^{19}$ proposed a different approach using organic dyes as unimolecular fluorescent temperature probes for dualemission-wavelength measurements in aqueous solutions. The basic concept relies on a non-thermal chemical reaction (either a conformational transition or a protonation) inducing a modification of the dye emission spectra as the temperature changes. A sophisticated temperature sensing method using a DNA molecular beacon that spontaneously exchanges its configuration from a closed state (displaying a stem and a loop) to an open form was recently proposed (Fig. 7). ${ }^{19}$ The optical signal comes from the labelling of the beacon extremities by a pair of fluorophores engaged in FRET conferring appropriate photophysical properties for a ratiometric analysis. The authors describe a Fluorescein-Texas-Red donor-acceptor pair thermometer for the temperature interval 278-318 K with $S_{\mathrm{m}}=$ $4.5 \% \mathrm{~K}^{-1}$ at $295 \mathrm{~K}$ (Table 2 and Fig. 2). Using $130 \mu \mathrm{m}$ thick microfluidic chamber locally heated by a thin film resistor, temperature measurements were illustrated by ratiometric fluorescence imaging, exciting at $480 \mathrm{~nm}$ and monitoring the ratio of the intensities at 535 and $620 \mathrm{~nm}$. Microfluidics minimizes undesired photobleaching and the experimental conditions were setup in order to avoid crosstalk with $\mathrm{pH}$ and ionic strength changes in the fluid induced by temperature changes. The temperature profiles were compared with simulated results showing a concordance of $0.15 \mathrm{~K}$ within the experimental error of the reference thermocouple used..$^{19}$ The approach might have limitations to measure temperature in biological tissues or even in moving fluids.

2.4.2 Organic-inorganic hybrids based systems. The synergy of the intrinsic characteristics of organic-inorganic hosts with the luminescence features of emitting centres (e.g. organic dyes, QDs and $\mathrm{Ln}^{3+}$ ions) offer excellent prospects for designing new luminescent organic-inorganic hybrids with enhanced desired characteristics, therefore opening exciting new directions in materials science and related technologies, with noteworthy results in the ecofriendly integration, miniaturization, and multifunctionalization of devices. ${ }^{153,162-166}$

Progress in nano and biotechnology craves the miniaturization of luminescent thermometers down to the micro- and nanoscale regimes with high spatial resolution; the intracellular temperature mapping is, for instance, an example. Organic-inorganic hybrids embedded organic dyes, QDs or $\mathrm{Ln}^{3+}$ ions - particularly processed in the form of NPs - have emerged as an interesting class of materials to develop new micro- and nanothermometers, mostly due to: 

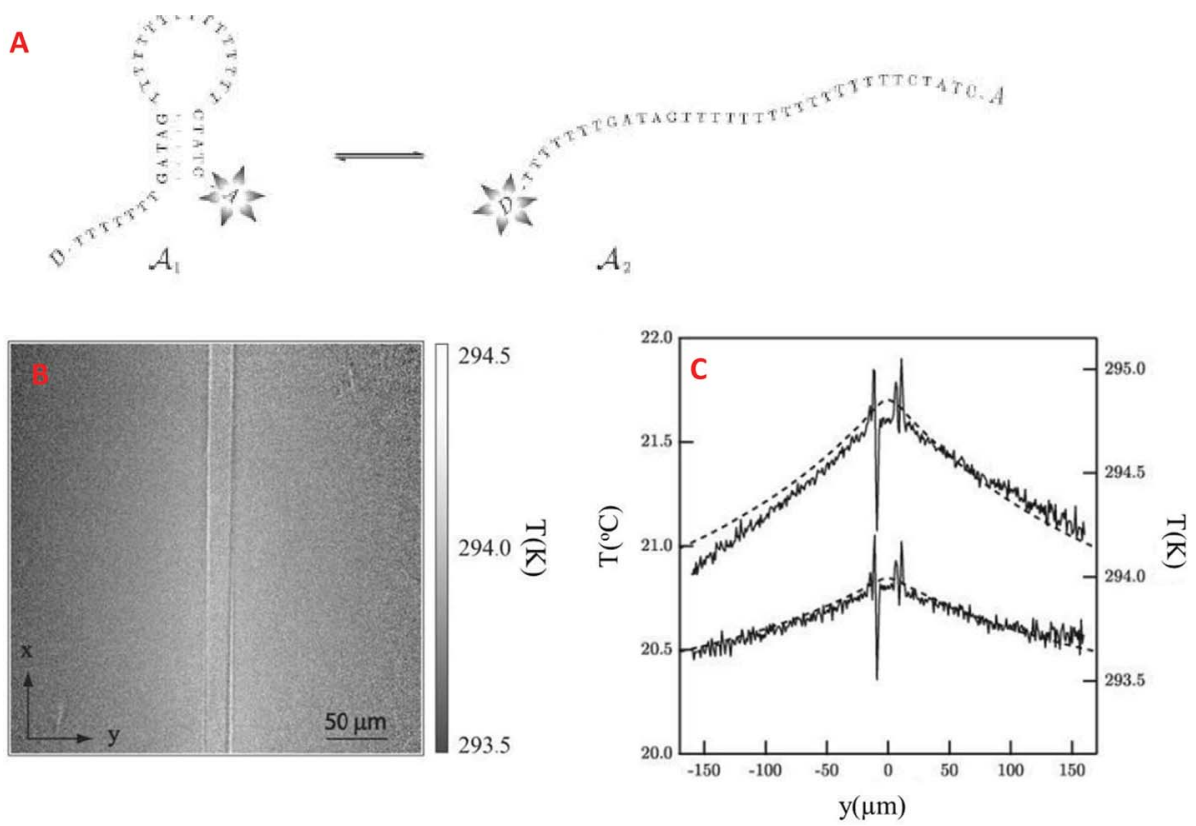

Fig. 7 (A) The molecular beacon platform: in the closed state $\left(A_{1}\right)$, stable at the lowest temperatures, the two fluorophores engaged in energy transfer (i.e., the Fluorescein D and Texas-Red A) are in close proximity. Hence, upon exciting the donor, one essentially collects fluorescence emission from the acceptor. In contrast, at the largest temperatures the open state $\left(\mathrm{A}_{2}\right)$ is favored, the two fluorophores are distant, and the donor excitation essentially results in the donor; (B) normalized ratiometric image $(x, y)$ from which the temperature field can be retrieved using the temperature calibration curve emission. (C) FEM simulations (dashed line) and experimental (solid line) temperature profiles along the $y$-axis for two different values for the current ( $i=2.83 \mathrm{~mA}$ on top and $2.00 \mathrm{~mA}$ at bottom). Reproduced with permission from ref. 19. Copyright American Chemical Society 2009 .

- Flexibility, relative facile chemistry, and highly controlled purity, since they are synthesized from pure precursors;

- Low processing temperature, a key factor for devices' miniaturization and for reduction of the processing cost;

- Encapsulation of large amounts of emitting centres, isolated from each other and protected by the organic-inorganic host, enabling the control of nonradiative decay pathways;

- Amelioration of the thermal and optical stability and mechanical properties, relative to those of the isolated emitting centres, overcoming, therefore, some of the main drawbacks of the use of isolate dyes, QDs and $\mathrm{Ln}^{3+}$ chelates as long-term monitoring luminescent thermometers.

Non-ratiometric ${ }^{37,167}$ and ratiometric ${ }^{29,38,39,89}$ thermometers acting at the sub-micron scale were fabricated using $\mathrm{Ln}^{3+}$-based organic-inorganic hybrids. There are few examples reported in the last 2-3 years of thermometers encompassing mixtures of organic dyes with $\mathrm{Ln}^{3+} \beta$-diketonate complexes ${ }^{37,39}$ and $\mathrm{Eu}^{3+}$ / $\mathrm{Tb}^{3+} \beta$-diketonate complexes ${ }^{38,58,89,167}$ embedded into siloxane matrices These examples, as mentioned above, are among the few involving $\mathrm{Ln}^{3+}$ ions that effectively illustrate the temperature sensing/mapping at micron and sub-micron scale.

Peng et al ${ }^{37}$ reported the incorporation of the Eu-DT complex into siloxane hybrid NPs (formed by a BTD-PMMA hybrid matrix with a silica outer layer). The NPs display strong temperature dependence, in both luminescence intensity and ${ }^{5} \mathrm{D}_{0}$ lifetime, over the physiological range. In fact, the intensity of the ${ }^{5} \mathrm{D}_{0} \rightarrow{ }^{7} \mathrm{~F}_{2}$ transition decreases by $3.07 \% \mathrm{~K}^{-1}$ on increasing the temperature from 298 to $318 \mathrm{~K}$, corresponding to $S_{\mathrm{m}}=6.8 \% \mathrm{~K}^{-1}$ at $323 \mathrm{~K}$ (Table 2 and Fig. 1). The temperature resolution is $\sim 0.3 \mathrm{~K}$, assuming a precision of $1 \%$ in emission intensity. The ${ }^{5} \mathrm{D}_{0}$ lifetime drops rapidly with the increase of temperature in that range displaying a maximum relative sensitivity of $S_{\mathrm{m}}=$ $3.2 \% \mathrm{~K}^{-1}$ at $320 \mathrm{~K}$ (ref. 37) (Table 2 and Fig. 3). Another example of a non-ratiometric thermometer was presented by Tan and Wang ${ }^{167}$ involving a dual luminophore probe based on a mixture of several $\mathrm{Eu}^{3+}$ and $\mathrm{Tb}^{3+}$ complexes $\left(\mathrm{Eu}(\mathrm{dbm})_{3} \cdot 2 \mathrm{H}_{2} \mathrm{O}\right.$, $\mathrm{Eu}(\mathrm{acac})_{3} \cdot 2 \mathrm{H}_{2} \mathrm{O}, \mathrm{Tb}(\mathrm{acac})_{3} \cdot 2 \mathrm{H}_{2} \mathrm{O}$ and $\left.\mathrm{Tb}(\mathrm{ca})\right)$. The hydrogels (based on PAA and OTES) are able to measure the temperature in the range $283-323 \mathrm{~K}$ with $S_{\mathrm{m}}=2.1 \% \mathrm{~K}^{-1}$ at $320 \mathrm{~K}$ (ref. 167) (Table 2 and Fig. 1).

Ratiometric thermometers were demonstrated by Peng et al. ${ }^{39}$ using siloxane hybrid NPs formed by a BTD-PMMA core incorporating the Eu-DT complex and a OASN reference covered with a silica outer layer $\left(S_{\mathrm{m}}=7.2 \% \mathrm{~K}^{-1}\right.$ at $323 \mathrm{~K}$, Table 2 and Fig. 2) ${ }^{39}$ and by Brites et al. using magnetic hybrid NPs co-doped with $\mathrm{Eu}^{3+}$ and $\mathrm{Tb}^{3+}$ chelates. ${ }^{38,58,89}$

In these latter examples, siloxane-based hybrid magnetic nanoclusters (size ranging from 100 to $400 \mathrm{~nm}$ ) formed by a $\gamma-\mathrm{Fe}_{2} \mathrm{O}_{3}$ maghemite core (hydrodynamic size of $21.0 \pm 4.0 \mathrm{~nm}$ ) coated with a TEOS-APTES organosilica shell and co-doped with $\left[\mathrm{Eu}(\mathrm{btfa})_{3}(\mathrm{MeOH})(\right.$ bpeta)$]$ and $\left[\mathrm{Tb}(\mathrm{btfa})_{3}(\mathrm{MeOH})(\right.$ bpeta) $]$ $\beta$-diketonate chelates were prepared by combining (i) self-referencing allowing absolute measurements; (ii) $S_{\mathrm{m}}=4.9 \% \mathrm{~K}^{-1}$ at $143 \mathrm{~K}$, Table 2 and Fig. 2 (better than $0.5 \% \mathrm{~K}^{-1}$ in the physiological temperature range); (iii) high photostability for long-term use; (iv) ability to fine-tune emission colour as a function of temperature, $\mathrm{Eu}^{3+} / \mathrm{Tb}^{3+}$ proportion and hybrid host; (v) a temperature uncertainty of $0.5 \mathrm{~K}$; and (vi) multifunctionality, as it can be hosted in silica-coated magnetic NPs. ${ }^{38}$ Self-referenced luminescent thermometers were also demonstrated using di-ureasil hybrid films embedding the superparamagnetic maghemite NPs and the $\mathrm{Eu}^{3+} / \mathrm{Tb}^{3+}$ chelates. ${ }^{89}$ The temperature 
operation range with $S_{\mathrm{m}}$ up to $1.0 \% \mathrm{~K}^{-1}$ (Table 2 and Fig. 2) was extended to $300-350 \mathrm{~K}$, relative to that of the maghemite covered TEOS-APTES NPs incorporating the same complexes. A spatial

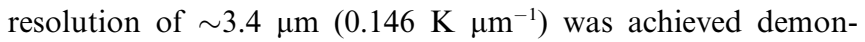
strating that the combination of the molecular thermometer with a nanometric magnetic/luminescent host matrix provides multifunctionality at the submicron scale. ${ }^{89}$

Layer double hydroxides (LDHs) are another class of organicinorganic hybrids also used in complex thermometric systems. LDH layers promote temperature changes in alignment, packing and or conformational constraints of an optically responsive part, which is sensitive to those changes. ${ }^{122,123}$ While Itoh et al. ${ }^{122}$ use changes in intensity to monitor the temperature, Yan et al. ${ }^{123}$ use the ratio between two fluorescence intensities. Nevertheless, in both examples, rather than a thermometer the material is presented as an on-off sensor working between 293 and $373 \mathrm{~K}$.

\subsection{Intracellular thermometers}

Temperature biological sensors are an integral part of cell membranes and their role is essential for the cell's survival. The understanding of how these biological sensors process thermal information and how thermal processes develop at cellular level is of utmost importance in cell physiology. Apart from biological and structural approaches based on the conformation changes of DNA, RNA, proteins and lipids and their catalytic influence on subsequent biological processes, ${ }^{168,169}$ there has been strong interest in the direct measuring and mapping of intracellular temperature. ${ }^{3,9,10}$ Temperature influences both the cell equilibrium constants and its biochemical reaction kinetics governing, for instance, the creation and maintenance of concentration gradients, the metabolism and a large variety of other cellular activities..$^{5,6,8,30}$ Moreover, the cellular pathogenesis of diseases (e.g. cancer) is characterized by extraordinary heat production (pathological cells are warmer than normal ones because of their enhanced metabolic activity, as mentioned in the introduction $)^{6,30,170}$ and temperature fluctuations of a few degrees are significant, for instance, in biomedical and cancer diagnosis and during hypothermia therapy or surgery. ${ }^{75}$ Direct observation of intracellular temperature distribution and of its time evolution open new possibilities for understanding endogenous energy management in the cell, whether by performing work or by producing heat (thermogenesis), and how heat is released and to determine exogenous heat impact (thermal shocks). ${ }^{171}$ Furthermore, the direct observation of inhomogeneous intracellular temperature progression raises interesting new possibilities, including further innovations in nanomaterials for sensing local responses, as well as the concept of subcellular temperature gradient for signalling and regulation in cells. ${ }^{8}$ Intracellular temperature mapping will result in a better understanding of cellular events and the establishment of novel diagnoses and therapies. This section describes developments oriented to measured temperature inside the cell. Complementary descriptions of thermometry developments based on biological entities, particularly mRNA can be found in Section 3.4.

Looking ahead to cellular temperature measurements, the introduction of fluorescent probes (NBD and LAURDAN) within the cells' membranes was reported by Chapman et al. ${ }^{3} \mathrm{~A}$ considerable temperature-dependent Stokes shift was reported, as the membranes undergo a gel-to-liquid-crystalline phase transition. LAURDANs microenvironmental sensitivity permits a good temperature resolution $(0.1-1.0 \mathrm{~K})$ on a short dynamic range determined by the bilayer properties of the membrane. On the other hand, NBD is responsible for rapid, heat-induced electronic changes resulting in good sensitivity on fluorescence lifetime, which can provide temperature resolution of $\sim 2 \mathrm{~K}$ and $S_{\mathrm{m}}=1.5 \% \mathrm{~K}^{-1}$ at $340 \mathrm{~K}$ (ref. 3) (Table 2 and Fig. 3).

The work of Zohar et al. ${ }^{4}$ was a pioneering example on thermal imaging of metabolic heat signals in single cells. Combining diffraction-limited spatial $(30 \mathrm{~nm})$ and sampling-rate-limited time resolution and using the temperature dependent luminescence intensity of the $\mathrm{Eu}(\mathrm{tta})_{3} \cdot 3 \mathrm{H}_{2} \mathrm{O}$ complex, intracellular heat waves generated by ligand-receptor interactions in single Chinese hamster ovary cells were imaged. ${ }^{4}$ A decade after, Suzuki et al. reported a technique for detection and measurement of the temperature changes in a single HeLa cervical cancer cell using a devised microthermometer comprising a glass micropipette filled with the same thermosensitive $\mathrm{Eu}(\mathrm{tta})_{3} \cdot 3 \mathrm{H}_{2} \mathrm{O}$ complex. ${ }^{5}$ The micrometer size of the tip of this pipette was able to measure the local temperature with $0.1 \mathrm{~K}$ precision and micrometer spatial resolution (upon $365 \mathrm{~nm}$ excitation). ${ }^{172}$ The heat production in a single HeLa cell occurred with some time delay after the ionomycin-induced $\mathrm{Ca}^{2+}$ influx from the extracellular space. The time delay inversely depended on extracellular $\left[\mathrm{Ca}^{2+}\right]$ and the increase in temperature was suppressed when $\mathrm{Ca}^{2+}$-ATPases were blocked by thapsigargin. These observations strongly suggest that the enzymatic activity of $\mathrm{Ca}^{2+}$-ATPases in endoplasmic reticulum leads to the heat production. ${ }^{5}$

More recently, Gota et al., ${ }^{6}$ reported the first polymer-based intracellular thermometer, where cell-to-cell resolution $(\sim 10 \mu \mathrm{m})$ was achieved (Fig. 8). The system is composed of the thermoresponsive PNIPAM combined with the water-sensitive fluorophore, DBD-AA. It was designed to be biocompatible, to avoid cell-induced fluorescence quench and intra-cell precipitation, and to be $\mathrm{pH}$ insensitive. A practical use of this thermometer was verified by measuring cell-by-cell temperature increases after exposing them to an external chemical stimuli which causes heat production. ${ }^{6}$ The internalised thermometer works in the $300-306 \mathrm{~K}$ range with a temperature resolution of $\sim 0.3$ to 0.5 degrees and $S_{\mathrm{m}}=9.4 \% \mathrm{~K}^{-1}$ at $304 \mathrm{~K}$ (Table 2 and Fig. 1); outside the cell $S_{\mathrm{m}}$ is larger, $12.7 \% \mathrm{~K}^{-1}$ at $308 \mathrm{~K}$ (Table 2 and Fig. 1). The thermometer could not reveal, however, intracellular temperature distribution, as the relative large size (>62 nm in hydrodynamic diameter) and low hydrophilicity of the fluorescent nanogel hindered its spreading throughout the cell.

McCabe et al. ${ }^{173}$ reported the first demonstration of a biomolecular intracellular thermometer through temperature-sensitive mutants of lacI controlling LacZ expression which is sensitive to the intracellular heat content of Escherichia coli in near-real time. ${ }^{173}$ LacI is a DNA-binding protein which inhibits the expression of genes coding for proteins involved in the metabolism of lactose in bacteria. Calibrated fluorometric (and colorimetric) measurements showed that both whole $E$. coli cells and lysates expressed significant repeatable changes in $\beta$-galactosidase activity in the physiologically relevant temperature functional range ( 298 to $318 \mathrm{~K}$ ) with at least 0.7 degree sensitivity (between 308 and $318 \mathrm{~K}$ ), $S_{\mathrm{m}}=19.6 \% \mathrm{~K}^{-1}$ at $318 \mathrm{~K}$ (Table 2 and Fig. 1). This model system suggests that changes in cellular heat 
A
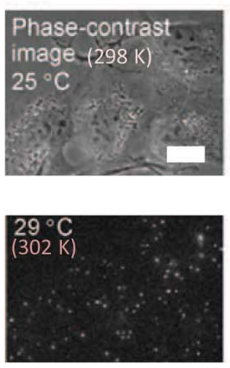
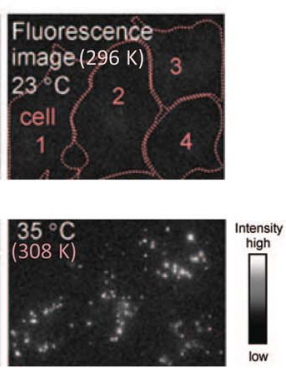

B

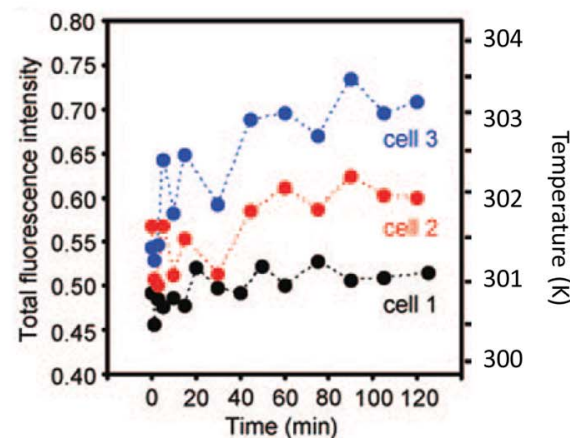

Fig. 8 (A) Phase contrast and fluorescence images of living COS7 cells (scale bar corresponds to $20 \mu \mathrm{m}$ ); (B) temperature evolution of three different cells after the addition of camptothecin. Reproduced with permission from ref. 6. Copyright American Chemical Society 2009.

content can be detected independently of the medium in which cells are kept, a feature of particular importance when the medium is heterogeneous or nonaqueous, or otherwise has a low heat transfer capacity. ${ }^{173}$

The use of mesoporous materials as vehicles for the storage and controlled release of entrapped specific chemicals includes examples which respond to temperature changes as external stimuli. ${ }^{174,175}$ Based on this possibility, Aznar et al. ${ }^{176}$ have developed a temperature sensor that can be internalised in a cell. The sensor consists of mesoporous silica NPs loaded with Safranin $O$ and functionalised with paraffin, as a capping molecule that can melt at a defined temperature. The paraffin forms a hydrophobic layer that can block the pores and inhibit guest release at a temperature below the paraffin melting point. Above this temperature the paraffin melts uncapping the pores. The NPs were endocited by HeLa cells and the stain was released above $312 \mathrm{~K}$, the specific melting temperature of the paraffin used in the experiments. As paraffins have a well-defined melting point, varying the paraffin type permits us to develop temperature sensors at correspondingly different temperatures.

Intracellular thermal measurements are one of the great challenges for the application of photoluminescent QDs, which would complement their present use in chemically selective imaging. ${ }^{103}$ In the past 2-3 years the general thermal sensitivity properties of QDs (e.g. streptavidin-coated CdSe-ZnS core-shell QDs, QD655) have been used to measure intracellular temperatures in a single living cell (upon external chemical and physical stimuli). ${ }^{7,8,35}$ For instance, the photoluminescence spectral shifts from endocytosed QD655 QDs were used to map intracellular heat generation in NIH/3T3 cells following $\mathrm{Ca}^{2+}$ stress and cold shock, showing that individual cells (like drosophila embryos, for instance) may use transient thermal gradients for signalling. ${ }^{8}$

The imaging of living tissues up to a high depth requires NIR excitation in the biological window through multiphoton processes. The technique of two-photon fluorescent microscopy has been recently developed using femtosecond lasers and it has been shown that QDs present a large NIR two-photon excitation cross-section. Maestro et al. ${ }^{35,109,177}$ demonstrated the potential use of CdSe and CdTe QDs as thermal mapping probes, as the emission peak and intensity depend on the environment temperature and can be imaged by means of a high-resolution two-photon fluorescence microscope. The authors performed studies with QDs in phosphate buffered saline solutions and in
HeLa cervical cancer cells. The NIR two-photon excitation leads to a temperature sensitivity of the QDs emission and intensity changes much higher than those achieved under visible onephoton excitation. Reported relative maximum sensitivity is $0.3 \times 10^{-1} \% \mathrm{~K}^{-1}$ at $330 \mathrm{~K}$ (Table 2 and Fig. 1), for $2 \mathrm{~nm}$ sized $\mathrm{QD}$, emitting near $525 \mathrm{~nm}$ at room temperature, when excited with a $900 \mathrm{~nm}$ laser.

Another very interesting example has been reported by Huang et al. involving local heating of superparamagnetic streptavidincoated $\mathrm{MnFe}_{2} \mathrm{O}_{4}$ NPs conjugated with DyLight549 to convert a $r f$ magnetic signal into cell stimuli. ${ }^{7}$ The NPs were targeted to specific proteins on the plasma membrane of HEK 293 cells and heated by a $r f$ magnetic field ( $40 \mathrm{MHz}, 8.4 \mathrm{G}$ ) between 303 and $319 \mathrm{~K}$. The temperature profile was studied through the temperature dependence of the fluorescence intensity of DyLight549 (exclusively localized on the plasma membrane of the expressing cells) and Golgi-targeted GFP (co-expressed within the cell) as nanoscale thermometers. After applying the $r f$ magnetic field, the local temperature increased at the plasma membrane with the corresponding decrease in the DyLight549 fluorescence intensity $\left(S_{\mathrm{m}}=1.5 \% \mathrm{~K}^{-1}\right.$ at $\sim 305 \mathrm{~K}$, Table 2 and Fig. 1), while the Golgi-targeted GFP fluorescence intensity remained essentially unchanged (Fig. 9), clearly demonstrating that the heat is generated locally at the plasma membrane without cytoplasmic heating. ${ }^{7}$ The $r f$ magnetic field-induced NPs heating is sufficient to trigger the opening of TRPV1 ion channels within seconds, as established by measuring the calcium influx into HEK 293 cells. The potential of this approach to study neuronal signalling was demonstrated triggering behavioural responses in C. elegans worms.

Fluorescent NPs of Eu(tta) $)_{3} \cdot 3 \mathrm{H}_{2} \mathrm{O}$ and fluorescein 5(6)-isothiocyanate (to allow the observation of the particles in confocal laser microscopy) doped PMMA have been designed by Oyama et al. ${ }^{178}$ to monitor temperature changes without $\mathrm{pH}(4-10)$ and ionic strength (0-500 $\mathrm{mM})$ sensitivity. The NPs, decorated with poly(allylamine hydrochloride) to facilitate binding to the anionic cell membrane, spontaneously enter living HeLa cells via endocytosis and then are transported along microtubules in a temperature-dependent manner, working as "walking nanothermometers". The non-ratiometric nanothermometer (average hydrodynamic diameter of $211 \pm 85 \mathrm{~nm}$ ) works with $S_{\mathrm{m}}=$ $4.4 \% \mathrm{~K}^{-1}$, at $330 \mathrm{~K}$ (Table 2 and Fig. 4). A temperature uncertainly of 0.3 degree, in the $293-333 \mathrm{~K}$ range, and a spatial 
A

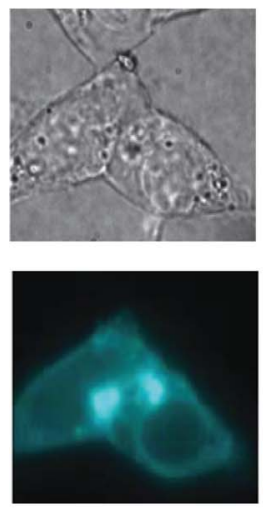

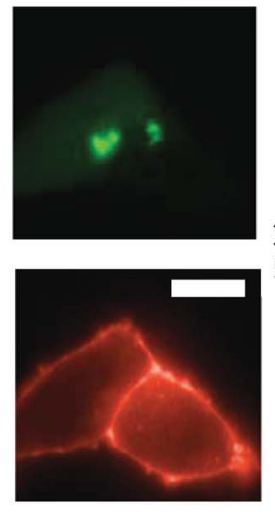

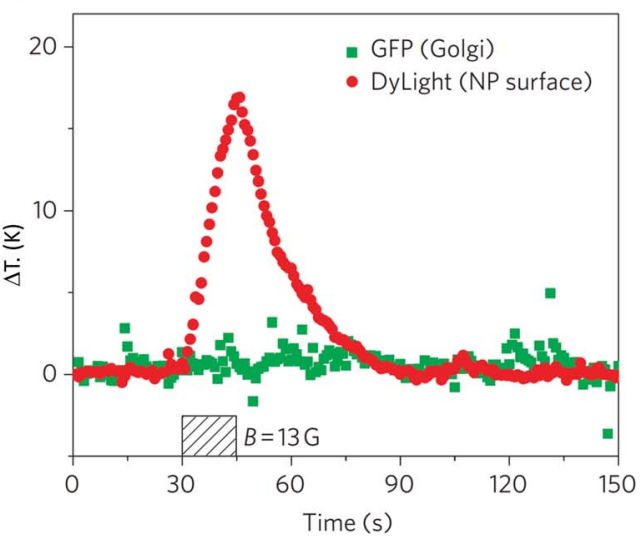

Fig. 9 (A) Differential interference contrast (DIC) image displaying cells' green fluorescence image indicating the Golgi localized GFP cyan fluorescence marking the membrane protein AP-CFP-TM red fluorescence of the DyLight549 on the NPs, which are exclusively localized on the plasma membrane of the AP-CFP-TM expressing cells. The scale bar corresponds to $20 \mu \mathrm{m}$. (B) The application of the $13 \mathrm{G} r f$ magnetic field (hatched box), leads to the local temperature increase at the plasma membrane (red, measured by DyLight549 fluorescence). In the same time period, the temperature remained constant at the Golgi apparatus (green, measured by of Golgi-targeted GFP). Reproduced with permission from ref. 7. Copyright Nature 2010.

resolution of $5.3 \mathrm{~nm}$ were estimated using the standard error of the mean of the centroid position of single nanothermometers in optical microscope images (taken at $30.68 \mathrm{~Hz}$ with a high-power stable light source).

The cellular thermometers discussed so far are non-ratiometric and rely on measuring changes in the luminescence signal at a single wavelength. Highly efficient and reliable cellular measurements require, however, luminescent temperature sensors that besides being nontoxic and having a bright optical signal to prevail over the background cell autofluorescence should also display ratiometric (or self-referencing) readout. Vetrone et al., ${ }^{40}$ Fischer et al., ${ }^{41}$ Ye et al. ${ }^{30}$ and Donner et al. ${ }^{179}$ showed a major step forward towards the development of ratiometric cellular thermometers.

Vetrone et al. devised a nanothermometer based on the temperature-sensitive UC green emission of $\mathrm{NaYF}_{4}: \mathrm{Er}, \mathrm{Yb}$ NPs. ${ }^{40}$ The UCNPs are excited through low power and inexpensive NIR lasers with wavelengths in the optical penetration window of cells and tissues. The internalization of the NPs by HeLa cervical cancer cells exploits the thermal sensitivity of the ratiometric intensity ratio between the $\mathrm{Er}^{3+2} \mathrm{H}_{11 / 2} \rightarrow{ }^{4} \mathrm{I}_{15 / 2}$ (green emission) and ${ }^{4} \mathrm{~S}_{3 / 2} \rightarrow{ }^{4} \mathrm{I}_{15 / 2}$ (yellow-green emission) transitions to create a nanothermometer capable of measuring the internal temperature of a living cancer cell, from $298 \mathrm{~K}$ to its thermally induced death at $318 \mathrm{~K} .{ }^{40}$ The cells were placed in a confocal fluorescence microscope and excited at $920 \mathrm{~nm}$ so that the UC $\mathrm{Er}^{3+}$ fluorescence permitted the measurement of the inner HeLa cell temperature with $S_{\mathrm{m}}=1.0 \% \mathrm{~K}^{-1}$ at $298 \mathrm{~K}$ (Table 2 and Fig. 4). Temperature-dependent confocal fluorescence microscopy images of HEK 293 cells transfected with similar NaY$\mathrm{F}_{4}$ :Er, $\mathrm{Yb}$ NPs with sub-micrometer resolution were obtained by Fischer et $a l .{ }^{41}$ based on the ratiometric sensing of the green and red $\left({ }^{4} \mathrm{~F}_{9 / 2} \rightarrow{ }^{4} \mathrm{I}_{15 / 2}\right) \mathrm{Er}^{3+}$ lines. The NPs are able to detect (without using an exterior reference) the cellular changes occurring between 298 and $318 \mathrm{~K}$, as a result of the external heating. However, the thermometer sensitivity is not reported and no data are published to estimate it. These NPs are one of the few examples reported so far of cellular thermometers based on $\mathrm{Ln}^{3+}$ ions, the other four examples involve the $\mathrm{Eu}(\mathrm{tta})_{3} \cdot 3 \mathrm{H}_{2} \mathrm{O}$ complex. 4,5,172,178 Two-photon excited NIR-to-visible UCNPs $\left(\mathrm{NaYF}_{4}: \mathrm{Yb}^{3+} / \mathrm{Ln}^{3+}, \mathrm{Ln}=\mathrm{Er}, \mathrm{Ho}, \mathrm{Tm}\right.$, and $\mathrm{CaF}_{2}: \mathrm{Yb}^{3+} / \mathrm{Ln}^{3+}, \mathrm{Ln}$ $=\mathrm{Er}, \mathrm{Tm}$ ) were also used for high-contrast intracellular fluorescence images of HeLa cells ${ }^{64,68,124}$ and in vivo whole body nude mouse. ${ }^{180}$ A cost-effective $915 \mathrm{~nm}$ laser is employed as a new promising excitation approach for better NIR-to-NIR UC photoluminescence in vitro or in vivo imaging providing drastically less heating of the biological specimen and larger imaging depth, due to quite low water absorption. ${ }^{180}$ Tissue penetration depths in the biological window as large as $2 \mathrm{~mm}$ were also demonstrated using the $\mathrm{CaF}_{2}: \mathrm{Tm}^{3+} / \mathrm{Yb}^{3+}$ UCNPs (due to the $\mathrm{Tm}^{3+}$ NIR emission at $\sim 800 \mathrm{~nm}$ ), which are more than 4 times those achievable based on the visible emissions of the particles with $\mathrm{Er}^{3+} .^{87}$ Furthermore, as the $\mathrm{Tm}^{3+}{ }^{3} \mathrm{H}_{4} \rightarrow{ }^{3} \mathrm{H}_{6}$ transition is sensitive to temperature changes, the authors also demonstrated the ability of $\mathrm{CaF}_{2}: \mathrm{Tm}^{3+} / \mathrm{Yb}^{3+} \mathrm{UCNPs}$ as nanothermometers ${ }^{87}$ (Table 2 and Fig. 4).

Pdots formed by $\mathrm{RhB}$ attached to amphiphilic amino-terminated PS blended with semiconducting polymers (Pdot-RhB NPs) showed ratiometric temperature sensing under $\sim 450 \mathrm{~nm}$ excitation that matches well the physiologically relevant temperature range. ${ }^{30}$ After internalization into live HeLa cells (via endocytosis) the Pdot-RhB NPs (size-tuned between 20 and $160 \mathrm{~nm}$ ) can measure intracellular temperatures in a live-cell confocal fluorescence imaging mode with $S_{\mathrm{m}}=2.6 \% \mathrm{~K}^{-1}$ at $343 \mathrm{~K}$ (Table 2 and Fig. 4). The average cell temperatures reported are in very good agreement with those measured with conventional thermocouples. ${ }^{30}$

Donner et $a l .{ }^{179}$ used GFP as an efficient temperature nanoprobe by monitoring its FPA. The method is tested on GFP transfected human HeLa and U-87 (primary glioblastoma) cell cancer lines measuring the heat delivery by photothermal heating of gold nanorods that surround the cells. The FPA temperature dependence is rationalized using population of fluorophores illuminated by a linearly polarized light that re-emits partially 


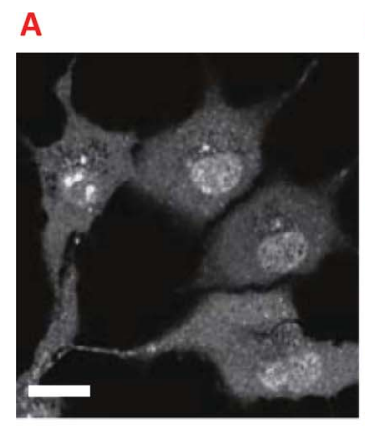

B
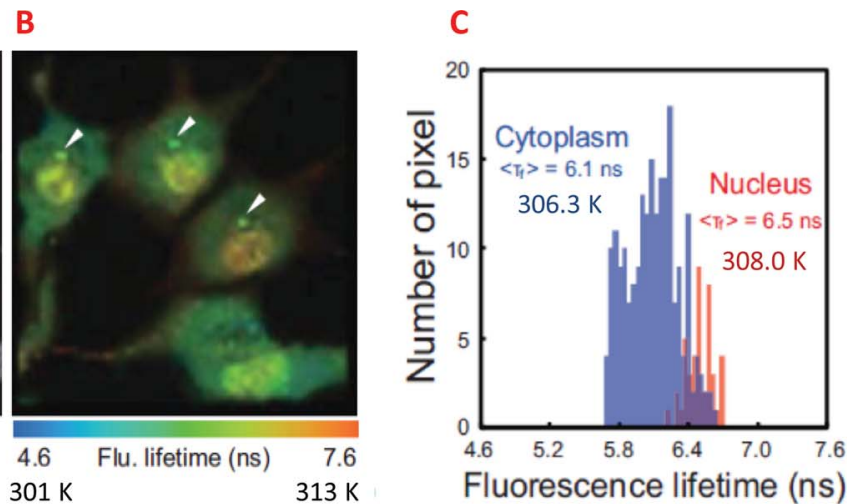

Fig. 10 Temperature mapping in living COS7 cells. Confocal fluorescence image (A) and fluorescence lifetime image (B) of a fluorescent polymer ${ }^{9}$ internalized in the COS7 cells, demonstrating higher temperature in the nucleus than in the cytoplasm of the cell. (C) Histograms of the fluorescence lifetime (and correspondent temperature) in the nucleus and in the cytoplasm in a representative cell (the leftmost cell in A) demonstrating a mean temperature gradient of $1.9 \mathrm{~K}$. The room temperature was maintained constant at $293 \mathrm{~K}$ during the measurement. The scale bar corresponds to $20 \mu \mathrm{m}$. Reproduced with permission from ref. 9. Copyright Nature 2012.

polarized fluorescence due to the random orientation of the molecular dipoles. The ratio of the intensities of the fluorescence polarized parallel and perpendicular to the incident polarization gives a ratiometric output in the temperature range 293-333 K with $S_{\mathrm{m}}=0.5 \% \mathrm{~K}^{-1}$ at $333 \mathrm{~K}$ and a spatial resolution of $\sim 300 \mathrm{~nm}$ (Table 2 and Fig. 4). The temperature accuracy is about 0.4 degrees.

Although rare, there are also some reports on non-luminescent cellular thermometers, ${ }^{10,181,182}$ (non-luminescent thermometers are discussed in general in the next section). Wang et al. have designed a thermocouple device for detecting intracellular temperature accurately. ${ }^{10}$ The thermocouple consists of a sandwich structure formed by a tungsten substrate, an insulating layer made of polyurethane and a platinum tip. Calibration experiments using different $P t$ thicknesses showed that a $100 \mathrm{~nm}$ one matched almost perfectly the temperature-tension curves produced by standard thermocouples of macro scale. The device showed a temperature resolution better than 0.1 degrees and a time response of $\sim 400 \mathrm{~ns}$. Insertion of the thermocouple in a single U251 cell allowed the observation of intracellular temperature fluctuations induced by the addition of camptothecin, a DNA topoisomerase I inhibitor that can promote tumour cell death. Other examples of the use of non-luminescent temperature sensors in biological systems with subcellular resolution include complex RNA structures that change their conformation in response to temperature ${ }^{181}$ and MWCNTs filled with cuprous iodide, which displays strong temperature-dependent NMR characteristics. ${ }^{182}$ In addition, an AFM cantilever with a heating resistor above a sharp silicon tip of 5-10 nm has been used to investigate heat conductance on biological materials with nanometric spatial resolution. ${ }^{183}$

Very recently Okabe et al. claimed the development of the first effective intracellular temperature mapping. It is based on the temperature-dependent fluorescence lifetime of a polymeric thermometer using time-correlated single photon counting coupled with fluorescence lifetime imaging microscopy. ${ }^{9}$ The polymer chains encompass thermosensitive, hydrophilic and fluorescent units and can effectively diffuse throughout the cells. With a spatial resolution at the diffraction limit level $(200 \mathrm{~nm})$ and $S_{\mathrm{m}}=4.4 \% \mathrm{~K}^{-1}$ at $311 \mathrm{~K}$ (Table 2 and Fig. 1 ) - at $307 \mathrm{~K}$ for
$S_{\mathrm{m}}$ calculated based on the lifetime (Table 2 and Fig. 3) - the intracellular temperature mapping reported indicates that (i) the nucleus and centrosome of a $\operatorname{COS} 7$ cell displayed a significantly higher temperature than the cytoplasm and (ii) the temperature gap between the nucleus and the cytoplasm depends on the cell cycle (Fig. 10). The heat production from mitochondria was also observed as a nearby local temperature increase. ${ }^{9}$

\section{Non-luminescent thermometers}

This section covers a large variety of thermometric systems of nano-size and molecular dimensions, in which thermometric property is not directly related to luminescence. Some of them cannot be considered thermometers or even sensors in a strict sense, as they only respond to a given temperature threshold. Driving forces for the development of this kind of thermometry have been the endless demands in nanolithography and microelectronics, developments in the use of nanotubes, whether carbon or metal oxides, in addition to the many application possibilities offered by these systems as well as strong clinical needs to monitor temperature at the cellular level and to map temperature distributions in tissues with high spatial resolution.

\subsection{Scanning thermal microscopy}

Soon after the invention of the $\mathrm{STM}^{184}$ the interest in measuring temperatures with very high spatial resolution became an obvious step forward. The technique, known as scanning thermal microscopy, was developed in 1986 by Williams and Wickramasinghe employing a STM probe with a thermocouple junction of $\sim 100 \mathrm{~nm}$ fabricated at the probe tip. ${ }^{185}$ Monitoring the two metals that constitute the thermocouple performs the temperature measurement. Temperature differences as small as $1 \mathrm{mK}$ between the thermocouple junctions could be detected. The main purpose, however, of this first SThM was not for mapping the temperature distribution on a surface but to provide a means for materialindependent profiling of surfaces. Combined STM/SThM devices, where a thermal sensor is employed as a tunnelling source and as a temperature detector, have also been used ${ }^{186,187}$ The use of such instruments is limited to conducting surfaces. 


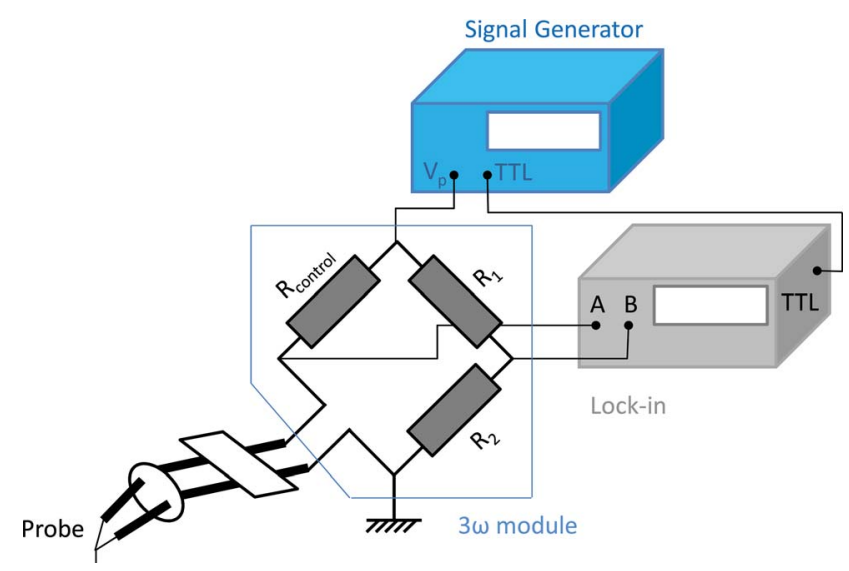

Fig. 11 Schematic view of an AFM/SThM device based on ac heating of the resistive probe and monitoring $a c$ current. Temperature at the tip is related to the third harmonic of the voltage. Reproduced with permission from ref. 191. Copyright American Institute of Physics 2005.

A wider variety of samples can be imaged using the AFM for SThM, as the specimens do not need to be conductors. Two main types of scanning probes have been developed. The first one is a thermocouple junction situated at the extremity of the tip as described in the previous paragraph for the STM-based devices. ${ }^{188,189}$ The second probe is a resistive wire bent at its extremity to form a sharp tip. The sample temperature is determined by measuring the variation of the electrical resistance of the wire. ${ }^{187,190,191}$ Resistive tips were initially used in $d c$ mode, the measurements being relevant only for low thermal conductivity materials. However, quantitative thermal conductivity measurements can be performed with uncertainty several orders of magnitude smaller using the tip in the $a c$ mode. Contrary to $d c$ data, the dependence of $a c$ measurements on the ambient temperature is negligible. One example is the so-called $3-\omega$ method based on that under $a c$ heating and given the linear dependence of the probe electrical resistance to temperature, the third harmonic of the tip voltage is also linear to the temperature. ${ }^{191} \mathrm{~A}$ schematic description of the experimental setup is depicted in Fig. 11. A large number of SThM probes have been developed, either as individually crafted cantilevers and sensors, ${ }^{188,192-196}$ or as batch fabricated thermocouples. ${ }^{199,197-199}$ Cretin et al. give an updated description of the working principles of various near-field microscopes, recent developments and the kind of information that can be obtained. ${ }^{200} \mathrm{~A}$ number of developments based on new cantilevers and new AFM-based temperature measuring techniques have been stated in recent years. ${ }^{43,45,201-210}$

Sadat et al. ${ }^{23}$ have reported a thermometric AFM-based technique which does not require integrated temperature sensors in AFM probes. The technique allows direct mapping of topography and temperature fields of metal surfaces with $\sim 0.01$ degree temperature resolution and $<100 \mathrm{~nm}$ spatial resolution. It uses point contact junctions that consist of the measurement of the thermoelectric voltage of a platinum-gold point contact that is a function of the local temperature. The authors prepared a $\mathrm{Si}$ AFM cantilever with a tip radius of $\sim 20 \mathrm{~nm}$, depositing a double $\mathrm{Ti} / \mathrm{Pt}(5 / 40 \mathrm{~nm})$ layer on both sides of the cantilever. On a gold surface a temperature distribution was scanned using the AFM tip in soft contact $(\sim 10 \mathrm{nN})$. The Ti/Pt-coated AFM cantilever (estimated to have a contact diameter of $\sim 10 \mathrm{~nm}$ ) was anchored to a thermal reservoir at room temperature and produces a welldefined and reproducible electrical conductance that depends only on the local temperature of the point contact. Fig. 12 shows a topographical image of the test device with a varying area of cross-section, the temperature distribution along a measuring line and a three-dimensional representation of the temperature field in a section of the test device. The technique is intrinsically limited to metals and is not applicable to biological systems. ${ }^{23}$

Instead, cantilever-based AFM has been specifically designed to investigate heat conductivity in biological materials. ${ }^{183}$ The AFM cantilevers were a modification of those developed in the millipede project. ${ }^{211}$ It was made entirely of silicon and to improve the resolution of heat-conductivity measurements a resistor for Joule heating was placed above a sharp silicon tip etched to a tip radius of $5-10 \mathrm{~nm}$. Thermal conductivity in proteoliposomes, human hair and collagen samples was measured with a spatial resolution of $\sim 10 \mathrm{~nm}$ and thermal resolution of $50 \mathrm{nW}$ as depicted in Fig. 13.
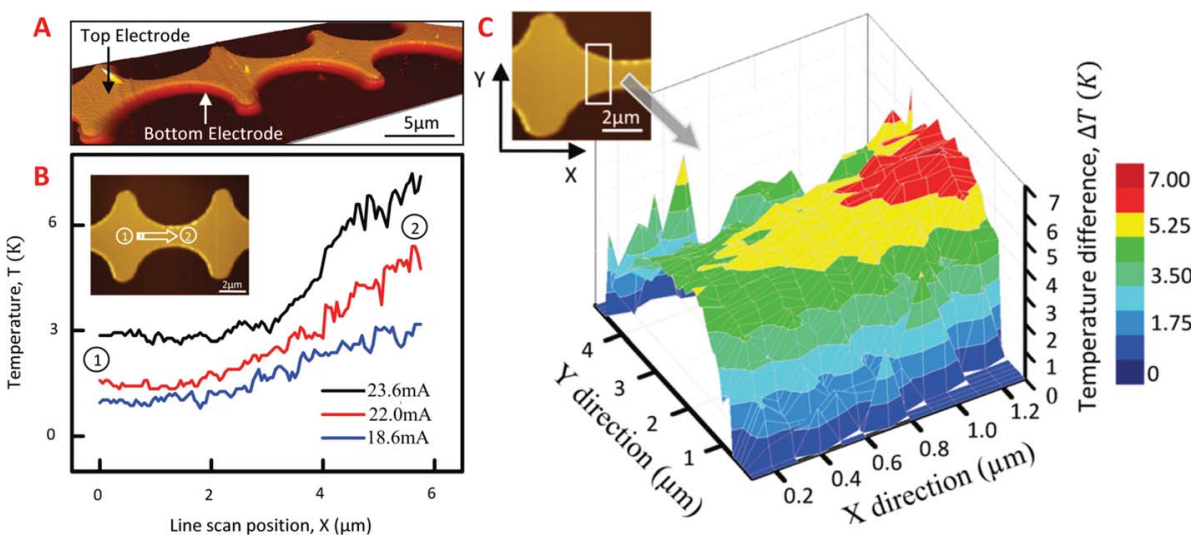

Fig. 12 (A) Topographical image of a test device with varying cross-sections. The device features a bottom electrode (100 nm thick) that is electrically isolated from the top electrode ( $30 \mathrm{~nm}$ thick) by a $10 \mathrm{~nm}$ thick $\mathrm{Al}_{2} \mathrm{O}_{3}$ layer. An electric current injected into the bottom electrode leads to temperature gradients in both electrodes. (B) The temperature distribution along a line from point 1 to 2 (shown in inset) is measured with $50 \mathrm{~nm}$ spatial resolution for three different bottom electrode heating currents. (C) Three-dimensional representation of the temperature field in a section of the test device indicated in the inset. Reproduced with permission from ref. 23. Copyright American Chemical Society 2010. 
Optical techniques, particularly luminescent ones, can be very useful to measure temperatures and to map temperature distribution on a surface as described in detail in previous sections. The combination of AFM and a luminescent probe allows overcoming the so-called Rayleigh diffraction limit which fixes the minimum dimensions of a focusing spot to about half the size of the wavelength used. The use of this technique, known as NSOM, for thermometric purposes has been reviewed by Cahill et al..$^{67}$ and Christofferson et al..$^{26}$

An interesting technique based on the tunnelling of the free electron gas has been demonstrated by Pavlov. ${ }^{54}$ The relative shift in the Fermi levels between two metallic electrodes, e.g. a copper substrate coated with copper oxide and a STM platinum tip in the demonstrator, should correlate with absolute temperature according to the Fermi-Dirac equation. Measuring the tunnelling current at zero voltage between the tip and the substrate, Pavlov has shown that the Fermi-level shift provides a measure of the substrate from room temperature up to $1250 \mathrm{~K}$, with $S_{\mathrm{m}}=0.5 \% \mathrm{~K}^{-1}$ at $500 \mathrm{~K}$ (Table 3) and nanometer spatial resolution $(\sim 20 \mathrm{~nm}){ }^{54}$ The temperature measuring technique is limited to metallic substrates and tips.
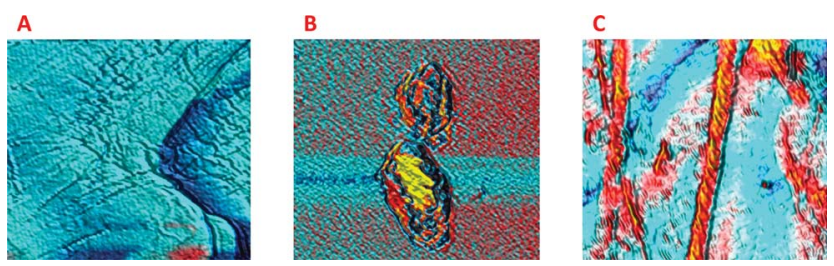

Fig. 13 (A) $2.2 \mu \mathrm{m}$ scan on a human hair that was bleached and pretreated with strong detergents. The colour texture corresponds to variations in the heat flux of about $100 \mathrm{nW}$ from dark blue to violet, with decreasing heat conductance towards violet. (B) $2.2 \mu \mathrm{m}$ scan of a vesicle preparation with reconstituted membrane proteins prepared on a silica wafer surface with highly resolved differences in thermal conductivity within the vesicles. (C) $8.8 \mu \mathrm{m}$ scan of a preparation of collagen fibres on a glass substrate with a colour texture corresponding to a high thermal conductance for dark blue and lower thermal conductance from red to yellow. Reproduced with permission from ref. 183. Copyright Elsevier 2006.

\subsection{Nanolithography thermometry}

A number of temperature sensors and thermocouples fabricated using vapour deposition or lithography techniques and suitable for the temperature observation at the nanoscale have been described. As an example, a focused $\mathrm{Ga}^{+}$beam has been used to deposit a Pt nano-strip by decomposition of an organometallic precursor like $\left(\mathrm{CH}_{3}\right)_{3} \mathrm{Pt}$ on a tungsten nano-strip previously deposited on an electrical insulator substrate by decomposition of $\mathrm{W}(\mathrm{CO})_{6}$ molecules. ${ }^{212}$ The resulting $\mathrm{Pt}(\mathrm{Ga})-\mathrm{W}(\mathrm{Ga})$ nanoscale junction has a temperature coefficient of approximately $5.4 \mathrm{mV}$ per degree, a value more than 100 times larger than conventional k-type thermocouples. Another temperature sensor consists in a parallel array of nanoscale thermocouples formed by two $\mathrm{p}$ - and n-type nanowire electrodes deposited in a substrate. The number of electrodes can be very large, those resulting in an array of thermocouples connected to each other in parallel banks of series-connected thermocouples. ${ }^{213}$ Unfortunately, no data regarding temperature sensitivity are provided and so comparison with other nanosensors is difficult. Nanolithography techniques have also been used to deposit metal strips and thermocouples in AFM tips, some of which have been described in the previous section. ${ }^{183,189,214}$

Microfabricated metallic structures have also been used to develop temperature sensors and thermometers. ${ }^{46,195,215,216} \mathrm{Chu}$ et al. ${ }^{47}$ have developed thin-film gold-nickel thermocouples with junction areas as small as $100 \mathrm{~nm}^{2}$ on silicon and $500 \mathrm{~nm}^{2}$ on quartz to measure temperature increases in transient resist heating processes at the microsecond scale. Irradiation by a $15 \mathrm{keV}, 150 \mathrm{nA}$ electron beam of $1.7 \mu \mathrm{m}$ radius for $100 \mu \mathrm{s}$ yielded an increase of temperature at the resist bottom surface of approximately $62 \mathrm{~K}$ on quartz substrates and of $18 \mathrm{~K}$ on silicon substrates. An example of the design of a sub-micrometer thermometer by miniaturizing microscopic traditional thermometers was presented by Shapira et al. ${ }^{46}$ The rationale was to miniaturize a Au-Ni thermocouple and to measure its thermovoltage. The thermometer presents $S_{\mathrm{m}}=0.4 \% \mathrm{~K}^{-1}$ at $300 \mathrm{~K}$ (Table 3) with a temporal resolution of $12 \mu$ s (to detect a decrease in the measured signal of $5 \%$ of its initial value) and a spatial resolution of $\sim 5 \mu \mathrm{m}$.

Table 3 Figure of merit of non-luminescent molecular thermometers including the thermometric property associated with each example. When reported, the spatial resolution is indicated

\begin{tabular}{|c|c|c|c|c|}
\hline & $S_{\mathrm{m}}$ & $\Delta T\left(T_{\mathrm{m}}\right)$ & Thermometric property & Observations \\
\hline \multicolumn{5}{|l|}{ Non-luminescent thermometers } \\
\hline$\beta-\mathrm{Ga}_{2} \mathrm{O}_{3}$, filled with an $\mathrm{Au}(\mathrm{Si})$ alloy ${ }^{228}$ & 0.3 & $573-1073(940)$ & Thermal expansion & $\begin{array}{l}\text { For temperatures above } 1073 \mathrm{~K} \text { the } \\
\mathrm{Ga}_{2} \mathrm{O}_{3} \text { becomes unstable }\end{array}$ \\
\hline $\mathrm{Pb}$ filled $\mathrm{ZnO}$ nanotubes ${ }^{50}$ & 1.1 & $293-573(573)$ & Thermal expansion & $\begin{array}{l}\text { Expansion thermometer working } \\
\text { in the solid state }\end{array}$ \\
\hline In filled silica nanotubes ${ }^{227}$ & 0.4 & $293-773(530)$ & Thermal expansion & Working in high temperature ranges \\
\hline Silicon micromechanical resonators ${ }^{53}$ & 1.2 & $295-370(320)$ & Resonator quality factor $(Q)$ & $\begin{array}{l}\text { Temperature resolution of better } \\
\text { than } 2 \mathrm{mK} \text { in a } 1 \mathrm{~Hz} \text { bandwidth }\end{array}$ \\
\hline n-doped Si nanowires ${ }^{52}$ & 5.4 & $15-30(27)$ & Peak width of the conductance dip & $\begin{array}{l}\text { Coulomb blockade behaviour at } \\
\text { temperatures up to } 20 \mathrm{~K}\end{array}$ \\
\hline $\mathrm{Ag} \mathrm{NPs}{ }^{28}$ & 0.4 & $600-1000(800)$ & NP diameter & Maximum spatial resolution of $16 \mathrm{~nm}$ \\
\hline & 0.2 & $600-1000(790)$ & NPs areal density & \\
\hline Au-Ni nanowires ${ }^{46}$ & 0.4 & $295-300(300)$ & Thermovoltage & $\begin{array}{l}\text { Spatial resolution } \sim 1 \mu \mathrm{m} \text { and } \\
\text { temporal resolution of } 12 \mu \mathrm{s}\end{array}$ \\
\hline
\end{tabular}




\subsection{Carbon nanotube thermometry}

The use of a CNT as a thermometer was first suggested by Gao and Bando $^{48}$ by measuring the thermal expansion of liquid gallium inside a CNT. The thermometer resembles a common mercury thermometer in the nanosize. As the authors observed, the thermal expansion coefficient of Ga varies linearly and reproducibly in the temperature range between 323 and $773 \mathrm{~K}$ with values close to those corresponding to macroscopic volumes. Thermodynamic analysis shows that the surface tension in a one-dimensional nanoscale liquid Ga column inside a CNT affects the column's inner pressure, the effect increasing as the column's diameter decreases. The analysis provides a quantitative explanation of why a $75 \mathrm{~nm}$ diameter column of liquid $\mathrm{Ga}$ has the same expansion coefficient as that of $\mathrm{Ga}$ in a macroscopic state in the temperature range of 323 to $773 \mathrm{~K}^{217}$ In a first experiment, a CNT was filled with Ga and placed in a Gatan holder equipped with a twin heating system inside a scanning electron microscope. The meniscus of the gallium column was rising and falling as the temperature was increased and reduced in the range $323-773 \mathrm{~K}$, as shown in Fig. 14. In later experiments it was shown that Ga remains liquid inside the encapsulating CNT at temperatures as low as 203 or $193 \mathrm{~K}$, depending on the Ga phase formed during solidification. ${ }^{218}$ These are temperatures significantly lower than solidification temperature of bulk Ga $(237.6 \mathrm{~K})$ and extend the operative range of this kind of thermometer to as low as $204 \mathrm{~K}$. Similar CNT thermometers were also developed using In as low melting metal filling, operated in the temperature range between $443 \mathrm{~K}$ and $650 \mathrm{~K},{ }^{219}$ and with Ge. ${ }^{220}$ The possibility to use the thermometer outside the microscope camera in a standard air environment was later reported based on the observation that the surface of a gallium column inside a one-side open CNT oxidizes at high temperature in the presence of oxygen with partial pressure $\geq 6.66 \times 10^{-5} \mathrm{~Pa}$. Consequently, the meniscus leaves a tiny mark around the CNT wall corresponding to the Ga oxide layer which is clearly observed by TEM. ${ }^{49,221}$ The temperature accuracy is estimated within $5-10 \%$.

CNTs have, however, a limited stability at high temperature in air, suffering fast degradation above $873 \mathrm{~K} \cdot{ }^{222,223}$ Consequently, other nanothermometers based on the same idea of nanotubes filled with metals of low-melting point have been developed. The same group of Bando et al. has developed Ga-filled single-
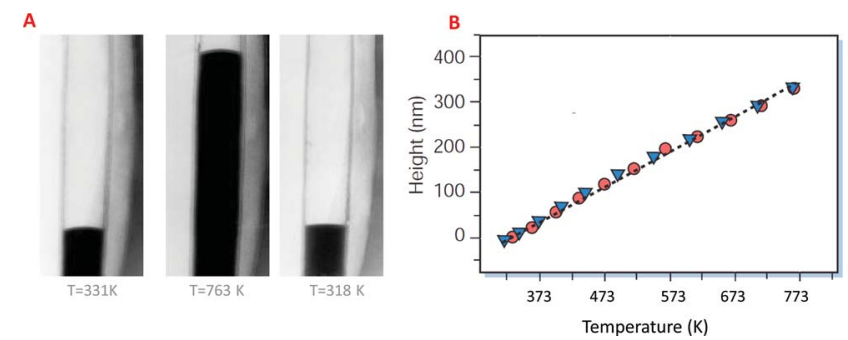

Fig. 14 Expansion of gallium inside a CNT. With temperature increase the level of the gallium meniscus increases (A). The height of the gallium meniscus plotted against temperature, measured in steps of $30-50{ }^{\circ} \mathrm{C}$ in the range $50-500{ }^{\circ} \mathrm{C}$ produces a calibration curve for temperature determination (B); the average (dotted line) mimics the measurements obtained during heating (red circles) and cooling (blue triangles) stages. Reproduced with permission from ref. 48. Copyright Nature 2002. crystalline $\mathrm{MgO}$ nanotubes which can serve as nanothermometers over a wider temperature range than CNTs. ${ }^{224} \mathrm{~A}$ $\mathrm{MgO}$ nanotube was filled with two fragments of $\mathrm{Ga}$, one at each end of the nanotube, and the nanotube sealed. The distance between the tips of each Ga fragment was taken as the thermometric variable and found to have a linear dependence with the temperature in the range between 303 and $967 \mathrm{~K}$ (ref. 224) which was also reversible, e.g., the distance decreased as the temperature was increased and vice versa. The working range depends on the total length of the Ga segments and on the distance between their respective tips and in principle its limits are given by the high stability of the single-crystalline $\mathrm{MgO}$ nanotube with a melting point of $3073 \mathrm{~K}$ and the wide temperature range of $303-2478 \mathrm{~K}$ for the Ga in liquid state. ${ }^{225}$ Such a wide temperature range together with the low vapour pressure of liquid Ga makes these types of thermometers quite promising to measure high temperatures with nanospatial resolution. This will be particularly so if the use of microscopies, whether TEM or AFM, for the thermometer calibration and reading out of the temperature can be overcome.

Indium has also been used as filling metal of low melting point in single crystalline $\mathrm{In}_{2} \mathrm{O}_{3}$ nanotubes ${ }^{226}$ and in silica ones. ${ }^{227}$ The as-prepared silica nanotubes consist of an array of nanotubes that can easily be dispersed into individual nanothermometers by an ultrasonic vibration process. The thermal expansion of the liquid In has a linear dependence with the temperature in the range around $425 \mathrm{~K}$, the melting point temperature of In, and $773 \mathrm{~K}$, the highest temperature in the experiments. Although it is not reported, the thermometer maximum sensitivity can be estimated from the linear dependence of the column expansion with the temperature (Fig. $4 \mathrm{~b}$ of ref. 227 ) as $0.4 \% \mathrm{~K}^{-1}$ at $530 \mathrm{~K}$ (Table 3).

Gallium oxide nanotubes, $\beta-\mathrm{Ga}_{2} \mathrm{O}_{3}$, filled with an $\mathrm{Au}(\mathrm{Si})$ alloy have also been used to develop nanothermometers for high temperature measurements as shown in Fig. 15. ${ }^{228}$ The $\mathrm{Au}(\mathrm{Si})$ filling alloy, where $\sim 6 \%$ is $\mathrm{Si}$, has a rather large coefficient of thermal expansion of $1.5 \times 10^{-4} \mathrm{~K}^{-1}$, ten times larger than that of bulk $\mathrm{Au}$ and more than twice that of $\mathrm{Ga}$. The coefficient of thermal expansion of the $\beta-\mathrm{Ga}_{2} \mathrm{O}_{3}$ nanotube is more than two orders of magnitude smaller, so the influence of the expansion of the nanotube on the filling alloy can be neglected. The filling starts to be fluid-like at $\sim 623 \mathrm{~K}$ and it becomes fluid at $\sim 673 \mathrm{~K}$, however, the $\mathrm{Au}(\mathrm{Si})$ shows linear expansion already at $573 \mathrm{~K}$ and all the way up to $1173 \mathrm{~K}$, where $\mathrm{Ga}_{2} \mathrm{O}_{3}$ becomes unstable. The reported safe range for temperature measurements is 573 $1073 \mathrm{~K}$. The maximum relative sensitivity is $0.3 \% \mathrm{~K}^{-1}$ at $940 \mathrm{~K}$ (Table 3). Nanotube-based thermometers have been further developed to include a solid filling instead of liquid-like or liquid ones. Such is the case of the $\mathrm{Pb}$ filled $\mathrm{ZnO}$ nanotube with a working temperature region between 293 and $573 \mathrm{~K}$ and a maximum relative sensitivity of $1.1 \% \mathrm{~K}^{-1}$ at $573 \mathrm{~K}$ (Table 3 ). ${ }^{50}$ The solid filling makes the structural integrity of the outer shell much less demanding than in the case of the liquid-filled thermometers. The drawback of this thermometric design is the high temperature limitation due to some leaking of $\mathrm{Pb}$ as it starts melting at above $573 \mathrm{~K}$. The use of single crystalline nanotubes stable at higher temperatures could extend the applicability of $\mathrm{Pb}$ as filling material in nanotube thermometry to a second region with $\mathrm{Pb}$ in liquid state. 

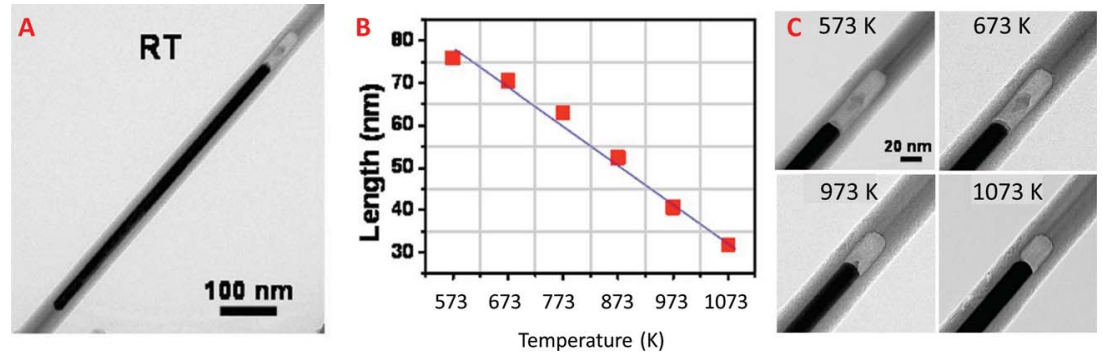

Fig. 15 (A) TEM image of a $\mathrm{Ga}_{2} \mathrm{O}_{3}$ nanotube before heating. (B) Distance of the Au filling to the top of the cavity during heating as a function of temperature. (C) TEM images of an Au-filled $\mathrm{Ga}_{2} \mathrm{O}_{3}$ nanotube during heating at different temperatures. Reproduced with permission from ref. 228. Copyright American Institute of Physics 2008.

Dorozhkin et al. observed that electrical conductivity through an empty CNT is diffusive with a resistance per unit of length of $10 \mathrm{k} \Omega \mathrm{mm}^{-1}$, whereas a Ga-filled CNT shows metallic behaviour with a low resistance per unit of length of $100 \Omega \mathrm{mm}^{-1}$, two orders of magnitude smaller. ${ }^{229}$ Based on this observation, these authors developed an electrically controlled temperature sensor that can also act as a switch, using electrical conductivity as the thermometric property. The thermometer can work in a wide temperature range from 353 up to $773 \mathrm{~K}$. However, the thermometer calibration and resistivity reading must be measured using an AFM, thus rendering its use as rather complicated.

Bichoutskaia et al. ${ }^{230}$ have proposed an electromechanical nanothermometer based on the conductivity changes induced by the thermal interaction and relative motion of the components of double-walled CNT. The nanothermometer can be calibrated as a thermocouple.

In thin films of MWCNTs the turn-on field and emission current at a fixed applied electric field are temperature independent above $373 \mathrm{~K}$, the higher the temperature the larger the emission current. ${ }^{231}$ Consequently, a film of $\sim 7 \mathrm{~nm}$ can form a simple thermometer in the temperature range 373 to $600 \mathrm{~K}$ under vacuum. The sensitivity of the thermometer can be modified by the applied electric field and by the area of the MWCNTs.

When the number of charge carriers, e.g. electrons, moving across a potential barrier is sufficiently small, the uncertainties due to independent random events become significant. This effect, known as shot noise, e.g., each electron that tunnels through the barrier can be considered as a discrete "shot", is independent of frequency up to several hundred GHz. When shot noise is measured in combination with Johnson noise, Spietz et al. ${ }^{22,232}$ showed recently that shot noise can be exploited to achieve accurate temperature measurements from the $\mathrm{mK}$ range to many hundreds of Kelvin. More recently, Sayer et al. ${ }^{233}$ have reported on a CNT thermometer that operates on these principles. The thermal resistance of SWCNT is determined from Johnson and shot electrical noise measurements of the SWCNT in a porous anodic alumina template. As the magnitude of the shot noise does not follow the expected curve for an isothermal device due to significant self-heating of the CNT device, measurements are fitted to a self-heating shot noise model that assumes constant device resistance. The resulting thermal resistance of the SWCNT device is found to be $(1.5 \pm 0.1) \times 10^{8} \mathrm{~K} \mathrm{~W}^{-1}$.

A thermometer based on MWCNTs developed for a contactless temperature control in biological systems has already been mentioned in Section 2.5. The result shows that functionalized
CNTs can make valid thermometric systems in biomedical applications. ${ }^{182}$

\subsection{Biomolecular-based thermometry}

Among the many techniques developed to determine temperature at the nanoscale, the use of temperature-dependent molecules and biological components is probably one of the most fascinating ones. Some of these techniques, like those based on the thermo-conformation changes of DNA, RNA, proteins and lipids and their catalytic influence on subsequent biological processes, ${ }^{168,169}$ or on differences on the electronic properties of fluorescent probes associated with temperature-dependent structural or conformational changes, ${ }^{3,6}$ have been used to sense temperature inside cells and have been described in Section 2.5. This section describes thermometry developments based on biological entities, like DNA, mRNA and others.

Living cells are able to sense harmful temperature changes and induce either heat-shock or cold-shock proteins. The sensing of temperature is made by proteins, nucleic acids and mRNAs that either act as true thermometers, responding directly to temperature changes by modifying their conformation structure, or indirectly undergoing complex reactions. ${ }^{234}$ In particular, Narberhaus et al. ${ }^{181,235,236}$ and Shah and Gilchrist ${ }^{237}$ have described that certain mRNAs respond to temperature changes by threedimensional conformational changes. RNA thermometers are located in some specific areas of the RNA structure, particularly in the $5^{\prime}$-end untranslated region that shields the ribosomebinding sites at physiological temperatures. With the onset of heat shock, destabilisation of the RNA starts and favours the release of the ribosome-binding sites and translation initiation. In the case of a temperature downshift, on the other hand, cell growth comes to an almost complete stop, bulk gene expression is drastically reduced and cold-shock proteins are expressed. Some of these mRNA proteins undergo a structural rearrangement to a conformation thermodynamically more stable at low temperature and less susceptible to degradation. ${ }^{168,238-240}$ The conformational change of RNA thermometers can be followed by NMR and UV spectroscopy.

While naturally occurring thermometers are complex systems, considerably simpler RNA thermometers that can be used to induce or repress gene expression by a simple temperature shift have been developed as depicted in Fig. 16..$^{241-243}$ The thermometers, which are fully operational in vivo as translational regulators at physiological temperatures, are built from a single 
small RNA stem-loop structure containing the ribosome binding site. The thermometers were optimised to work at $310 \mathrm{~K}$, however, following the same principles should be possible to design a thermometer optimised to work at any temperature by selecting different loop sizes. ${ }^{243}$

The mimicking of natural thermometry for the development of recording temperature devices has been proposed by Höfinger and Zerbetto. ${ }^{244}$ The principal components of their temperature sensor are short RNA sequences forming individual helical hairpins and each having a characteristic transition temperature to a different conformation structure. The detection system is based on the subsequent hybridization to specific RNA sequences and the analysis is carried out with the help of a statistical mechanical package specifically designed to study conformation changes in RNA. A list of eight RNA sequences operational in the range from 263 to $333 \mathrm{~K}$ at intervals of 10 degrees is proposed. The device, still waiting for experimental validation, could be the basis of a new ex situ thermometric technology of interest for the quality control of perishable products.

\subsection{Miscellaneous}

In this section, we gather a few families and scattered examples of micro- and nanoscale thermometry that do not fit in the families outlined in the preceding sections.
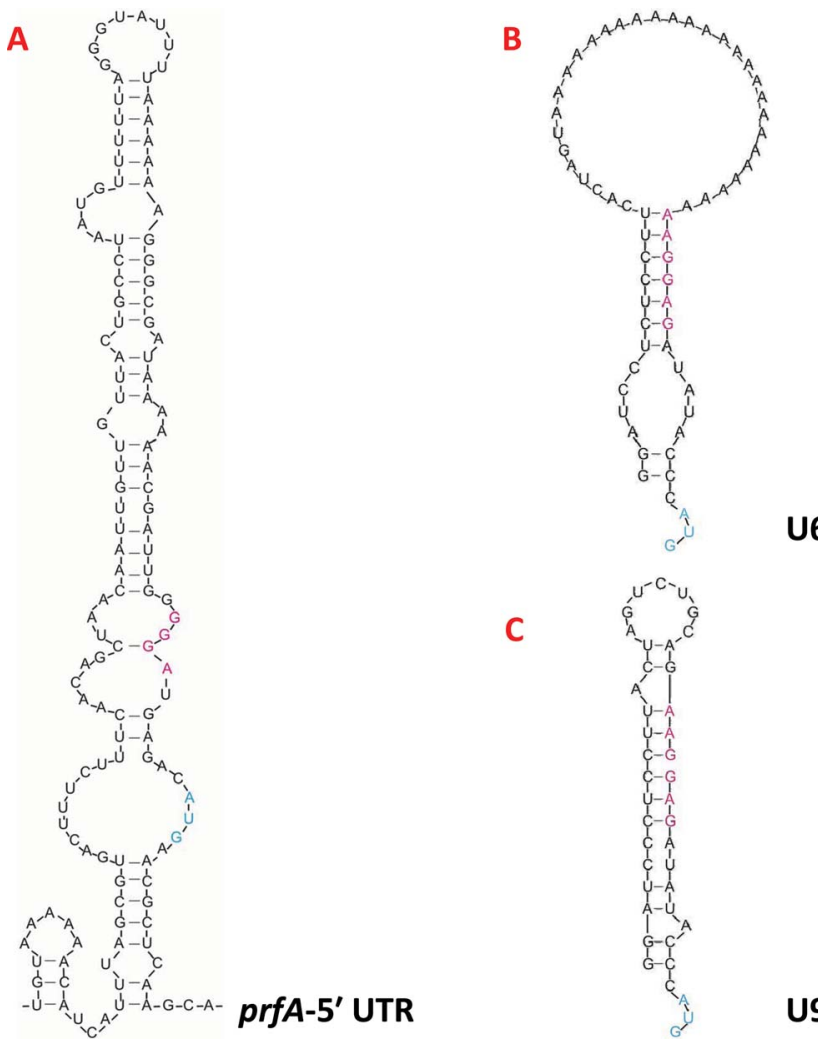

Fig. 16 Examples of a natural and two synthetic RNA thermometers. (A) Proposed RNA secondary structure of the 5' UTR (untranslated region) from the prfA gene of the pathogenic bacterium Listeria monocytogenes, which functions as an RNA thermometer, ${ }^{250}$ (B) secondary structure of the synthetic RNA thermometer U6; ${ }^{241}$ (C) structure of the synthetic RNA thermometer U9. ${ }^{241}$ Reproduced with permission from ref. 243. Copyright Nature 2009.
Coulomb blockade thermometers exploit the differential resistance of tunnel junctions as thermometric parameters at cryogenic temperatures. The advanced design gathers superconductor-insulator-normal metal tunnel junctions embedded in a $r f$ resonant circuit with nanometric dimensions (typically hundreds of nanometres). ${ }^{51,52,245}$ While conductance at zero bias voltage is suppressed, the conductance at non-zero broadens as temperature increases, resulting in a peak with a fwhm being proportional to the number of junctions and to $k_{\mathrm{B}} T$. Moreover the high temperature limit is determined by the electric characteristics of the junction, which allows the tailoring of the thermometer using an appropriate configuration. The sensitivity of Coulomb blockade thermometers decreases when temperature increases, resulting in hypothetical infinite maximum relative sensitivity at the limit of $\mathrm{T} \rightarrow 0 \mathrm{~K}$. For temperatures of the order of tens of Kelvin a monotonical decrease of $S_{\mathrm{m}}$ towards 1 is expected. This tendency is exactly what has been reported by Schmidt et al., ${ }^{51}$ presenting meaningless maximum relative sensitivity $S_{\mathrm{m}}>100 \% \mathrm{~K}^{-1}$, for $T<0.9 \mathrm{~K} .{ }^{51}$ In line with these results Tilke et $a .^{52}$ reported $S_{\mathrm{m}}=5.4 \% \mathrm{~K}^{-1}$ at $27 \mathrm{~K}$, using n-doped silicon nanowires (Table 3 ).

An interesting microthermometer was proposed by Hopcroft et $a l .{ }^{53}$ The motivation for this thermometer was the need for highly accurate temperature determination in high performance resonators in order to account for the temperature dependence of the resonant frequency. The proposed solution was to use the resonator itself, by an indirect measure of the temperature dependence of its quality factor. The thermometer works between 295 and $370 \mathrm{~K}$ with $S_{\mathrm{m}}=1.2 \% \mathrm{~K}^{-1}$ at $320 \mathrm{~K}$ (Table 3 ).

A completely different approach of nanothermometry based on one-use ex situ thermometers, which can record the temperature they were exposed to and be read later when the event is over, was suggested by Lan et al. ${ }^{28}$ and by Wang and Huang ${ }^{246}$ based on the irreversible temperature-activated growth of NPs. The nanothermometer proposed by Lan et $a .^{28}$ works by measuring the diameter and areal density of silver NPs deposited on a carbon supporting film coated with a TEM copper-grid. The spatial resolution achieved between 570 and $1000 \mathrm{~K}, \sim 16 \mathrm{~nm}$, is controlled by the distance between neighbouring nanospheres, related to the nanosphere size and areal density. ${ }^{28}$ The maximum relative sensitivity is $0.4 \% \mathrm{~K}^{-1}$ at $800 \mathrm{~K}$ (Table 3 ). The thermometer proposed by Wang and Huang ${ }^{246}$ is also based on the growth of NPs exposed to a thermal event (characterized by a given temperature and time). In this case, size is indirectly determined by changes in the Raman scattering of semiconductor NPs due to boundary effects that induce asymmetric broadening and a shift in Raman peaks. Two sets of NPs exposed to the same thermal history are used in order to determine both the maximum temperature and duration of the thermal event. This concept was demonstrated using anatase and rutile $\mathrm{TiO}_{2}$ NPs, works between 673 and $973 \mathrm{~K}$ and 5-60 s.

Brintlinger et $a l^{247}$ have reported a method for mapping temperature at the nanoscale using a transmission electron microscope and the melting point of metal islands. The germanium metal islands are deposited on the reverse side of a commercial silicon nitride membrane whereas local temperature gradients are produced by Joule heating in a thin wire in the front side of the membrane. As the solid-liquid transition in the islands induces contrast changes, the absolute temperature 
(above or below the melting temperature) can be mapped over the whole field of view with spatial resolution of the order of $100 \mathrm{~nm}$. The technique is applicable to a variety of materials with spatial resolution that can be scaled down to lengths approaching characteristic scattering distances of thermal carriers of $\sim 10$ to $100 \mathrm{~nm}$.

Another example consists of a miniaturized device based on the Seebeck effect. ${ }^{248}$ The nanoscale thermocouple is composed of $\mathrm{Cu}$ and $\mathrm{Cu}-\mathrm{Ni}$ joined tips with a diameter of $\sim 50 \mathrm{~nm}$, having an expected Seebeck coefficient of $39.45 \mu \mathrm{V} \mathrm{K}^{-1}$, corresponding to a minimum detectable temperature change of $28 \mathrm{~K}$ with the used device. The joined tips can be then manipulated in a TEM in order to sense local temperature that changes due to the electron beam and due to an electric current passing through a MWCNT. The thermometer was also used to study the relationship between melting/deformation and the local temperature increase on a metallic filler.

\section{Conclusions and outlook}

The diversity of luminescent and non-luminescent thermometers operating at the sub-micron scale described in this review clearly point out the emergent interest of nanothermometry in numerous fields, such as electronic and optoelectronic machines and devices, micro- and nanofluidic systems, living cells and tissues, nanostructures, and in many other conceivable applications, such as thermally induced drug release and wherever exothermal chemical or enzymatic reactions occur at submicron scale. Nanothermometry has indeed experienced a continuous and unprecedented growth over the past five years following, in most examples, the technological trends of sub-micron miniaturization and it is foreseen that this trend will continue for the next coming years. Innovation in the rational design of new thermometric systems in the nanoscale will undoubtedly lead to qualitatively new progress in nanothermometry, with consequences in nanotechnology we cannot yet foresee. However, despite actual promising progress, the research can be considered as in its early stages and more basic knowledge is still needed before nanothermometer prototypes become a commercial reality.

The examples addressed in this review comprehend nonluminescent thermometers using scanning thermal microscopy, nanolithography, CNTs and biomaterials and luminescent thermometers based both on individual thermal probes (e.g. organic dyes, QDs and $\mathrm{Ln}^{3+}$-based UCNPs and $\beta$-diketonate chelates) and more complex systems formed by those probes embedded into polymer and organic-inorganic hybrid matrices. Up to now, the performance of the different thermometers reported in the literature has not been compared and this is undoubtedly one of the major landmarks of this review. The absence of a single parameter facilitating such comparison encouraged us to use the definition of relative maximum sensitivity, eqn (1), as a figure of merit for both luminescent (Table 2) and non-luminescent (Table 3) thermometric systems. Sorting nanothermometers in this way enables some interesting comparative observations. In the interval between 280 and $350 \mathrm{~K}$ all the scrutinised thermometers display maximum relative sensitivities ranging from 0.1 to $10 \% \mathrm{~K}^{-1}$ and only a few cases present $S_{\mathrm{m}}$ values practically constant in this temperature range. The relative maximum sensitivity values of non-luminescent thermometers seem to be slightly lower than those of the luminescent ones. The computed $S_{\mathrm{m}}$ values of different thermometers belonging to a particular family can now be assembled within the same temperature and sensitivity regions (Fig. 1-4), which also enables further comparative conclusions. For instance, organic dyes embedded into polymers and LDHs display higher relative sensitivity values but in a considerably narrower temperature range than other luminescent thermometers. On the other hand, although the $\mathrm{Ln}^{3+}$-based thermometers present lower $S_{\mathrm{m}}$ values, relative to those of polymers- and organic dye-based ones, they generally cover a wider temperature interval. For physiological temperatures, for instance, it is quite difficult to use the same polymer-based thermometer to cover the entire interval (Fig. 1-4). In fact, these systems are typically usable in a range of $\sim 10 \mathrm{~K}$, meaning that they are not wide-range thermometers but on-off temperature sensors.

Setting a reasonable limit of $0.5 \% \mathrm{~K}^{-1}$ as a quality threshold (meaning that the relative variation of the thermometric parameter is $0.5 \%$ per degree of temperature change), the wide variety of thermometers available is evident (Tables 2 and 3); however, this number drastically decreases if self-referencing is required, as shown in Fig. 2 for the luminescent thermometers. The lifetime-based methodology to sense temperature is intrinsically limited by the long acquisition times required to collect reliable data, as mentioned above, and does not present improved relative sensitivity values, when compared to those of the intensity-based ratiometric thermometers (Fig. 3).

Only a handful of luminescent (ratiometric and non-ratiometric) and non-luminescent thermometers report spatial resolution below $50 \mu \mathrm{m}$ (Fig. 4), since temperature sensing in spatial scales below $10 \mu \mathrm{m}$ still remains a major challenge, demanding in most cases the development of new methodologies, including new materials and sensing schemes. Among the examples displaying spatial resolution lower than $50 \mu \mathrm{m}$ (Tables 2 and 3 and Fig. 4), the review emphasises the intracellular luminescent thermometers based on organic dyes, thermoresponsive polymers, biomolecular materials, mesoporous silica NPs, QDs, and $\mathrm{Ln}^{3+}$-based UCNPs and $\beta$-diketonate complexes and the intracellular non-luminescent ones based on thermocouple devices, complex RNA structures, and MWCNTs filled with cuprous iodide (Section 2.5).

Despite the considerable amount of research on intracellular thermometry carried out over the past 3-4 years, accurate temperature distributions within living cells have not yet been satisfactorily addressed. The major obstacle for progress has been the unavailability of a single molecular thermometer with the following requirements (that should be simultaneously satisfied):

- High temperature resolution (<0.5 degree);

- Ratiometric temperature output;

- High spatial resolution $(<3 \mu \mathrm{m})$;

- Functional independency of changes in $\mathrm{pH}$, ionic strength and surrounding biomacromolecules;

- Concentration-independent output.

A new generation of nanothermometers is intended to exploit the synergetic integration of different functionalities in a nanometric platform, for instance assembling together heater and thermometer elements in the same NPs (e.g. a Fe-based magnetic core or an Au rod covered with luminescent centres). This idea 
applied to multiresponsive polymers was recently reviewed highlighting current advances on polymer chemistry to design multiresponsive polymeric materials that recognize independently or synergistically more than one stimulus exhibiting collective responses. ${ }^{249}$ Concerning thermometry, an interesting example is the thermoresponsive nonlinear PEG-based nanogel three-dimensional scaffold developed by the Shuiqin Zhou' group, which integrates $\mathrm{ZnO}$ QDs and metallic $\mathrm{Au}$ into a single hybrid nanogel particle $(<100 \mathrm{~nm}) .{ }^{141}$ The nanoplatform, integrates three important applications: ratiometric fluorescent sensing of temperature change in physiological fluid, fluorescent cell imaging, and thermal/photothermal-regulated drug delivery for synergistic chemo-photothermal treatment. A temperature resolution better than 0.25 degrees over the $310-315 \mathrm{~K}$ physiological range is reported, with a precision of $\pm 1.0 \%$ in the determination of the emission intensity of the QDs (emission quantum yield of 0.23). Moreover, the photoluminescence response is nearly independent of the environmental $\mathrm{pH}$ over $5.0-7.4( \pm 0.19 \%)$ and of ion strengths. ${ }^{141}$

Another example is the thermo and magnetic responsive beads composed of magnetite NPs embedded in a functionalised siliceous backbone coated by a fluorescent acrylamide-NIPAM copolymer. ${ }^{133}$ NIPAM based polymer beads are thermoresponsive in the $298-318 \mathrm{~K}$ range with $S_{\mathrm{m}}=16.7 \% \mathrm{~K}^{-1}$ at $314 \mathrm{~K}$. Under an external alternate magnetic field, the magnetic moment of the magnetite NPs relaxes by the rotation of the beads in water. In a given frequency range, the beads cannot follow the field, dissipating energy. This frequency range shifts with temperature mostly due to the abrupt change of the hydrodynamic size of the NPs with the PNIPAM transition. Dye-based thermometers may also be included as a part of a multifunctional platform. Much progress has been reported in the last 2-3 years, in a clear trend for the total integration of the thermometric system within the cellular medium. An interesting example was presented by Huang et al. ${ }^{7}$ reporting a device operating via a magnetic field to control the temperature inside HEK 293 cells by means of fluorometric measurement of DyLight549 and GFP fluorescence intensity. The innovative aspect lies in the remote control of ion channels in cells using $r f$ magnetic-field heating of NPs, although the detailed photophysics of the temperature dependence remains to be investigated. For the first time, a device controlling simultaneously the local heating and the temperature monitoring has been described, as a clear step forward for hyperthermia studies in cellular cultures.

In conclusion, the gate to the nanothermometry world has only been slightly opened and there is still plenty of room at the bottom for developing this stimulating new field of research. A major challenge remains with the need to combine efforts from a large number of quite different disciplines such as coordination and supramolecular chemistry, thermodynamics, photophysics, nanotechnology, microelectronics, distinct microscopy techniques, materials design, assembly and integration, and biomedicine.

\section{Abbreviations}

$\left[\mathrm{C}_{4} \mathrm{mpy}\right]\left[\mathrm{Tf}_{2} \mathrm{~N}\right]$ 1-Butyl-1-methylpyrrolidinium bis(trifluoromethylsulfonyl)imide
3HF-AM

AFM

APTES

BBS

bpeta

BTD

$\mathrm{btfa}^{-}$

$\mathrm{ca}$

CNT

cyclam

DBD-AA

$\mathrm{dbm}^{-}$

DEGMA

DNA

DPTB

dipyren

DT

FDA

FEM

FIR

FPA

FRET

fwhm

GFP

HS

HEK 293

IL

IR

LAURDAN

LDHs

LED

$\mathrm{Ln}^{3+}$

LS

MEMS

$\mathrm{MeOH}$

MOE

mRNA

MWCNT

NBD

NIPMAM

NIR

NMR

NNPAM

NP

NSOM

OASN

OTES

PAA

$\mathrm{P}(\mathrm{VDC}-c o-\mathrm{AN})$

PDA

PDMS

Pdot

PEG
2-[4-(3-Hydroxy-4-oxo-4H-chromen-2-yl)

phenoxy]ethylacrylamide

Atomic force microscope

3-Aminopropyltriethoxysilane

4,4'-Bis(2-benzoxazolyl)stilbene

1,2-Bis(4-pyridyl)ethane

2-Bis(trimethoxysilyl)decane

4,4,4-Trifluoro-1-phenyl-1,3-butanedionate

Citric acid

Carbon nanotube

1,4,8,11-Tetraazacyclotetradecane

$N$-[2-[(7- $N, N$-Dimethylaminosulfonyl)-2,1,3benzoxadiazol-4-yl](methyl)amino]ethyl- $N$ -

methylacrylamide

Dibenzoylmethanide

Di(ethylene glycol) methyl ether methacrylate

Deoxyribonucleic acid

Pyrene-containing triarylboron molecule

Dipyren-1-yl(2,4,6-triisopropylphenyl)borane

Tris(dinaphthoylmethane)-bis-

(trioctylphosphine oxide)

Food and drug administration

Finite elements method

Fluorescence intensity ratio

Fluorescence polarization anisotropy

Fluorescence resonant energy transfer

Full-width-at-half-maximum

Green fluorescent protein

High spin

Human embryonic kidney

Ionic liquid

Infrared

6-Dodeca-noy1-2-dimethylamino-naphthalene

Layer double hydroxides

Light emitting diode

Trivalent lanthanide

Low spin

Micro-electromechanical system

Methanol

2-Methoxyethyl ether

Messenger ribonucleic acid

Multiwalled carbon nanotube

7-Nitro-2,1,3-benzoxadiazole

$N$-Isopropylmethacrylamide

Near infrared

Nuclear magnetic resonance

$N$ - $n$-Propylacrylamide

Nanoparticle

Near-field scanning optical microscopy

$N$-Octyl-4-(3-aminopropyltrimethoxysilane)-

1,8-naphthalimide

Octyltriethoxysilane

Poly acrylic acid

Poly(vinylidene chloride- $c o$-acrylonitrile)

Polydiacetylene

Poly(dimethylsiloxane)

Polymer dot

Poly(ethyleneglycol) 


\begin{tabular}{|c|c|}
\hline PEO & Polyethylene oxide \\
\hline PMMA & Poly(methyl methacrylate) \\
\hline PNIPAM-co- & Poly $(N$-isopropylacrylamide) incorporating \\
\hline BODIPY & boron-dipyrromethene \\
\hline PNIPAM & $\operatorname{Poly}(N$-isopropylacrylamide $)$ \\
\hline PNIPAM:FMA & $\begin{array}{l}\text { Poly }(N \text {-isopropylacrylamide }) \text { incorporating } \\
\text { fluorescent modified acrylamide }\end{array}$ \\
\hline $\begin{array}{l}\text { PNIPAM-co- } \\
\text { HC }\end{array}$ & $\begin{array}{l}\text { Poly }(N \text {-isopropylacrylamide) incorporating } \\
\text { hemicyanine }\end{array}$ \\
\hline PPO & $\operatorname{Poly}(p$-phenylene oxide $)$ \\
\hline PS & Polystyrene \\
\hline PtBMA & Poly(tert-butyl methacrylate) \\
\hline PTBS & Poly-(tert-butyl styrene) \\
\hline PtOEP & $\begin{array}{l}2,3,7,8,12,13,17,18-\text { Octaethyl } 21 H, 23 H \text { - } \\
\text { porphyrin platinum(II) }\end{array}$ \\
\hline PtTFPP & $\begin{array}{l}5,10,15,20 \text {-Tetrakis(pentafluorophenyl) } \\
\text { porphyrin platinum(II) }\end{array}$ \\
\hline PVA & Poly(vinyl alcohol) \\
\hline PyMMA & $\begin{array}{l}\text { Polymerizable pyrene dye methacrylate } \\
\text { monomer }\end{array}$ \\
\hline QD & Quantum dot \\
\hline$r f$ & Radio-frequency \\
\hline Rh-110 & Rhodamine-110 \\
\hline RhB & Rhodamine B \\
\hline RNA & Ribonucleic acid \\
\hline Ruphen & Tris-(1,10-phenanthroline)ruthenium(II) \\
\hline$S_{\mathrm{m}}$ & Maximum relative sensitivity \\
\hline SThM & Scanning thermal microscope \\
\hline STM & Scanning tunnelling microscope \\
\hline SWCNT & Single-walled carbon nanotube \\
\hline TEM & Transmission electron microscopy \\
\hline TEOS & Tetraethyl orthosilicate \\
\hline$T_{\mathrm{m}}$ & $\begin{array}{l}\text { Temperature of maximum relative sensitivity is } \\
\text { maximum }\end{array}$ \\
\hline $\mathrm{tta}^{-}$ & Thenoyltrifluoroacetonate \\
\hline $\mathrm{UC}$ & Up-conversion \\
\hline UCNP & Up-converting nanoparticle \\
\hline UV & Ultraviolet. \\
\hline
\end{tabular}

\section{Acknowledgements}

The authors are grateful to Fundação para a Ciência e a Tecnologia (FCT, Portugal), COMPETE and FEDER programs (PEst-C/CTM/LA0011/2011 and PTDC/CTM/101324/2008) and Integrated Spanish-Portuguese Action PT2009-0131 for financial support. The work in Zaragoza has been supported by the grants MAT2007-61621 and CONSOLIDER CSD2007-00010 from the Ministry of Education. LDC acknowledges Nanobiotec-CAPES network for a grant, whereas as CDSB (SFRH/BD/38472/2007 grant), PPL (SFRH/BPD/34365/2006 grant) and NJOS (Ciência 2008 program) thank FCT.

\section{References}

1 J. Lee and N. A. Kotov, Nano Today, 2007, 2, 48-51.

2 K. M. McCabe and M. Hernandez, Pediatr. Res., 2010, 67, 469-475.

3 C. F. Chapman, Y. Liu, G. J. Sonek and B. J. Tromberg, Photochem. Photobiol., 1995, 62, 416-425.
4 O. Zohar, M. Ikeda, H. Shinagawa, H. Inoue, H. Nakamura, D. Elbaum, D. L. Alkon and T. Yoshioka, Biophys. J., 1998, 74, $82-89$.

5 M. Suzuki, V. Tseeb, K. Oyama and S. Ishiwata, Biophys. J., 2007, 92, L46-L48.

6 C. Gota, K. Okabe, T. Funatsu, Y. Harada and S. Uchiyama, J. Am. Chem. Soc., 2009, 131, 2766-2767.

7 H. Huang, S. Delikanli, H. Zeng, D. M. Ferkey and A. Pralle, Nat. Nanotechnol., 2010, 5, 602-606.

8 J. M. Yang, H. Yang and L. W. Lin, ACS Nano, 2011, 5, 5067-5071.

9 K. Okabe, N. Inada, C. Gota, Y. Harada, T. Funatsu and S. Uchiyama, Nat. Commun., 2012, 3, 705.

10 C. L. Wang, R. Z. Xu, W. J. Tian, X. L. Jiang, Z. Y. Cui, M. Wang, H. M. Sun, K. Fang and N. Gu, Cell Res., 2011, 21, 15171519.

11 P. Kolodner and J. A. Tyson, Appl. Phys. Lett., 1983, 42, 117-119.

12 L. Aigouy, G. Tessier, M. Mortier and B. Charlot, Appl. Phys. Lett., 2005, 87, 184105.

13 G. Tessier, M. Bardoux, C. Boue and D. Fournier, Appl. Phys. Lett., 2007, 90, 171112.

14 W. J. Liu and B. Z. Yang, Sens. Rev., 2007, 27, 298-309.

15 W. Jung, Y. W. Kim, D. Yim and J. Y. Yoo, Sens. Actuators, A, 2011, 171, 228-232.

16 H. B. Mao, T. L. Yang and P. S. Cremer, J. Am. Chem. Soc., 2002, 124, 4432-4435.

17 R. Samy, T. Glawdel and C. L. Ren, Anal. Chem., 2008, 80, 369-375.

18 C. Gosse, C. Bergaud and P. Löw, Molecular Probes for Thermometry in Microfluidic Devices, in Thermal Nanosystems and Nanomaterials, Topics in Advanced Physics, ed. S. Volz, Springer-Verlag, Berlin, 2009, vol. 118, pp. 301-341.

19 T. Barilero, T. Le Saux, C. Gosse and L. Jullien, Anal. Chem., 2009, 81, 7988-8000.

20 E. M. Graham, K. Iwai, S. Uchiyama, A. P. de Silva, S. W. Magennis and A. C. Jones, Lab Chip, 2010, 10, 1267-1273.

21 J. Feng, K. J. Tian, D. H. Hu, S. Q. Wang, S. Y. Li, Y. Zeng, Y. Li and G. Q. Yang, Angew. Chem., Int. Ed., 2011, 50, 8072-8076.

22 L. Spietz, K. W. Lehnert, I. Siddiqi and R. J. Schoelkopf, Science, 2003, 300, 1929-1932.

23 S. Sadat, A. Tan, Y. J. Chua and P. Reddy, Nano Lett., 2010, 10, 2613-2617.

24 A. Majumdar, Annu. Rev. Mater. Sci., 1999, 29, 505-585.

25 M. Asheghi and Y. Yang, Micro- and Nano-Scale Diagnostic Techniques for Thermometry and Thermal Imaging of Microelectronic and Data Storage Devices, in Microscale Diagnostic Techniques, ed. K. S. Breuer, Springer-Verlag, Berlin, 2005, pp. 155-196.

26 J. Christofferson, K. Maize, Y. Ezzahri, J. Shabani, X. Wang and A. Shakouri, J. Electron. Packaging, 2008, 130, 041101-041106.

27 J. B. Weaver, Nat. Nanotechnol., 2010, 5, 630-631.

28 Y. C. Lan, H. Wang, X. Y. Chen, D. Z. Wang, G. Chen and Z. F. Ren, Adv. Mater., 2009, 21, 4839-4844.

29 X. D. Wang, X. H. Song, C. Y. He, C. J. Yang, G. N. Chen and X. Chen, Anal. Chem., 2011, 83, 2434-2437.

30 F. M. Ye, C. F. Wu, Y. H. Jin, Y. H. Chan, X. J. Zhang and D. T. Chiu, J. Am. Chem. Soc., 2011, 133, 8146-8149.

31 E. J. McLaurin, V. A. Vlaskin and D. R. Gamelin, J. Am. Chem. Soc., 2011, 133, 14978-14980.

32 C. H. Hsia, A. Wuttig and H. Yang, ACS Nano, 2011, 5, 9511-9522.

33 G. Walker, V. Sundar, C. Rudzinski, A. Wun, M. Bawendi and D. Nocera, Appl. Phys. Lett., 2003, 83, 3555.

34 S. Li, K. Zhang, J. M. Yang, L. W. Lin and H. Yang, Nano Lett., 2007, 7, 3102-3105.

35 L. M. Maestro, E. M. Rodríguez, F. S. Rodríguez, M. C. Iglesias-de la Cruz, A. Juarranz, R. Naccache, F. Vetrone, D. Jaque, J. A. Capobianco and J. G. Solé, Nano Lett., 2010, 10, 5109-5115.

36 S. M. Borisov and O. S. Wolfbeis, Anal. Chem., 2006, 78, 5094-5101.

37 H. S. Peng, M. I. J. Stich, J. B. Yu, L. N. Sun, L. H. Fischer and O. S. Wolfbeis, Adv. Mater., 2010, 22, 716-719.

38 C. D. S. Brites, P. P. Lima, N. J. O. Silva, A. Millán, V. S. Amaral, F. Palacio and L. D. Carlos, Adv. Mater., 2010, 22, 4499-4504.

39 H. S. Peng, S. H. Huang and O. S. Wolfbeis, J. Nanopart. Res., 2010, 12, 2729-2733.

40 F. Vetrone, R. Naccache, A. Zamarron, A. J. de la Fuente, F. SanzRodriguez, L. M. Maestro, E. M. Rodriguez, D. Jaque, J. G. Sole and J. A. Capobianco, ACS Nano, 2010, 4, 3254-3258. 
41 L. H. Fischer, G. S. Harms and O. S. Wolfbeis, Angew. Chem., Int. Ed., 2011, 50, 4546-4551.

42 M. G. Cerruti, M. Sauthier, D. Leonard, D. Liu, G. Duscher, D. L. Feldheim and S. Franzen, Anal. Chem., 2006, 78, 32823288 .

43 L. Aigouy, E. Saidi, L. Lalouat, J. Labeguerie-Egea, M. Mortier, P. Low and C. Bergaud, J. Appl. Phys., 2009, 106, 074301.

44 E. Saïdi, B. Samson, L. Aigouy, S. Volz, P. Löw, C. Bergaud and M. Mortier, Nanotechnology, 2009, 20, 115703.

45 L. Aigouy, L. Lalouat, M. Mortier, P. Low and C. Bergaud, Rev. Sci. Instrum., 2011, 82, 036106.

46 E. Shapira, D. Marchak, A. Tsukernik and Y. Selzer, Nanotechnology, 2008, 19, 125501.

47 D. C. Chu, W. K. Wong, K. E. Goodson and R. F. W. Pease, J. Vac. Sci. Technol., B: Microelectron. Nanometer Struct.-Process., Meas., Phenom., 2003, 21, 2985-2989.

48 Y. H. Gao and Y. Bando, Nature, 2002, 415, 599.

49 Y. H. Gao, Y. Bando, Z. W. Liu, D. Golberg and H. Nakanishi, Appl. Phys. Lett., 2003, 83, 2913-2915.

50 C. Y. Wang, N. W. Gong and L. J. Chen, Adv. Mater., 2008, 20, 4789-4792.

51 D. R. Schmidt, C. S. Yung and A. N. Cleland, Appl. Phys. Lett., 2003, 83, 1002-1004.

52 A. T. Tilke, L. Pescini, H. Lorenz and R. H. Blick, Appl. Phys. Lett., 2003, 82, 3773-3775.

53 M. A. Hopcroft, B. Kim, S. Chandorkar, R. Melamud, M. Agarwal, C. M. Jha, G. Bahl, J. Salvia, H. Mehta, H. K. Lee, R. N. Candler and T. W. Kenny, Appl. Phys. Lett., 2007, 91, 013505.

54 A. Pavlov, Appl. Phys. Lett., 2004, 85, 2095-2097.

55 C. Y. Wang and L. J. Chen, Eur. J. Inorg. Chem., 2010, 4298-4303.

56 M. Hartmann, Contemp. Phys., 2006, 47, 89-102.

57 M. Hartmann, G. Mahler and O. Hess, Phys. Rev. Lett., 2004, 93, 080402-080406.

58 C. D. S. Brites, P. P. Lima, N. J. O. Silva, A. Millán, V. S. Amaral, F. Palacio and L. D. Carlos, New J. Chem., 2011, 35, 1177-1183.

59 L. Shi and A. Majumdar, Microscale Thermophys. Eng., 2001, 5, 251-265.

60 D. G. Cahill, K. Goodson and A. Majumdar, Journal of Heat Transfer-Transactions of the ASME, 2002, 124, 223-241.

61 A. Rabhiou, J. Feist, A. Kempf, S. Skinner and A. Heyes, Sens. Actuators, A, 2011, 169, 18-26.

62 M. I. J. Stich, L. H. Fischer and O. S. Wolfbeis, Chem. Soc. Rev., 2010, 39, 3102-3114.

63 C. Pietsch, U. S. Schubert and R. Hoogenboom, Chem. Commun., 2011, 47, 8750-8765.

64 K. E. Goodson and M. Asheghi, Microscale Thermophys. Eng., 1997, 1, 225-235.

65 D. A. Fletcher, G. S. Kino and K. E. Goodson, Microscale Thermophys. Eng., 2003, 7, 267-273.

66 D. Teyssieux, L. Thiery and B. Cretin, Rev. Sci. Instrum., 2007, 78, 034902 .

67 D. G. Cahill, W. K. Ford, K. E. Goodson, G. D. Mahan, A. Majumdar, H. J. Maris, R. Merlin and P. Sr, J. Appl. Phys., 2003, 93, 793-818.

68 J. Christofferson and A. Shakouri, Rev. Sci. Instrum., 2005, 76, 024903.

69 O. S. Wolfbeis, Adv. Mater., 2008, 20, 3759-3763.

70 S. Allison and G. Gillies, Rev. Sci. Instrum., 1997, 68, 2615.

71 P. R. N. Childs, J. R. Greenwood and C. A. Long, Rev. Sci. Instrum., 2000, 71, 2959-2978.

72 S. Uchiyama, A. P. de Silva and K. Iwai, J. Chem. Educ., 2006, 83, $720-727$.

73 A. L. Heyes, J. Lumin., 2009, 129, 2004-2009.

74 N. Chandrasekharan and L. A. Kelly, J. Am. Chem. Soc., 2001, 123, 9898-9899.

75 G. A. Baker, S. N. Baker and T. M. McCleskey, Chem. Commun., 2003, 2932-2933.

76 J. M. Lupton, Appl. Phys. Lett., 2002, 81, 2478-2480.

77 C. Pietsch, A. Vollrath, R. Hoogenboom and U. S. Schubert, Sensors-Basel, 2010, 10, 7979-7990.

78 C. T. Chen and C. Y. Chen, Chem. Commun., 2011, 47, 994-996.

79 C. Baleizão, S. Nagl, S. M. Borisov, M. Schäferling, O. S. Wolfbeis and M. N. Berberan-Santos, Chem.-Eur. J., 2007, 13, 3643-3651.

80 V. A. Vlaskin, N. Janssen, J. van Rijssel, R. Beaulac and D. R. Gamelin, Nano Lett., 2010, 10, 3670-3674.
81 P. A. S. Jorge, M. A. Martins, T. Trindade, J. L. Santos and F. Farahi, Sensors-Basel, 2007, 7, 3489-3534.

82 X. Wang, X. G. Kong, Y. Yu, Y. J. Sun and H. Zhang, J. Phys. Chem. C, 2007, 111, 15119-15124.

83 M. A. R. C. Alencar, G. S. Maciel, C. B. de Araújo and A. Patra, Appl. Phys. Lett., 2004, 84, 4753-4755.

84 S. K. Singh, K. Kumar and S. B. Rai, Sens. Actuators, A, 2009, 149, $16-20$.

85 V. Tikhomirov, K. Driesen, V. Rodriguez, P. Gredin, M. Mortier and V. Moshchalkov, Opt. Express, 2009, 17, 11794-11798.

86 S. K. Singh, K. Kumar and S. B. Rai, Appl. Phys. B: Lasers Opt., 2009, 94, 165-173.

87 N. N. Dong, M. Pedroni, F. Piccinelli, G. Conti, A. Sbarbati, J. E. Ramirez-Hernandez, L. M. Maestro, M. C. Iglesias-de la Cruz, F. Sanz-Rodriguez, A. Juarranz, F. Chen, F. Vetrone, J. A. Capobianco, J. G. Sole, M. Bettinelli, D. Jaque and A. Speghini, ACS Nano, 2011, 5, 8665-8671.

88 V. de Zea Bermudez, L. Carlos and L. Alcácer, Chem. Mater., 1999, 11, 569-580.

89 C. D. S. Brites, P. P. Lima, N. J. O. Silva, A. Millán, V. S. Amaral, F. Palacio and L. D. Carlos, J. Lumin., 2012, DOI: 10.1016/ j.jlumin.2011.12.050.

90 D. Ross, M. Gaitan and L. E. Locascio, Anal. Chem., 2001, 73, $4117-4123$.

91 X. L. Guan, X. Y. Liu and Z. X. Su, J. Appl. Polym. Sci., 2007, 104, $3960-3966$.

92 R. B. Mikkelsen and D. F. H. Wallach, Cell Biol. Int. Rep., 1977, 1, $51-55$.

93 X. X. He, J. H. Duan, K. M. Wang, W. H. Tan, X. Lin and C. M. He, J. Nanosci. Nanotechnol., 2004, 4, 585-589.

94 F. Wang, W. B. Tan, Y. Zhang, X. P. Fan and M. Q. Wang, Nanotechnology, 2006, 17, R1-R13.

95 M. E. Köse, B. F. Carroll and K. S. Schanze, Langmuir, 2005, 21, 9121-9129.

96 M. E. Köse, A. Omar, C. A. Virgin, B. F. Carroll and K. S. Schanze, Langmuir, 2005, 21, 9110-9120.

97 D. Wei and A. Ivaska, Anal. Chim. Acta, 2008, 607, 126-135.

98 A. Bousseksou, G. Molnar, L. Salmon and W. Nicolazzi, Chem. Soc. Rev., 2011, 40, 3313-3335.

99 Spin Crossover in Transition Metal Compounds I-III, in Topics in Current Chemistry, ed. P. Gütlich and H. A. Goodwin, Springer, Berlin, 2004, vol. 233-235.

100 M. Engeser, L. Fabbrizzi, M. Licchelli and D. Sacchi, Chem. Commun., 1999, 1191-1192.

101 C. Quintero, G. Molnár, L. Salmon, A. Tokarev, C. Bergaud and A. Bousseksou, presented in part at the 16th International Workshop on Thermal Investigations of ICs and Systems (THERMINIC), Barcelona, 2010.

102 L. Salmon, G. Molnar, D. Zitouni, C. Quintero, C. Bergaud, J. C. Micheau and A. Bousseksou, J. Mater. Chem., 2010, 20, 5499-5503.

103 I. L. Medintz, H. T. Uyeda, E. R. Goldman and H. Mattoussi, Nat. Mater., 2005, 4, 435-446.

104 R. Beaulac, P. I. Archer, J. van Rijssel, A. Meijerink and D. R. Gamelin, Nano Lett., 2008, 8, 2949-2953.

105 W. G. J. H. M. van Sark, P. L. T. M. Frederix, A. A. Bol, H. C. Gerritsen and A. Meijerink, ChemPhysChem, 2002, 3, 871-879.

106 Isnaeni, K. H. Kim, D. L. Nguyen, H. Lim, T. N. Pham and Y. H. Cho, Appl. Phys. Lett., 2011, 98, 012109-012112.

107 M. Nakamura, S. Ozaki, M. Abe, T. Matsumoto and K. Ishimura, J. Mater. Chem., 2011, 21, 4689-4695.

108 A. Hoshino, K. Fujioka, T. Oku, M. Suga, Y. F. Sasaki, T. Ohta, M. Yasuhara, K. Suzuki and K. Yamamoto, Nano Lett., 2004, 4, 2163-2169.

109 L. M. Maestro, J. E. Ramírez-Hernández, N. Bogdan, J. A. Capobianco, F. Vetrone, J. G. Solé and D. Jaque, Nanoscale, 2012, 4, 298-302.

110 L. W. Zhang and N. A. Monteiro-Riviere, Toxicol. Sci., 2009, 110, $138-155$.

111 R. G. Aswathy, Y. Yoshida, T. Maekawa and D. S. Kumar, Anal. Bioanal. Chem., 2010, 397, 1417-1435.

112 J. B. Yu, L. N. Sun, H. S. Peng and M. I. J. Stich, J. Mater. Chem., 2010, 20, 6975-6981.

113 S. P. Wang, S. Westcott and W. Chen, J. Phys. Chem. B, 2002, 106, $11203-11209$. 
114 M. Mitsuishi, S. Kikuchi, T. Miyashita and Y. Amao, J. Mater. Chem., 2003, 13, 2875-2879.

115 A. H. Khalid and K. Kontis, Meas. Sci. Technol., 2009, 20, 025305.

116 G. Tessier, M. Bardoux, C. Filloy, C. Boue and D. Fournier, Sens. Rev., 2007, 27, 291-297.

117 S. Allison, G. Gillies, A. Rondinone and M. Cates, Nanotechnology, 2003, 14, 859-863.

118 F. Wang and X. G. Liu, Chem. Soc. Rev., 2009, 38, 976-989.

119 J. Zhou, Z. Liu and F. Li, Chem. Soc. Rev., 2012, 41, 13231349.

120 J. M. Hu and S. Y. Liu, Macromolecules, 2010, 43, 8315-8330.

121 X. X. Guo, F. Z. Zhang, D. G. Evans and X. Duan, Chem. Commun., 2010, 46, 5197-5210.

122 T. Itoh, T. Shichi, T. Yui, H. Takahashi, Y. Inui and K. Takagi, J. Phys. Chem. B, 2005, 109, 3199-3206.

123 D. P. Yan, J. Lu, J. Ma, M. Wei, D. G. Evans and X. Duan, Angew. Chem., Int. Ed., 2011, 50, 720-723.

124 V. Augusto, C. Baleizão, M. N. Berberan-Santos and J. P. S. Farinha, J. Mater. Chem., 2010, 20, 1192-1197.

125 O. Yarimaga, S. Lee, D. Y. Ham, J. M. Choi, S. G. Kwon, M. Im, S. Kim, J. M. Kim and Y. K. Choi, Macromol. Chem. Phys., 2011, 212, 1211-1220.

126 H. G. Schild, Prog. Polym. Sci., 1992, 17, 163-249.

127 K. Iwai, Y. Matsumura, S. Uchiyama and A. P. de Silva, J. Mater. Chem., 2005, 15, 2796-2800.

128 C. Gota, S. Uchiyama, T. Yoshihara, S. Tobita and T. Ohwada, J. Phys. Chem. B, 2008, 112, 2829-2836.

129 Y. Shiraishi, R. Miyarnoto and T. Hirai, Langmuir, 2008, 24, 42734279.

130 L. Tang, J. K. Jin, A. J. Qin, W. Z. Yuan, Y. Mao, J. Mei, J. Z. Sun and B. Z. Tang, Chem. Commun., 2009, 4974-4976.

131 D. P. Wang, R. Miyamoto, Y. Shiraishi and T. Hirai, Langmuir, 2009, 25, 13176-13182.

132 Q. Yan, J. Y. Yuan, Y. Kang, Z. N. Cai, L. L. Zhou and Y. W. Yin, Chem. Commun., 2010, 46, 2781-2783.

133 A. P. Herrera, M. Rodriguez, M. Torres-Lugo and C. Rinaldi, J. Mater. Chem., 2008, 18, 855-858.

134 C. Gota, S. Uchiyama and T. Ohwada, Analyst, 2007, 132, 121-126.

135 T. Wu, G. Zou, J. M. Hu and S. Y. Liu, Chem. Mater., 2009, 21, 3788-3798.

136 K. Iwai, K. Hanasaki and M. Yamamoto, J. Lumin., 2000, 87-89, 1289-1291.

137 M. Honda, Y. Saito, N. I. Smith, K. Fujita and S. Kawata, Opt. Express, 2011, 19, 12375-12383.

138 X. J. Wan and S. Y. Liu, J. Mater. Chem., 2011, 21, 10321-10329.

139 M. Mitsuishi, Y. Koishikawa, H. Tanaka, E. Sato, T. Mikayama, J. Matsui and T. Miyashita, Langmuir, 2007, 23, 7472-7474.

140 J. Lee, A. O. Govorov and N. A. Kotov, Angew. Chem., Int. Ed., 2005, 44, 7439-7442.

141 W. T. Wu, J. Shen, P. Banerjee and S. Q. Zhou, Adv. Funct. Mater., 2011, 21, 2830-2839.

142 S. Y. Lee, S. Lee, I. C. Youn, D. K. Yi, Y. T. Lim, B. H. Chung, J. F. Leary, I. C. Kwon, K. Kim and K. Choi, Chem.-Eur. J., 2009, 15, 6103-6106.

143 W. T. Wu, J. Shen, P. Banerjee and S. Q. Zhou, Biomaterials, 2010, 31, 7555-7566.

144 Y. Chen and X. Li, Biomacromolecules, 2011, 12, 4367-4372.

145 C. Pietsch, R. Hoogenboom and U. S. Schubert, Polym. Chem., 2010, 1, 1005-1008.

146 T. Shiraki, A. Dawn, Y. Tsuchiya and S. Shinkai, J. Am. Chem. Soc., 2010, 132, 13928-13935.

147 F. H. C. Wong, D. S. Banks, A. Abu-Arish and C. Fradin, J. Am. Chem. Soc., 2007, 129, 10302-10303.

148 J. Li, X. Hong, Y. Liu, D. Li, Y. W. Wang, J. H. Li, Y. B. Bai and T. J. Li, Adv. Mater., 2005, 17, 163-166.

149 S. M. Sadeghi, IEEE Transactions on Nanotechnology, 2011, 10, 566571.

150 G. E. Khalil, K. Lau, G. D. Phelan, B. Carlson, M. Gouterman, J. B. Callis and L. R. Dalton, Rev. Sci. Instrum., 2004, 75, 192-206.

151 S. Katagiri, K. Manseki, Y. Tsukahara, K. Mitsuo and Y. Wada, J. Alloys Compd., 2008, 453, 1-3.

152 L. N. Sun, J. B. Yu, H. S. Peng, J. Z. Zhang, L. Y. Shi and O. S. Wolfbeis, J. Phys. Chem. C, 2010, 114, 12642-12648.

153 L. D. Carlos, R. A. S. Ferreira, V. de Zea Bermudez and S. J. L. Ribeiro, Adv. Mater., 2009, 21, 509-534.
154 J. A. Kai, M. C. F. C. Felinto, L. A. O. Nunes, O. L. Malta and H. F. Brito, J. Mater. Chem., 2011, 21, 3796-3802.

155 P. P. Lima, F. A. A. Paz, R. A. S. Ferreira, V. de Zea Bermudez and L. D. Carlos, Chem. Mater., 2009, 21, 5099-5111.

156 S. Uchiyama, N. Kawai, A. P. de Silva and K. Iwai, J. Am. Chem. Soc., 2004, 126, 3032-3033.

157 C. Pietsch, R. Hoogenboom and U. S. Schubert, Angew. Chem., Int. Ed., 2009, 48, 5653-5656.

158 H. Sugiyama and I. Saito, J. Am. Chem. Soc., 1996, 118, 70637068.

159 J. M. Jean and K. B. Hall, Proc. Natl. Acad. Sci. U. S. A., 2001, 98, $37-41$.

160 J. M. Jean and K. B. Hall, Biochemistry, 2002, 41, 13152-13161.

161 R. Tashiro and H. Sugiyama, Angew. Chem., Int. Ed., 2003, 42, 6018-6020.

162 C. Sanchez, B. Julián-López, P. Belleville and M. Popall, J. Mater. Chem., 2005, 15, 3559-3592.

163 P. Escribano, B. Julián-López, J. Planelles-Aragó, E. Cordoncillo, B. Viana and C. Sanchez, J. Mater. Chem., 2008, 18, 23-40.

164 C. Sanchez, P. Belleville, M. Popall and L. Nicole, Chem. Soc. Rev., 2011, 40, 696-753.

165 L. D. Carlos, R. A. S. Ferreira, V. de Zea Bermudez, B. Julián-López and P. Escribano, Chem. Soc. Rev., 2011, 40, 536-549.

166 B. Lebeau and P. Innocenzi, Chem. Soc. Rev., 2011, 40, 886-906.

167 C. L. Tan and Q. M. Wang, Inorg. Chem. Commun., 2011, 14, 515518.

168 B. Klinkert and F. Narberhaus, Cell. Mol. Life Sci., 2009, 66, 26612676.

169 D. Albanesi, M. Martin, F. Trajtenberg, M. C. Mansilla, A. Haouz, P. M. Alzari, D. de Mendoza and A. Buschiazzo, Proc. Natl. Acad. Sci. U. S. A., 2009, 106, 16185-16190.

170 M. Karnebogen, D. Singer, M. Kallerhoff and R. H. Ringert, Thermochim. Acta, 1993, 229, 147-155.

171 B. B. Lowell and B. M. Spiegelman, Nature, 2000, 404, 652-660.

172 V. Zeeb, M. Suzuki and S. Ishiwata, J. Neurosci. Methods, 2004, 139, 69-77.

173 K. M. McCabe, E. J. Lacherndo, I. Albino-Flores, E. Sheehan and M. Hernandez, Appl. Environ. Microbiol., 2011, 77, 2863-2868.

174 Q. Fu, G. V. R. Rao, L. K. Ista, Y. Wu, B. P. Andrzejewski, L. A. Sklar, T. L. Ward and G. P. Lopez, Adv. Mater., 2003, 15, $1262-1266$.

175 A. Schlossbauer, S. Warncke, P. M. E. Gramlich, J. Kecht, A. Manetto, T. Carell and T. Bein, Angew. Chem., Int. Ed., 2010, 49, 4734-4737.

176 E. Aznar, L. Mondragon, J. V. Ros-Lis, F. Sancenon, M. D. Marcos, R. Martinez-Manez, J. Soto, E. Perez-Paya and P. Amoros, Angew. Chem., Int. Ed., 2011, 50, 11172-11175.

177 L. M. Maestro, C. Jacinto, U. R. Silva, F. Vetrone, J. A. Capobianco, D. Jaque and J. G. Solé, Small, 2011, 7, 17741778.

178 K. Oyama, M. Takabayashi, Y. Takei, S. Arai, S. Takeoka, S. i. Ishiwata and M. Suzuki, Lab Chip, 2012, 12, 1591-1593.

179 J. S. Donner, S. A. Thompson, M. P. Kreuzer, G. Baffou and R. Quidant, Nano Lett., 2012, 12, 2107-2111.

180 Q. Q. Zhan, J. Qian, H. J. Liang, G. Somesfalean, D. Wang, S. L. He, Z. G. Zhang and S. Andersson-Engels, ACS Nano, 2011, 5, 3744-3757.

181 F. Narberhaus, T. Waldminighaus and S. Chowdhury, FEMS Microbiol. Rev., 2006, 30, 3-16.

182 A. Vyalikh, A. U. B. Wolter, S. Dampel, D. Haase, M. Ritschel, A. Leonhardt, H. J. Grafe, A. Taylor, K. Kramer, B. Buchner and R. Klingeler, Nanomedicine (London, U. K.), 2008, 3, 321-327.

183 W. Haeberle, M. Pantea and J. K. H. Hoerber, Ultramicroscopy, 2006, 106, 678-686.

184 G. Binnig, H. Rohrer, C. Gerber and E. Weibel, Appl. Phys. Lett., 1982, 40, 178-180.

185 C. C. Williams and H. K. Wickramasinghe, Appl. Phys. Lett., 1986, 49, 1587-1589.

186 M. Stopka, L. Hadjiiski, E. Oesterschulze and R. Kassing, J. Vac. Sci. Technol., B: Microelectron. Nanometer Struct.-Process., Meas., Phenom., 1995, 13, 2153-2156.

187 A. Hammiche, M. Reading, H. M. Pollock, M. Song and D. J. Hourston, Rev. Sci. Instrum., 1996, 67, 4268-4274.

188 A. Majumdar, J. P. Carrejo and J. Lai, Appl. Phys. Lett., 1993, 62, 2501-2503. 
189 G. Mills, H. Zhou, A. Midha, L. Donaldson and J. M. R. Weaver, Appl. Phys. Lett., 1998, 72, 2900-2902.

190 P. G. Royall, V. L. Kett, C. S. Andrews and D. Q. M. Craig, J. Phys. Chem. B, 2001, 105, 7021-7026.

191 S. Lefevre and S. Volz, Rev. Sci. Instrum., 2005, 76, 033701.

192 A. Hammiche, H. M. Pollock, M. Song and D. J. Hourston, Meas. Sci. Technol., 1996, 7, 142-150.

193 J. Lai, M. Chandrachood, A. Majumdar and J. P. Carrejo, IEEE Electron Device Lett., 1995, 16, 312-315.

194 O. Nakabeppu, M. Chandrachood, Y. Wu, J. Lai and A. Majumdar, Appl. Phys. Lett., 1995, 66, 694-696.

195 K. Luo, Z. Shi, J. Lai and A. Majumdar, Appl. Phys. Lett., 1996, 68, 325-327.

196 R. J. Pylkki, P. J. Moyer and P. E. West, Jpn. J. Appl. Phys., Part 1, 1994, 33, 3785-3790.

197 L. Shi, O. Kwon, A. C. Miner and A. Majumdar, $J$. Microelectromech. Syst., 2001, 10, 370-378.

198 Y. Zhang, P. S. Dobson and J. M. R. Weaver, Microelectron. Eng., 2011, 88, 2435-2438.

199 P. S. Dobson, J. M. Weaver, D. P. Burt, M. N. Holder, N. R. Wilson, P. R. Unwin and J. V. Macpherson, Phys. Chem. Chem. Phys., 2006, 8, 3909-3914.

200 B. Cretin, S. Gomes, N. Trannoy and P. Vairac, Scanning Thermal Microscopy, in Microscale and Nanoscale Heat Transfer, Topics in Applied Physics, ed. S. Volz, Springer-Verlag, 2007, vol. 107, pp. 181-238.

201 Z. Dai, W. P. King and K. Park, Nanotechnology, 2009, 20, 095301 .

202 S. Kim, K. C. Kim and K. D. Kihm, Sensors-Basel, 2007, 7, 31563165.

203 H. M. ElShimy, M. Nakajima, F. Arai and T. Fukuda, Nano thermal sensors for sensing temperature in water environment, in 7th IEEE Conference on nanotechnology, IEEE-Nano, 2007, 1-3, $1045-1049$.

204 Y. L. Zhang, C. L. Hapenciuc, E. E. Castillo, T. Borca-Tasciuc, R. J. Mehta, C. Karthik and G. Ramanath, Appl. Phys. Lett., 2010, 96, 062107

205 Y. L. Zhang, E. E. Castillo, R. J. Mehta, G. Ramanath and T. Borca-Tasciuc, Rev. Sci. Instrum., 2011, 82, 024902.

206 E. Saidi, N. Babinet, L. Lalouat, J. Lesueur, L. Aigouy, S. Volz, J. Labeguerie-Egea and M. Mortier, Small, 2011, 7, 259-264.

207 G. Wielgoszewski, P. Sulecki, T. Gotszalk, P. Janus, P. Grabiec, M. Hecker, Y. Ritz and E. Zschech, Phys. Status Solidi B, 2011, 248, 370-374.

208 G. Wielgoszewski, P. Sulecki, P. Janus, P. Grabiec, E. Zschech and T. Gotszalk, Meas. Sci. Technol., 2011, 22, 094023-094029.

209 Y. J. Yu, M. Y. Han, S. Berciaud, A. B. Georgescu, T. F. Heinz, L. E. Brus, K. S. Kim and P. Kim, Appl. Phys. Lett., 2011, 99, $183105-183108$.

210 N. Barbosa III and A. J. Slifka, Microsc. Res. Techniq., 2008, 71 579-584.

211 G. Binnig, M. Despont, U. Drechsler, W. Häberle, M. Lutwyche, P. Vettiger, H. J. Mamin, B. W. Chui and T. W. Kenny, Appl. Phys. Lett., 1999, 74, 1329-1331.

212 US Pat., No. 6,905,736, Fabrication of nano-scale temperature sensors and heaters, 2005.

213 US Pat., No. 6,969,679, Fabrication of nanoscale thermoelectric devices, 2005

214 H. Zhou, A. Midha, G. Mills, S. Thoms, S. K. Murad and J. M. R. Weaver, J. Vac. Sci. Technol., B: Microelectron. Nanometer Struct.-Process., Meas., Phenom., 1998, 16, 54-58.

215 M. E. Bourg, W. E. van der Veer, A. G. Guell and R. M. Penner, Chem. Mater., 2008, 20, 5464-5474.
216 X. G. Zhang, H. Choi, A. Datta and X. C. Li, J. Micromech. Microeng., 2006, 16, 900-905.

217 Y. H. Gao and Y. Bando, Appl. Phys. Lett., 2002, 81, 3966-3968.

218 Z. W. Liu, Y. Bando, M. Mitome and J. H. Zhan, Phys. Rev. Lett., 2004, 93, 095504-095508.

219 Y. H. Gao, Y. Bando and D. Golberg, Appl. Phys. Lett., 2002, 81, $4133-4135$.

220 Y. Y. Wu and P. D. Yang, Appl. Phys. Lett., 2000, 77, 43-45.

221 Z. W. Liu, Y. Bando, J. Q. Hu, K. Ratinac and S. P. Ringer, Nanotechnology, 2006, 17, 3681-3684.

222 P. M. Ajayan, T. W. Ebbesen, T. Ichihashi, S. Iijima, K. Tanigaki and H. Hiura, Nature, 1993, 362, 522-525.

223 D. Golberg, Y. Bando, K. Kurashima and T. Sato, Scr. Mater., 2001, 44, 1561-1565.

224 Y. B. Li, Y. Bando, D. Golberg and Z. W. Liu, Appl. Phys. Lett., 2003, 83, 999-1001.

225 D. R. Lide, in Handbook of Chemistry and Physics, CRC Press, Ohio, 71st edn, 1990

226 Y. B. Li, Y. Bando and D. Golberg, Adv. Mater., 2003, 15, 581-585.

227 Y. B. Li, Y. Bando and D. Golberg, Adv. Mater., 2004, 16, 37-40.

228 N. W. Gong, M. Y. Lu, C. Y. Wang, Y. Chen and L. J. Chen, Appl. Phys. Lett., 2008, 92, 073101-073103.

229 P. S. Dorozhkin, S. V. Tovstonog, D. Golberg, J. H. Zhan, Y. Ishikawa, M. Shiozawa, H. Nakanishi, K. Nakata and Y. Bando, Small, 2005, 1, 1088-1093.

230 E. Bichoutskaia, A. M. Popov, Y. E. Lozovik, G. S. Ivanchenko and N. G. Lebedev, Phys. Lett. A, 2007, 366, 480-486.

231 C. M. Tan, J. J. Jia and W. B. Yu, Appl. Phys. Lett., 2005, 86, 263104

232 L. Spietz, R. J. Schoelkopf and P. Pari, Appl. Phys. Lett., 2006, 89, 183123.

233 R. A. Sayer, S. Kim, A. D. Franklin, S. Mohammadi and T. S. Fisher, IEEE Trans. Compon. Packag. Technol., 2010, 33, $178-183$.

234 F. Narberhaus, Arch. Microbiol., 2002, 178, 404-410.

235 J. Kortmann, S. Sczodrok, J. Rinnenthal, H. Schwalbe and F. Narberhaus, Nucleic Acids Res., 2011, 39, 2855-2868.

236 S. Chowdhury, C. Maris, F. H. T. Allain and F. Narberhaus, EMBO J., 2006, 25, 2487-2497.

237 P. Shah and M. A. Gilchrist, PLoS One, 2010, 5, e11308.

238 C. O. Gualerzi, A. M. Giuliodori and C. L. Pon, J. Mol. Biol., 2003, 331, 527-539.

239 A. M. Giuliodori, F. Di Pietro, S. Marzi, B. Masquida, R. Wagner, P. Romby, C. O. Gualerzi and C. L. Pon, Mol. Cell, 2010, 37, 21-33.

240 M. H. W. Weber and M. A. Marahiel, Sci. Progr., 2003, 86, 9-75.

241 J. Neupert, D. Karcher and R. Bock, Nucleic Acids Res., 2008, 36, e124.

242 T. Waldminghaus, J. Kortmann, S. Gesing and F. Narberhaus, Biol. Chem., 2008, 389, 1319-1326.

243 J. Neupert and R. Bock, Nat. Protoc., 2009, 4, 1262-1273.

244 S. Höfinger and F. Zerbetto, Chem. Phys., 2010, 369, 91-95.

245 H. O. Muller, A. Hadicke and W. Krech, Phys. Status Solidi B, 1995, 188, 667-677.

246 J. W. Wang and L. P. Huang, Appl. Phys. Lett., 2011, 98, 113102.

247 T. Brintlinger, Y. Qi, K. H. Baloch, D. Goldhaber-Gordon and J. Cumings, Nano Lett., 2008, 8, 582-585.

248 N. Kawamoto, M. S. Wang, X. L. Wei, D. M. Tang, Y. Murakami, D. Shindo, M. Mitome and D. Golberg, Nanotechnology, 2011, 22, 485707.

249 G. Pasparakis and M. Vamvakaki, Polym. Chem.-UK, 2011, 2, 1234 1248.

250 J. Johansson, P. Mandin, A. Renzoni, C. Chiaruttini, M. Springer and P. Cossart, Cell, 2002, 110, 551-561. 